Fall 2-24-2015

\title{
Social Support to Reduce Uncertainty in Childhood Cancer in South Texas: A Case Study
}

Martha Danielle Gunter

Follow this and additional works at: https://scholarworks.uttyler.edu/nursing_grad Part of the Nursing Commons

\section{Recommended Citation}

Gunter, Martha Danielle, "Social Support to Reduce Uncertainty in Childhood Cancer in South Texas: A Case Study" (2015). Nursing Theses and Dissertations. Paper 43.

http://hdl.handle.net/10950/251 
This page intentionally left blank 


\title{
SOCIAL SUPPORT TO REDUCE UNCERTAINTY IN CHILDHOOD CANCER IN SOUTH TEXAS: A CASE STUDY
}

\author{
By \\ MARTHA DANIELLE GUNTER
}

A dissertation submitted in partial fulfillment of the requirements for the degree of Doctorate of Philosophy in Nursing Department of Nursing Dr. Gloria Duke, Ph.D., RN

College of Nursing and Health Sciences

The University of Texas at Tyler December 2014 
The University of Texas at Tyler

Tyler, Texas

This is to certify that the Doctoral Dissertation of

\section{MARTHA DANIELLE GUNTER}

has been approved for the thesis/dissertation requirement on

November 17, 2014

For the Doctorate in Philosophy in Nursing degree

Approvals:

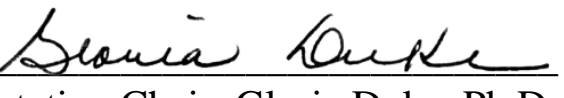

Dissertation Chair: Gloria Duke, Ph.D.

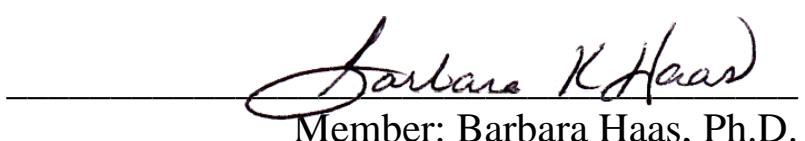

Member: Barbara Haas, Ph.D.
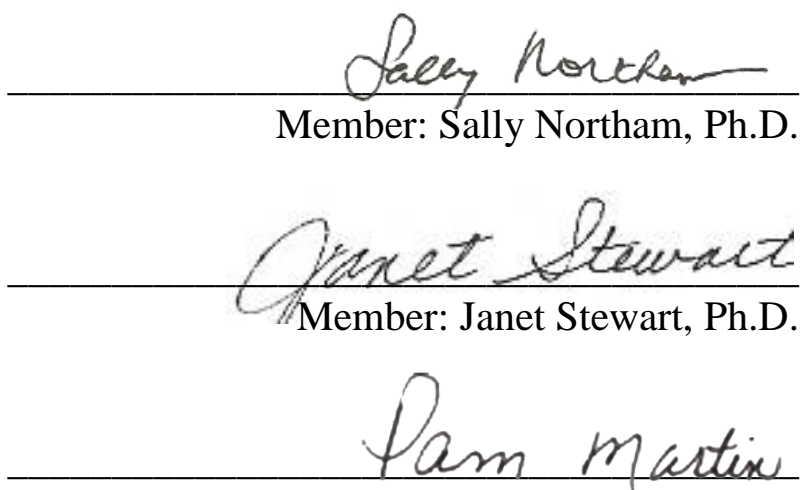

Chair, Department of Graduate Nursing

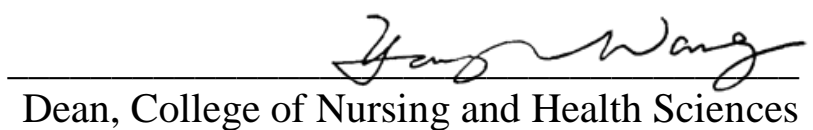




\section{Acknowledgements}

I would like to thank the many people involved in my successful completion of this doctoral program. First, all the faculty within the University of Texas at Tyler, College of Nursing have been extremely helpful and supportive. I have never met a more welcoming and enthusiastic group of people. Their passion for student success is worthy of a medal of honor.

Special thanks are also in order for the enormous support I have received from the faculty, dean and provost at the University of the Incarnate Word Ila Faye Miller School of Nursing and Health Professions. You offered me the opportunity and the time to see this through to completion. You have prayed for me and for my family so the spirit would lift us up and for that I am truly grateful. What a remarkable group of people with whom I can share this success. I hope that I can continue carrying on the mission of our wonderful community. Thank you so very much.

I could not have completed this project without the support of the staff, providers, and directors of the pediatric oncology and transplant unit at Methodist Children's Hospital. Together we will make things happen!

The members of my dissertation committee, Drs. Gloria Duke, Barbara Haas, Sally Northam, and Janet Stewart, have been my personal cheerleading squad and I don't know how to begin showing my gratitude except to say thank you from the bottom of my heart. Your patience, love, and eye for detail have kept me on track and guided the way. You actually made this a wonderful experience.

Lastly, I must give thanks for my wonderful family. Kim, Adrian and Alec, you have suffered much over the last four years. You have cried with me, read countless versions of these papers, eaten the meals I burned while too distracted to cook, and listened tirelessly to my ranting. To my parents Richard and Martha, my brother, Joseph and his family, to Mecky, and to Jean: thank you for never wavering in your enthusiasm for my completion of this degree. Your constant interest and patience mean so much to me. I could not have done this without you. To all my extended family thanks for always cheering me on.

Thanks to all of you for never doubting me. I love you each so much. 


\section{Table of Contents}

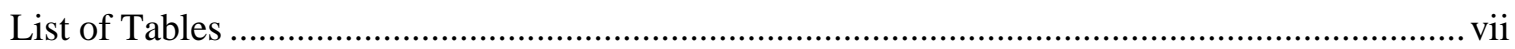

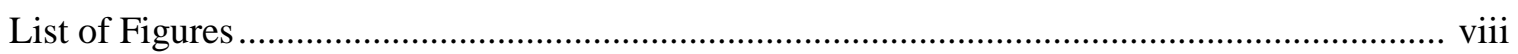

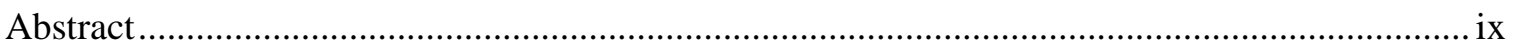

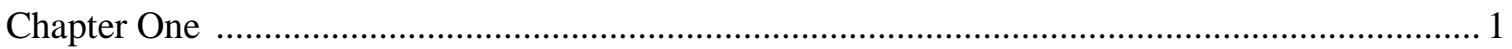

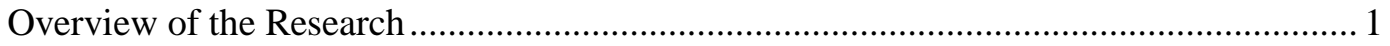

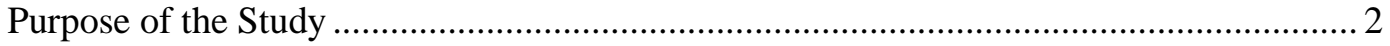

Protection of Human Subjects...................................................................................... 3

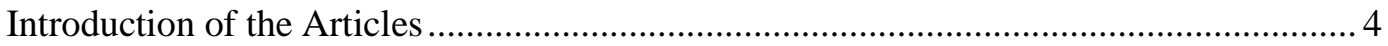

Chapter Two: Reducing Uncertainty in Families Dealing with Childhood Cancers:

An Integrative Literature Review ................................................................ 6

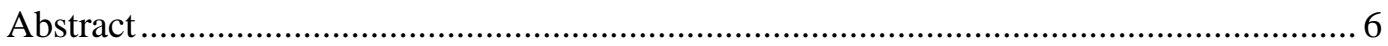

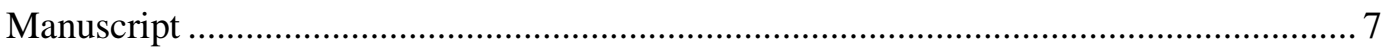

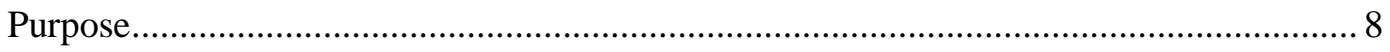

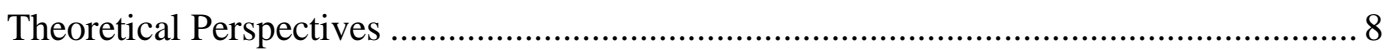

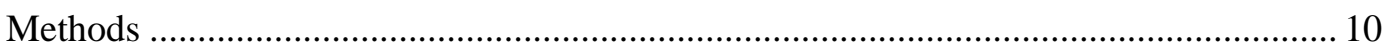

Inclusion and Exclusion Criteria................................................................... 11

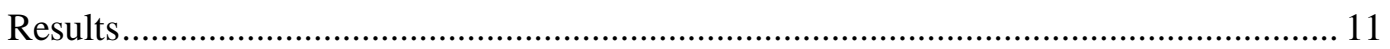

Uncertainty, Stress, and the Diagnostic Phase ................................................. 26

Uncertainty leading up to and immediately after diagnosis ...................26

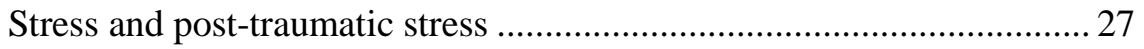

Timeframe for uncertainty .............................................................. 27

Healthy Adaptation to Diagnosis of Cancer and Chronic Illness........................ 28 


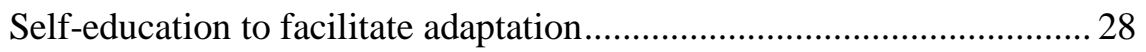

Personal relationships to facilitate healthy adaptation ........................... 29

Maintaining a positive outlook …..................................................... 30

Barriers to healthy adaptation to diagnosis of cancer and chronic illness............ 30

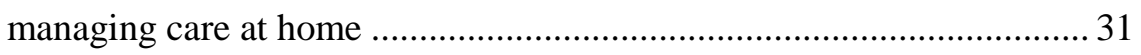

Interventions to Reduce Uncertainty Through Education and Psychosocial

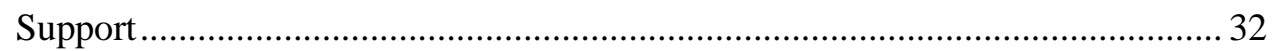

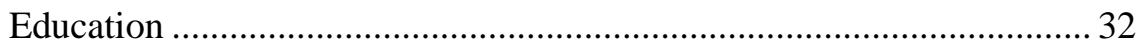

Psycho-social support for parents and family members......................... 33

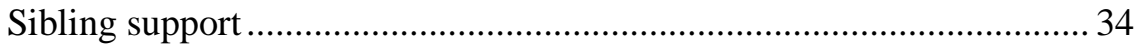

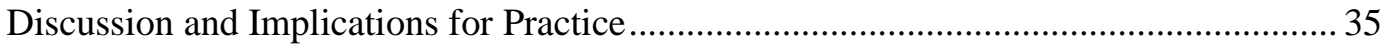

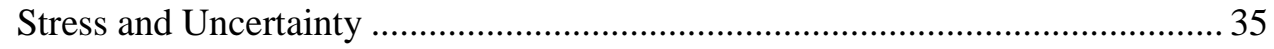

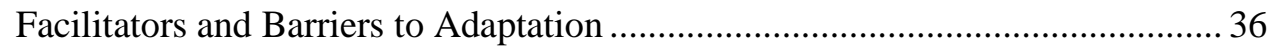

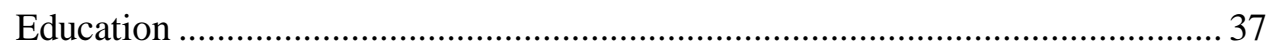

Early and Continued Psychosocial Support …................................................... 39

Theoretical Implications ........................................................................ 40

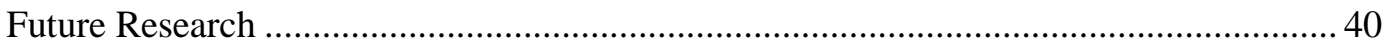

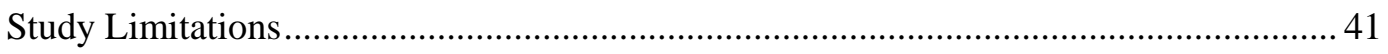

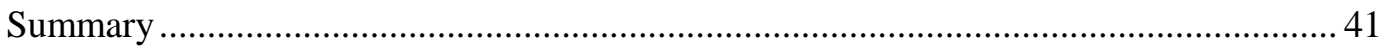

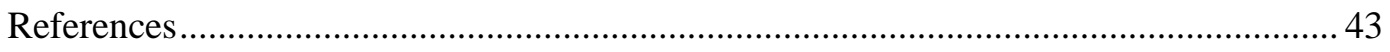

Chapter 3: Social Support to Reduce Uncertainty in Childhood Cancer in South Texas: A Case

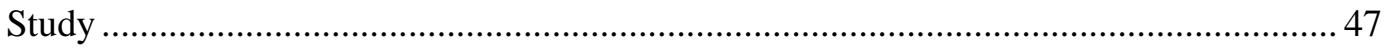

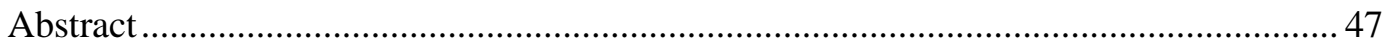

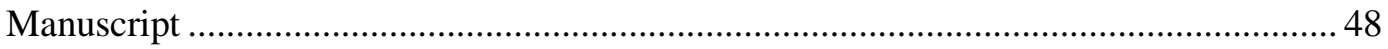

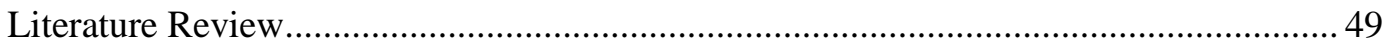

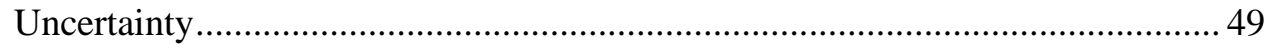


Psychosocial and Education Interventions .................................................... 53

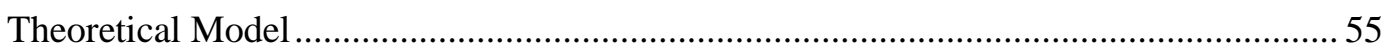

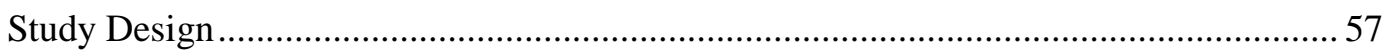

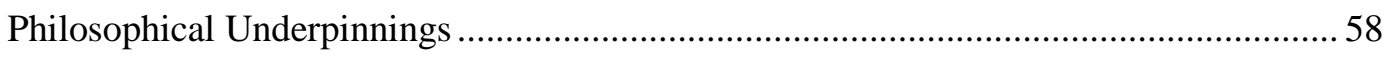

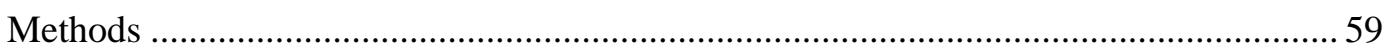

Research Questions and Propositions ............................................................ 59

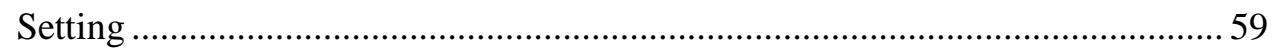

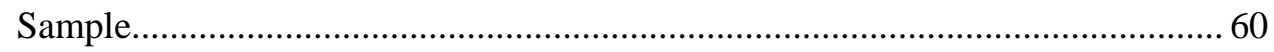

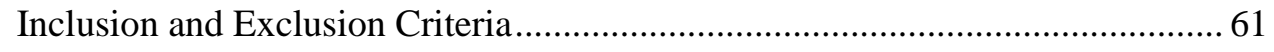

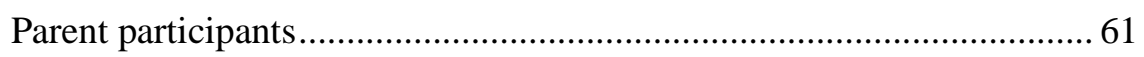

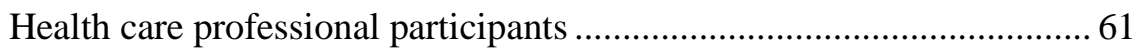

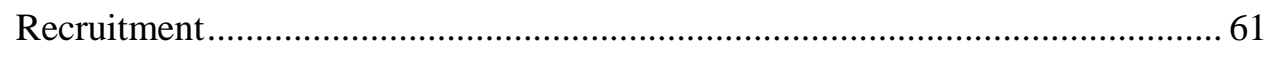

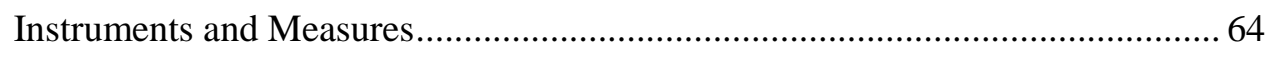

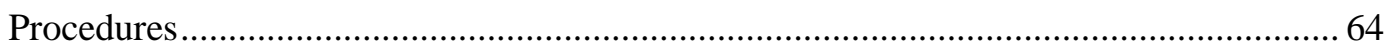

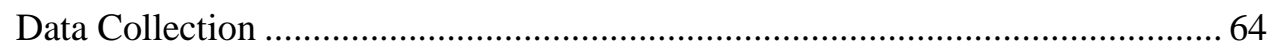

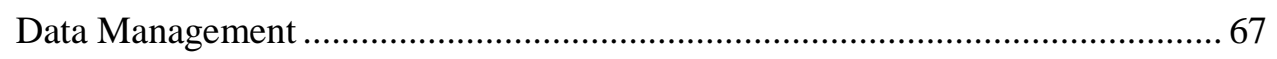

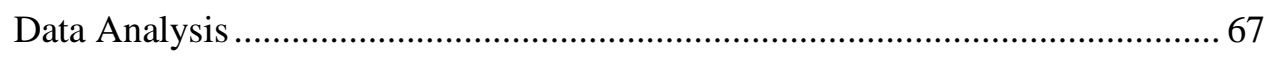

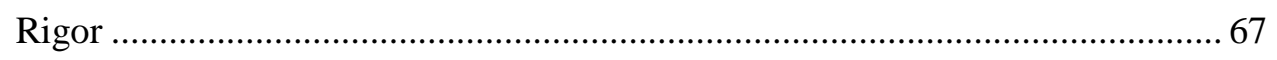

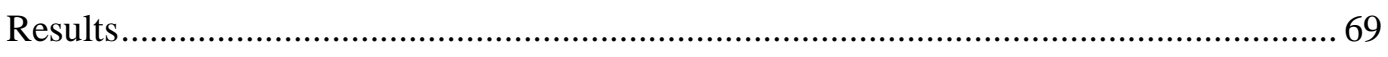

Meaning of Uncertainty in Parents and Members of the Health Care Team ....... 71

Shock and subsequent barrage of negative emotions............................ 71

Health care provider/physician uncertainty in guiding the steps of

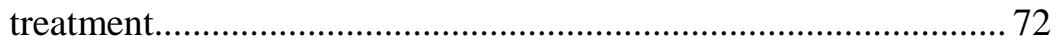

Looking through the black tunnel ...................................................... 72

Burden of ambiguity and decision making …....................................... 73 


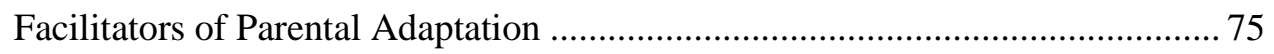

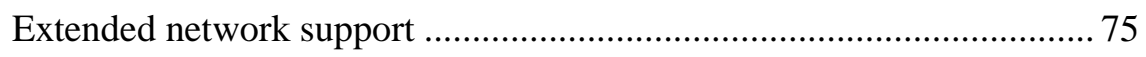

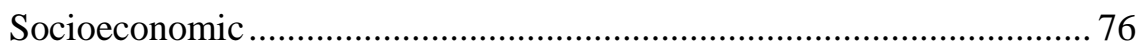

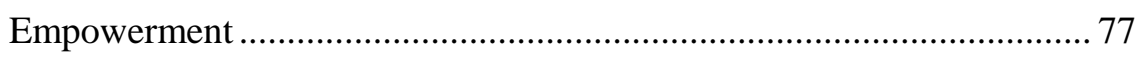

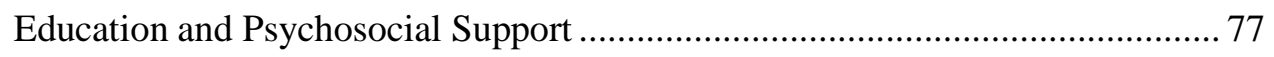

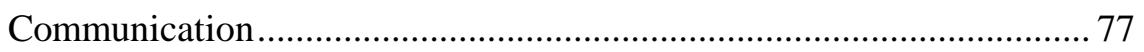

Providing information and sharing support............................................. 79

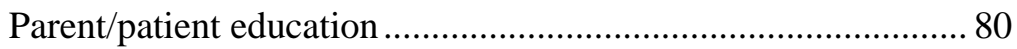

Timeframes for delivery of information................................... 80

Addressing individual patient needs with appropriate

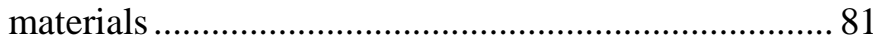

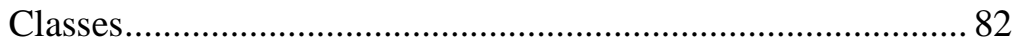

Earlier discharge from inpatient areas...................................... 82

Psycho-spiritual one-on-one support....................................... 83

Facilitating proactive behaviors through support...................... 84

Patient and Family Obstacles Hindering Successful Adaptation ......................... 84

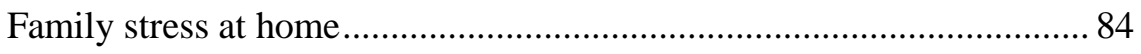

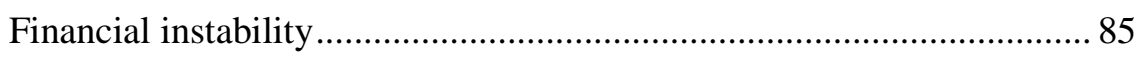

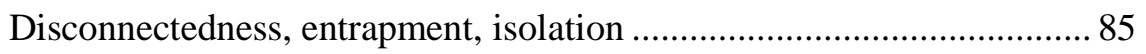

Lack of meaningfulness of social service provision ............................. 86

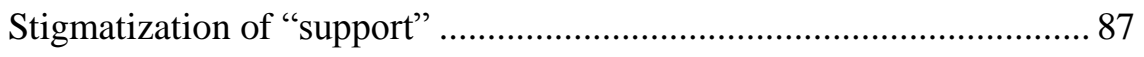

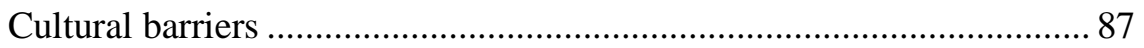

Differences in participation in the health care team................... 88

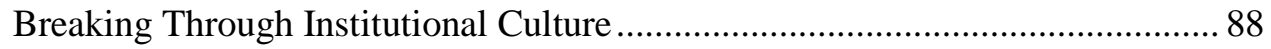

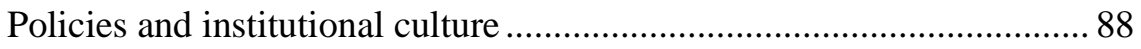

Lack of accreditation standards and advocacy .......................... 89 
Patient education is not a priority........................................... 90

Inhibition of family centered care …........................................ 90

Visitation policies.................................................. 91

Home-grown management experience.............................................. 91

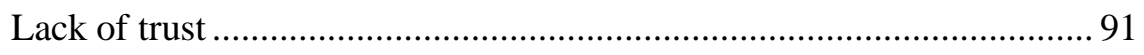

Interdisciplinary collaboration: an evolving model ............................ 92

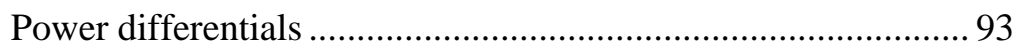

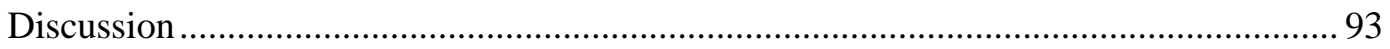

Meaning of Uncertainty in Parents and Members of the Health Care Team ....... 94

Facilitators of Parental Adaptation .................................................................. 94

Education and Psychosocial Support ................................................................ 95

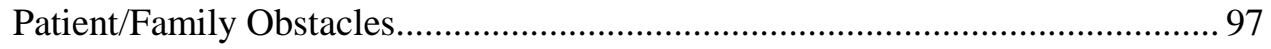

Breaking Through Institutional Culture .......................................................... 99

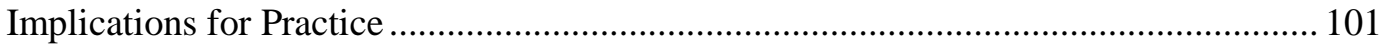

Meaning of Uncertainty in Parents and Members of the Health Care Team ..... 101

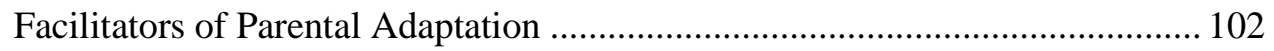

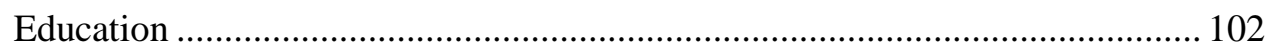

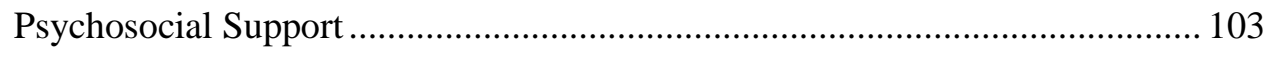

Patient and Family Obstacles …................................................................ 104

Breaking Through the Institutional Culture ….............................................. 105

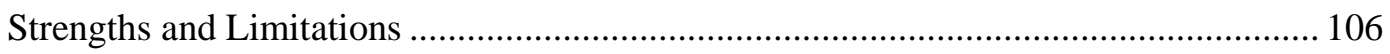

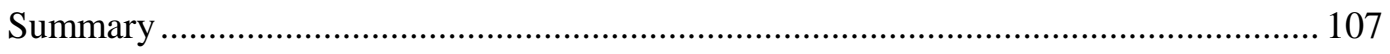

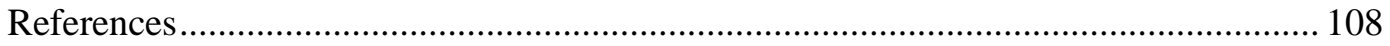

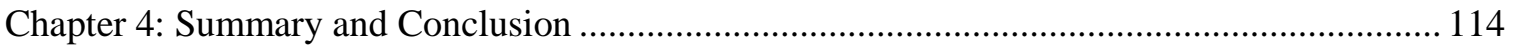

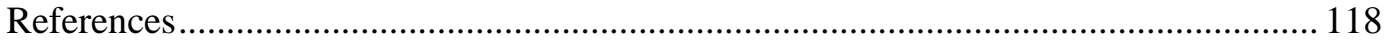

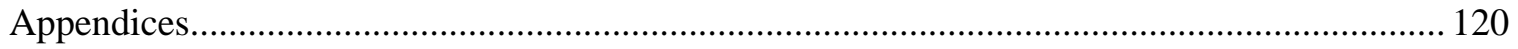


Appendix A: Model of Uncertainty in Illness.

Appendix B: Letter of Support to Conduct Research Within the Hospital Unit.

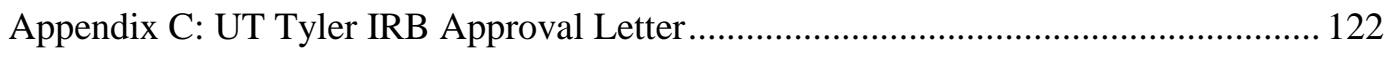

Appendix D: Health Care System Approval Letter .................................................... 124

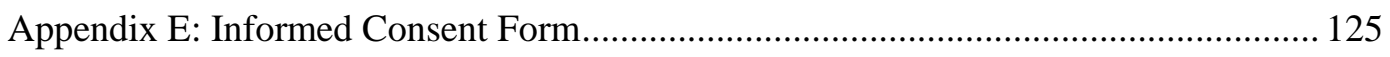

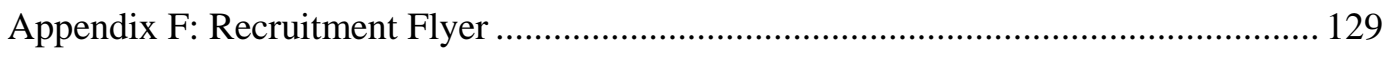

Appendix G: Uncertainty in Childhood Cancer Demographic Questionnaire for Parent Participants

Appendix H: Uncertainty in Childhood Cancer Demographic Questionnaire for Health

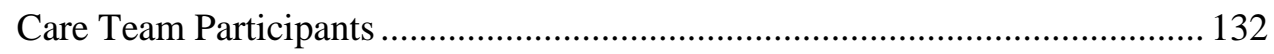

Appendix I: Parent Participant Interview Question Guide ......................................... 133

Appendix J: Health Care Team Participant Interview Question Guide ......................... 134

Appendix K: Journal of Pediatric Oncology Nursing Journal Submission Guidelines .. 135

Appendix L: Coding Guide: Meaning of Uncertainty in Parents and Members of the Health Care Team

Appendix M: Coding Guide: Facilitators of Parental Adaptation ................................ 147

Appendix N: Coding Guide: Education and Psychosocial Support.............................. 151

Appendix O: Coding Guide: Patient/Family Obstacles ............................................ 160

Appendix P: Coding Guide: Breaking Through Institutional Culture ........................... 168

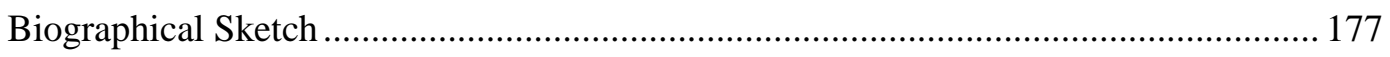




\section{List of Tables}

\section{Chapter Two}

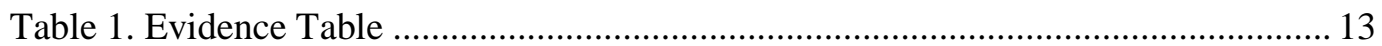

\section{Chapter Three}

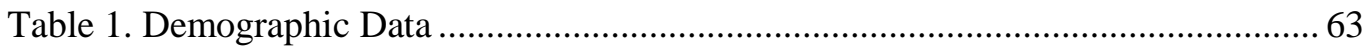

Table 2. Research Results: Themes and Subthemes ..................................................... 70 


\section{List of Figures}

\section{Chapter Two}

Figure 1. Model of Perceived Uncertainty in Illness Adapted from Mishel's Model of 


\title{
Abstract \\ SOCIAL SUPPORT TO REDUCE UNCERTAINTY IN CHILDHOOD CANCER IN SOUTH TEXAS: A CASE STUDY
}

\author{
M. Danielle Gunter \\ Dissertation Chair: Gloria Duke, Ph.D., RN
}

The University of Texas at Tyler

December 2014

Parents of children with cancer are faced with the complicated situation of not only learning their child is critically ill, but also of learning how to adapt to life with childhood cancer. For parents of a child with cancer uncertainty can lead to increased levels of stress, anxiety, fear, loss of control and depression. Successful psychosocial and educational interventions in reducing uncertainty in adult populations have been reported. However, these have not been well documented in families dealing with childhood cancer. Discovering how to best provide these interventions in south Texas will provide a foundation for future research interventions in this population. This case study research utilized extensive interviews, as described by Yin (2013), to identify strengths and barriers for implementation of psychosocial and educational interventions in addressing uncertainty in parents of children diagnosed with cancer.

Keywords: Uncertainty, Adaptation, Pyschosocial, Education, Parental, Childhood, Cancer 


\section{Chapter One}

\section{Overview of the Research}

Approximately 924 new cases of childhood cancer (ages 0-14 years) were diagnosed in the state of Texas between the years 2005-2009 (Texas Department of State Health Services, 2014). A diagnosis of childhood cancer can cause stress for each member of the family, but especially the parents. Parental uncertainty when faced with a childhood cancer diagnosis is fairly common (Boman, Lindahl, \& Bjork, 2003; Flury, Caflisch, Ullmann-Bremi, \& Spichiger, 2011; Mishel, 1983; Neville, 1998; Stewart \& Mishel, 2000). Uncertainty is caused when a person is unfamiliar with a stressful life event. The level of uncertainty one person may feel compared to another in a similar situation depends on each person's capability to understand the situation, attribute meaning to it, and how much education and social support is provided. These factors allow a person to appraise the uncertainty in a positive or negative light which then guides the coping strategies utilized by each person (Mishel, 1983; 1988). The process of parental uncertainty is described in Mishel's Model of Parental Uncertainty (Appendix A). The use of appropriate coping strategies ultimately affects the speed with which a person can adapt to the new situation.

Parents are particularly vulnerable in the first two to three months after their child's cancer diagnosis (Flury et al., 2011; Soanes, Hargrave, Smith \& Gibson, 2009). They are often overwhelmed by the information provided regarding the treatment regimen and the extensive changes in their lifestyle required to care for their ill child. Often one parent may quit his/her job to act as a primary caregiver at home. This affects the family's financial stability which can add more stress to the environment (Soanes et al., 2009). The burden of caring for a child with cancer can be exhausting and can leave parents feeling very isolated during this period of transition 
(Boyd \& Hunsberger, 1998). They are not yet familiar with the treatment routine. They have not yet become comfortable with the health care team or other parents they might meet at the hospital or clinic area, and as their extended family members begin to move past the initial shock the parents are just beginning to settle into life with childhood cancer. They may still be in shock and grieving the initial diagnosis. They may also be very angry with themselves and their child's doctors (Soanes et al., 2009). All of these could be attributed to uncertainty.

When left unchecked uncertainty can cause increased levels of anxiety and distress, even leading to post traumatic stress disorder (Fuemmeler, Mullins, \& Marx, 2001; Lee, Santacroce \& Sadler, 2007; Santacroce, 2003). The higher the level of uncertainty for longer periods of time, the more likely the parent is to have severe anxiety and post-traumatic stress disorder (Fuemmeler et al., 2001; Santacroce, 2003). However, if addressed early uncertainty can help empower parents to seek out learning opportunities and help decrease their perceptions of loss of control. Evidence suggests that interventions aimed specifically at addressing psychosocial supportive and educational needs could be effective in reducing uncertainty, anxiety and distress (Boman et al., 2003; Flury et al., 2011; Gannoni \& Shute, 2010; Hovey, 2005; Neville, 1998; Patiño-Fernández et al., 2008).

In a south Texas regional children's medical facility the hematology/oncology and bone marrow transplant (BMT) program has attempted to provide psychosocial supportive measures as well as educational interventions in recent years. However, these interventions have not been sustainable. The program administrators and health care team recognize the need for development of a plan to address parental uncertainty and distress. This dissertation study is part of that plan.

\section{Purpose of the Study}

The purpose of this study is to determine the types of supportive measures found to be most helpful and realistic for families of children with cancer during the first three months after diagnosis. This is done through a case study research design which allowed the principal investigator (PI) to examine problems related to uncertainty, psychosocial support and patient 
education from various perspectives within the unit. According to Yin (2013), a case study is defined as "an empirical inquiry that investigates a contemporary phenomenon (the "case") in depth and within its real world context especially when the boundaries between phenomenon and context may not be clearly evident" (p. 16). Case studies are used in most social science disciplines to help understand complex social interactions and concerns. They are ideal when multiple variables are possible causes of or contributors to the phenomenon.

Participants were members of one of two groups: health care team participants or parent participants. Health care team participants were members of the pediatric hematology/oncology and BMT health care team. This included an interdisciplinary approach that sought out nurses, administrators, physicians, social workers, case managers, counselors, educators, chaplains, and child life therapists. Parent participants were interested parents of a child diagnosed with cancer and were between the ages of 18 and 100 years old. All participants were asked to share their perspectives in a one hour interview conducted by the PI. According to Yin (2013) targeted interviews are a way to focus directly on the topic of the case study.

\section{Protection of Human Subjects}

Documentation of support from the nursing unit director to perform this research is included in Appendix B. Institutional Review Board (IRB) approval was obtained from the University of Texas at Tyler (Appendix C). IRB approval was not required at the hospital facility, but permission to conduct the study was obtained (Appendix D). Informed consent (Appendix E) was obtained from each participant and each parent participant was assured that participation in no way impacted the care they received from the health care team. The informed consent process included that all participants verbally repeat to the principal investigator (PI) the study purpose, risks, benefits, expectations for participation, and the voluntary nature of participation to verify understanding. All identifying information was held confidential and coded immediately after consent was obtained. Any document/file containing identifiable data including the name and research identification number was securely kept in a location separate from all data. 
Recruitment flyers, demographic questionnaires, and interview guides can be found in the Appendices F-J. All data were analyzed and only professional titles and research identification numbers were used, and at no time was the cancer center or location identified by name.

Demographic information at all times was kept locked in a cabinet within the PI's locked office to which only the PI has access. Interviews were kept to approximately one hour per meeting (45-60 minutes), and respect for every participant's concept of time and other obligations was of utmost importance. Audio recordings were completed digitally and the digital file stored in a locked and secured cabinet until transcribed to a digital file. At the completion of this write up all recordings were destroyed. The digital transcript was stored in a secure database on a locked computer file in the PI's office. Videography was not used in an effort to protect confidentiality. The researcher was available via phone, email, and in person throughout the research process to address concerns and questions. Prior to use, participant's permission was sought for all quotations used in publications or presentations to clarify that the PI's interpretation of meaning was correct and was an accurate representation of the participant's feelings at the time.

Data from the interviews were analyzed according to Yin (2013). Pattern matching was completed to compare results from within each participant's interview, and also to compare across all participants' interviews (Miles \& Huberman, 1994; Yin, 2013). These patterns were grouped into five themes: meaning of uncertainty in parents and members of the health care team, facilitators of parental adaptation, education and psychosocial support, patient/family obstacles, and breaking through the institutional culture. This research study illustrated key issues and ideas for developing effective interventions for this population that can be the basis for future interventional studies.

\section{Introduction of Articles}

The first manuscript "Reducing Uncertainty in Families Dealing with Childhood Cancers: An Integrative Literature Review" has been submitted for publication in the Journal of Pediatric Oncology Nursing. Guidelines for submission to the journal are included in Appendix K. This 
journal published by the Association of Pediatric Hematology/Oncology Nurses focuses on areas of interest to professional nurses working with children living with hematological disorders, cancers, or going through the bone marrow transplant process. It also includes research focused on survivorship and long term care for patients after they have completed treatment, are living with side effects from their treatment, or are transitioning to adulthood. This integrative review of the literature examines parental uncertainty and supportive/educational measures for parents of children with cancer. The article serves as a foundation for the research case study on social support to reduce uncertainty in childhood cancer.

The second manuscript titled "Social Support to Reduce Uncertainty in Childhood Cancer in South Texas: A Case Study" is a report of the descriptive single embedded case study. This manuscript is also prepared for submission to the Journal of Pediatric Oncology Nursing and was developed based on the analysis of 21 interviews with both parent and health care team member participants at a south Texas children's hematology/oncology and BMT program. It presents five themes which illustrate the participants' perceptions regarding parental uncertainty, factors that serve as facilitators and obstacles toward successful adaptation, and suggestions for psychosocial support and educational interventions to be utilized in future research endeavors. These themes are described in detail with examples of quotations from participants in Appendices L-P. 


\title{
Chapter 2
}

Reducing Uncertainty in Families Dealing with Childhood Cancers:

An Integrative Literature Review

M. Danielle Gunter, MSN, RN, CPN

\begin{abstract}
Uncertainty can decrease coping mechanisms in parents of children with cancer. Interventions to help families adapt more quickly and effectively are unknown. The purpose of this paper is to review research relating uncertainty to stress, anxiety, and adaptation. Recommendations regarding psychosocial support and educational interventions to facilitate adaptation in families dealing with childhood cancer are also discussed. Methodology: An integrative literature review was conducted through online databases. Limits were set for research articles and dissertations published since 1995 using search words of uncertainty, chronic, life threatening illness, diagnosis, anxiety, stress, adaptation, cancer, nursing, education, and support.

Results: Uncertainty, anxiety, and stress play a role in family adaptation and coping. Evidence suggests time-sensitive interventions directed towards education and psycho-social support for all patients/families dealing with a new diagnosis of chronic illnesses are needed.

Conclusions: Evidence-based interventions to reduce uncertainty and facilitate health adaptation for parents of children with cancer are needed.
\end{abstract}

Keywords: uncertainty, childhood cancer, adaptation, parent, support group 
According to the American Cancer Society (2010) approximately 10,700 children are diagnosed with cancer in the United States each year. In 1962 the five year survival for many common childhood cancers was less than 10\% (St. Jude's Children's Research Hospital, 2014). Despite the fact that cure rates for childhood cancer have dramatically increased in the last few decades, cancer is still considered the leading cause of death from disease for children and adolescents. Researchers and healthcare teams have made significant strides in treatment for childhood cancers, and now the current five-year survival rate for all childhood cancers combined is 83\% (American Cancer Society, 2014). This knowledge might provide hope to families with a child diagnosed with cancer. However, it does not lessen the uncertainty and fear commonly felt related to this diagnosis. Researchers report a wide variety of parental responses when faced with the diagnosis of childhood cancer: uncertainty, anxiety, depression, anger, loss of faith, and even post-traumatic stress (Hutchinson, Willard, Hardy, \& Bonner, 2009; Vrijmoet-Wiersma et al., 2008). The question is not if these emotions exist, but rather, how do these feelings affect coping behaviors necessary for appropriate adaptation to this diagnosis, as well as how should the healthcare team address this (Jackson et al., 2009)? In adult cancer regimens, the integration of purposeful psychological interventions have assisted patients in developing coping behaviors and finding meaning in the disease course and its role in their lives (Lee, Cohen, Edgar, Laizner, \& Gagnon, 2006).

Parental, sibling and patient uncertainty has numerous implications for nurses. If one cannot focus on the tasks at hand due to uncertainty from unpredictability and loss of control, then one cannot learn how to manage the disease process and restore optimum health. A primary role of nursing is to facilitate the shift from illness to optimum health by assisting the client in learning coping behaviors, facilitating adaptation to new functions of caring for the ill child, and addressing any negative symptoms through therapeutic interventions during this process (Santacroce, 2002). Research has shown that interventions aimed at reducing uncertainty should increase adaptation in persons who are chronically ill (Comer et al., 2009; Holm et al., 2008; 
Brashers at al., 1999). Further evidence suggests that levels and types of uncertainty change over time (Brashers et al., 1999). In order to provide interventions aimed at reducing uncertainty and promoting adaptation and coping behaviors, nurses must understand the attributes of uncertainty so they can recognize the risk factors and develop appropriate interventions to reduce the potential consequences associated with uncertainty.

\section{Purpose}

An integrative review was completed in order to summarize the evidence on parental and familial uncertainty in childhood cancer and to provide recommendations for psychosocial and educational interventions. The purposes of this paper are to (1) review the relationships among uncertainty, stress, anxiety, and adaptation and (2) discuss recommended psychosocial support and education interventions to reduce uncertainty and facilitate adaptation in families dealing with childhood cancer.

\section{Theoretical Perspectives}

The review of literature is guided by Mishel's Theory of Uncertainty through searching for the evidence regarding uncertainty and related concepts of stress, anxiety, and adaptation in childhood cancer and chronic illness (Mishel, 1983, 1988). Because uncertainty is commonly caused by fear of the unknown, lack of clarity and information, and unpredictability (Mishel, 1983, 1988), it is proposed that psychosocial support and education can greatly reduce uncertainty in this population. By focusing on common ways parents of children with cancer manifest uncertainty and how psychosocial support and education can help them adapt, the author hopes to identify recommendations in the literature for appropriately providing these types of interventions.

Uncertainty has been well documented in numerous and different settings and has been linked to both physical and mental health distress (Holm, Patterson, Rueter, \& Wamboldt, 2008; Katz, 2002). It is defined as a state of being uncertain and has synonyms such as mistrust, reservation, suspicion, and doubt. In nursing it is primarily described as pertaining to an illness 
experience, such as the period when a patient or family member is unsure of what the outcome of a procedure or disease process will entail (Penrod, 2001). Uncertainty is known to be common in cancer diagnoses, and is defined as a state when a stressful event cannot be organized due to lack of information or knowledge. It includes feelings of anxiety, stress, and loss of control and leaves the family unable to predict outcomes (Mishel, 1988). It can last for a short period until diagnostic test results are known or it can persist for years after completion of a cancer therapy regimen (Brashers et al., 1999; Horner, 1997). It is often associated with fear of the unknown, and has a direct link to increased familial stress patterns (Brashers et al., 1999; Holm et al., 2008; McGrath \& Phillips, 2008, \& Patiño-Fernández, Pai, Alderfer, Hwang, Reilly, 2008).

Mishel $(1981 ; 1983 ; 1988)$ proposes that uncertainty is comprised of three concepts: an event that acts as a stimulus, a structural framework, and the ability to process information. There must be an event that prompts one to feel uncertain regarding the future. The more familiar a subject is with the event, the less uncertainty will be present. A structural framework includes supporting mechanisms such as familial support, health care providers, and social support of other patients with similar stimuli. Having providers that are trusted by the subject in the stimuli area helps to reduce uncertainty. Lastly, a nurse must note the ability of a parent/patient to process information received or any mental or physical obstacles preventing the subject from doing so. Based on Mishel's (1988) conceptualization of uncertainty, (stimulus event, structural framework, and the ability to process information), important attributes of uncertainty include the following:

\section{Actual or anticipated loss of control}

2. Involvement in a dynamic experience where the outcome is unknown (ambiguity)

\section{Persistent and pervasive psychological distress}

This means a parent who is faced with their child's diagnosis of cancer (stimulus event) can process and understand the information given to them based on the support they have and receive, 
and their cognitive ability to understand (structural framework). However, despite how well they may or may not understand the diagnosis and treatment process or what steps will be necessary to help them adapt, they have no control over the actual diagnosis. They have little control over how their child's treatment will begin. This causes persistent distress. Whether or not this stress will be used toward a positive or negative appraisal of uncertainty can be affected by the information and support provided by the health care team as well as how the parent perceives, understands, and participates in that care. Based on this theoretical perspective, the literature search will be guided by the following questions. In parents of children who are newly diagnosed with cancer:

1. How are stress and anxiety linked to parental, sibling and patient uncertainty in the diagnostic phase?

2. How does the fear of the unknown, lack of clarity and information and unpredictability following the diagnosis of childhood cancer affect familial adaptation?

3. What educational and psychosocial support interventions have been done or are recommended to improve familial adaptation and/or to decrease uncertainty?

\section{Methods}

In an effort to identify evidence of uncertainty in the two to three weeks following diagnosis of cancer and any identified interventions that were shown to be helpful, an integrative literature review was conducted using the guidelines recommended in Torraco (2005). An integrative review rather than a systematic review was chosen because of the focus on psychosocial and educational interventions related to uncertainty. While not as comprehensive and expansive on all evidence related to uncertainty, this approach allowed the investigator to focus on the area of interest (psychosocial and support mechanisms) rather than reviewing all research on interventions for reducing uncertainty (Holopainen, Hakulinen-Viitanen \&Tossavainen, 2008; Polit and Beck , 2012; Torraco, 2005). The search was completed through online databases in nursing and psychology: Cinahl, Medline, Pubmed, and Psycinfo. Guidelines 
from Torraco (2005) were used to enhance the rigor of selection and analysis of the literature included.

\section{Inclusion and Exclusion Criteria}

Search limits were set for research journals and dissertations published from 1995-2014 using search words of uncertainty, adaptation, anxiety, cancer, chronic, life threatening illness, diagnosis, nursing, education, and support. Opposite terms such as certainty and knowledge were purposely excluded from the search to focus on the main concepts: uncertainty and adaptation and the development of them throughout the diagnosis and treatment phases. The 20 year publication period was chosen in order to catch any landmark articles establishing uncertainty as an occurrence in cancer and traumatic illness diagnosis. Articles that focused on both adults and children with cancer, as well as families were included. For the purposes of this study, family research can be defined as broader than the single, traditional, household unit. It is inclusive of how a child and caregiver define themselves in terms of the child and the child's primary caregiver(s). Articles were not limited based on research design, location or culture. Articles discussing uncertainty, stress, and adaptation in chronic illness were included. A preference was shown for studies based in the United States, Europe, and Asia although other sites and cultures were not excluded simply due to their location. Articles were excluded if they were only demonstrating the process or results of testing the efficacy of new measurement tools documenting uncertainty, anxiety, or other concepts related to the diagnosis of a childhood cancer or chronic illness.

\section{Results}

Forty-one articles were originally identified and then sorted according to the following topics: uncertainty during diagnosis, adapting and living with chronic childhood illness, and education and supportive care. Seven articles were excluded due to their inclusion of testing the validity of measurement tools. In the end, 34 articles were included for this review. Seventy-four percent of the articles located were published after the year 2000. Three articles focused on adult 
cancer populations and 15 articles dealt with parents of children with cancer or a chronic illness. Five were family based research and included both the child and parent(s) as couplets. Seven were based on research with children diagnosed with cancer or a chronic illness, adolescents and young adults, and survivors of childhood cancer. One was based on research with the diagnosed child's sibling only. Three were literature reviews. Of the 31 non literature review articles, 23 of them discussed care of cancer patients, and eight discussed chronically ill children. Forty-eight percent (15) were qualitative designs; $45 \%$ (14) were quantitative; and of those $79 \%$ were descriptive and $21 \%$ quantitatively tested an intervention. Two others were mixed designs and included both an intervention and qualitative interviews. The three literature reviews were specific to uncertainty in child or chronic illness. They were included because the review focused on stress, anxiety, and uncertainty and factors that affect adaptation. However, this integrative review was still warranted because two of these articles were focused primarily on stress in parents of children with cancer. The third was published 14 years ago and was focused on uncertainty in parents and children with cancer. It did not provide extensive evidence on suggested interventions for addressing uncertainty in order to facilitate adaptation. The results are presented according to three major concepts: a) those discussing uncertainty, stress and anxiety during the diagnostic phase, $b$ ) adaptation to cancer and chronic illness, and c) suggestions for educational and psychosocial interventions to reduce uncertainty through education and psychosocial support. Each of these is discussed separately and details regarding study design, samples, and concepts can be found in Table 1. 
Table 1

Evidence Table

\begin{tabular}{|c|c|c|c|c|c|}
\hline Author/ Year & Participants & Study Design & $\begin{array}{c}\text { Concept } \\
\text { Area }\end{array}$ & Results & Recommendations \\
\hline $\begin{array}{l}\text { Boman, Lindahl, } \\
\text { and Bjork (2003) }\end{array}$ & $\begin{array}{l}264 \text { parents of } \\
\text { children with } \\
\text { cancer being } \\
\text { treated in Sweden, } \\
146 \text { mothers, } 118 \\
\text { fathers }\end{array}$ & $\begin{array}{l}\text { Cross- } \\
\text { Sectional } \\
\text { design. } \\
\text { Questionnaires, } \\
\text { survey data }\end{array}$ & $\begin{array}{l}\text { Stress, } \\
\text { Uncertainty }\end{array}$ & $\begin{array}{l}\text { Uncertainty in high end of the spectrum, worried } \\
\text { about treatment and its success versus the possible } \\
\text { long term affects. Approximately half the } \\
\text { participants had high levels of anxiety as well. } \\
\text { The longer the period since the diagnosis the } \\
\text { lower the levels of stress. }\end{array}$ & $\begin{array}{l}\text { Provide individualized screening and } \\
\text { psychosocial support early after diagnosis } \\
\text { and continually throughout the treatment } \\
\text { process. }\end{array}$ \\
\hline $\begin{array}{l}\text { Boyd and } \\
\text { Hunsberger (1998) }\end{array}$ & $\begin{array}{l}\text { Six Chronically ill } \\
\text { children actively } \\
\text { undergoing } \\
\text { treatment and } \\
\text { repeated } \\
\text { hospitalizations, 9- } \\
13 \text { years old }\end{array}$ & $\begin{array}{l}\text { Grounded } \\
\text { theory, } \\
\text { qualitative }\end{array}$ & $\begin{array}{l}\text { Coping, } \\
\text { Stress }\end{array}$ & $\begin{array}{l}\text { Stressors included invasive procedures, fear, loss } \\
\text { of control, lack of independence, isolation. } \\
\text { Children had similar coping strategies as their } \\
\text { parents: information seeking, distractions, } \\
\text { avoiding, seeking social support. Need parental } \\
\text { and loved one's presence to help support them. } \\
\text { Need privacy and independence from health care } \\
\text { team. }\end{array}$ & $\begin{array}{l}\text { Assist them in identifying what works for } \\
\text { them, families should be actively involved } \\
\text { and present for care, HC team members } \\
\text { should explain all actions, and provide } \\
\text { information and have the same nurses as } \\
\text { often as possible. }\end{array}$ \\
\hline $\begin{array}{l}\text { Branstetter, } \\
\text { Domian, Williams, } \\
\text { Graff, \& } \\
\text { Piamjariyakul. } \\
\text { (2008) }\end{array}$ & $\begin{array}{l}30 \text { parent-sibling } \\
\text { couplets of } \\
\text { children with } \\
\text { cancer in the } \\
\text { Midwestern US }\end{array}$ & Qualitative & $\begin{array}{l}\text { Communicati } \\
\text { on and } \\
\text { support }\end{array}$ & $\begin{array}{l}\text { Found that open communication between siblings } \\
\text { and parents of children with cancer helped the } \\
\text { sibling and parent both adapt better. Important to } \\
\text { make time to spend family time connecting and } \\
\text { talking together. Redefined normalcy to fit their } \\
\text { current needs, not compared to others without } \\
\text { chronic illness conditions. Making all efforts to be } \\
\text { equally available for all children in the family } \\
\text { when they needed to be. Communication can be } \\
\text { fragmented due to care of ill child. Siblings } \\
\text { voiced uncertainty related to disease process and } \\
\text { diagnosis. }\end{array}$ & $\begin{array}{l}\text { Use identified themes to help develop } \\
\text { measurement and intervention tools in } \\
\text { assisting and empowering family } \\
\text { communication. }\end{array}$ \\
\hline $\begin{array}{l}\text { Corey, Haase, } \\
\text { Azzouz, \& } \\
\text { Monahan (2008). }\end{array}$ & $\begin{array}{l}\text { ARM 1: } 127 \\
\text { adolescents/ young } \\
\text { adults with cancer } \\
\text { (on or off } \\
\text { treatment); ARM } \\
\text { 2: } 72 \text { newly } \\
\text { diagnosed }\end{array}$ & $\begin{array}{l}\text { Descriptive, } \\
\text { Cross- } \\
\text { sectional; } \\
\text { Questionnaires: } \\
\text { McCorkle } \\
\text { Symptoms } \\
\text { Distress Scale, }\end{array}$ & $\begin{array}{l}\text { Stress, } \\
\text { depression, } \\
\text { adaptation }\end{array}$ & $\begin{array}{l}\text { Higher perceived support from family, friends and } \\
\text { the health care team all indicated higher levels of } \\
\text { mental health. More support from family and } \\
\text { friends was associated with less depressed mood, } \\
\text { and decreased anxiety when compared with } \\
\text { support from the health care team. Older age was } \\
\text { significant with worse mental health. Participants }\end{array}$ & $\begin{array}{l}\text { Encourage continuity in care provided to this } \\
\text { population. Provide mechanisms for } \\
\text { identification of support from family and } \\
\text { friends. Address and discuss transitions to } \\
\text { independence in older AYA patients. }\end{array}$ \\
\hline
\end{tabular}




\begin{tabular}{|c|c|c|c|c|c|}
\hline Author/ Year & Participants & $\begin{array}{l}\text { Study Design } \\
\text { Perceived } \\
\text { Social Support } \\
\text { from Friends } \\
\text { and Perceived } \\
\text { Social Support } \\
\text { from Family } \\
\text { Scales, Mental } \\
\text { health subscale } \\
\text { of the Short } \\
\text { Form Health } \\
\text { Survey- } \\
\text { Medical } \\
\text { Outcome } \\
\text { Study. }\end{array}$ & $\begin{array}{l}\text { Concept } \\
\text { Area }\end{array}$ & $\begin{array}{l}\text { Results } \\
\text { who remained positive and had more trust in their } \\
\text { team had less stress and insomnia. }\end{array}$ & Recommendations \\
\hline $\begin{array}{l}\text { Fiese and } \\
\text { Wamboldt (2003) }\end{array}$ & $\begin{array}{l}\text { Parents of children } \\
\text { with asthma }\end{array}$ & $\begin{array}{l}\text { Qualitative } \\
\text { interviews and } \\
\text { quantitative } \\
\text { questionnaires: } \\
\text { Family } \\
\text { Narrative } \\
\text { Consortium } \\
\text { Coding } \\
\text { Scheme, Five } \\
\text { Minute Speech } \\
\text { Sample for } \\
\text { Expressed } \\
\text { Emotion, } \\
\text { Impact on the } \\
\text { Family Scale }\end{array}$ & Coping & $\begin{array}{l}\text { When relationships with family members were } \\
\text { stronger then the parent of a child with a chronic } \\
\text { illness coped better and the illness had less of an } \\
\text { impact on the family. When relationships were } \\
\text { not strong the illness and care needed sometimes } \\
\text { causes mistrust between family members. }\end{array}$ & \\
\hline $\begin{array}{l}\text { Flury, Caflisch, } \\
\text { Ullmann-Bremi, } \\
\text { and Spichiger } \\
\text { (2011) }\end{array}$ & $\begin{array}{l}\text { Had a total of } \\
\text { twelve parents } \\
\text { (nine mothers and } \\
\text { three fathers) of } \\
\text { children with } \\
\text { cancer that } \\
\text { completed both } \\
\text { qualitative }\end{array}$ & $\begin{array}{l}\text { Qualitative } \\
\text { Interviews } \\
\text { studied the } \\
\text { experiences of } \\
\text { parents caring } \\
\text { for a child with } \\
\text { cancer } \\
\text { immediately }\end{array}$ & Uncertainty & $\begin{array}{l}\text { As the first discharge approached parents reported } \\
\text { increased uncertainty coming from a combination } \\
\text { of the information provided about the cancer } \\
\text { diagnosis and the fear related to that diagnosis } \\
\text { and the unknown success of the treatment } \\
\text { regimen. Parents feared making a mistake or } \\
\text { missing something crucial to the child's care. } \\
\text { Leaving them feeling as though they lived in a }\end{array}$ & $\begin{array}{l}\text { The authors suggest that to help parents } \\
\text { prepare for the first transition from inpatient } \\
\text { to home life, supportive interventions aimed } \\
\text { at providing a list of expectations and things } \\
\text { to do prior to discharge would help reduce } \\
\text { the uncertainty and fear parents face. } \\
\text { They suggest coordinating support between } \\
\text { families who have experienced this already }\end{array}$ \\
\hline
\end{tabular}




\begin{tabular}{|c|c|c|c|c|c|}
\hline Author/ Year & $\begin{array}{l}\text { Participants } \\
\text { interviews. }\end{array}$ & $\begin{array}{l}\text { Study Design } \\
\text { after the } \\
\text { diagnosis and } \\
\text { as they } \\
\text { transition home } \\
\text { for the first } \\
\text { time after that } \\
\text { diagnosis. }\end{array}$ & $\begin{array}{c}\text { Concept } \\
\text { Area }\end{array}$ & $\begin{array}{l}\text { Results } \\
\text { "permanent state of emergency" (Flury et al, } \\
2011, \text { p. 147). They equated that care to a full } \\
\text { time job, 24-7 duty }\end{array}$ & $\begin{array}{l}\text { Recommendations } \\
\text { and new families would be very helpful. } \\
\text { They also suggest including this specifically } \\
\text { in the education plan several days or weeks } \\
\text { ahead of discharge so parents have time to } \\
\text { adjust care needs prior to being immersed in } \\
\text { it at home. }\end{array}$ \\
\hline $\begin{array}{l}\text { Fuemmeler, } \\
\text { Mullins, and Marx } \\
\text { (2001) }\end{array}$ & $\begin{array}{l}\text { They had a total of } \\
28 \text { participants ( } 18 \\
\text { mothers and } 10 \\
\text { fathers), most of } \\
\text { which identified as } \\
\text { married, } \\
\text { Caucasian, middle } \\
\text { class parents of a } \\
\text { child with a brain } \\
\text { tumor. }\end{array}$ & $\begin{array}{l}\text { Descriptive. } \\
\text { Correlational. } \\
\text { Utilized the } \\
\text { PPUS to } \\
\text { measure } \\
\text { uncertainty, the } \\
\text { Post-Traumatic } \\
\text { Stress } \\
\text { Diagnostic } \\
\text { Scale (PDS) to } \\
\text { measure PTSD } \\
\text { symptoms, the } \\
\text { Brief Symptom } \\
\text { Inventory } \\
\text { (BSI) to } \\
\text { measure } \\
\text { distress, and } \\
\text { the Ways of } \\
\text { Coping } \\
\text { Questionnaire } \\
\text { to assess } \\
\text { coping } \\
\text { strategies. }\end{array}$ & PTSD & $\begin{array}{l}\text { PTSD symptoms meeting diagnostic criteria } \\
\text { found in } 42 \% \text { of participants. Possible that poorer } \\
\text { prognosis and higher risk treatment are risk } \\
\text { factors for development of PTSD. }\end{array}$ & $\begin{array}{l}\text { The authors recommend support } \\
\text { interventions aimed specifically at PTSD } \\
\text { symptoms. }\end{array}$ \\
\hline $\begin{array}{l}\text { Gannoni and Shute } \\
\text { (2010) }\end{array}$ & $\begin{array}{l}18 \text { children with } \\
\text { chronic illnesses at } \\
\text { least one year prior } \\
\text { and } 21 \text { of their } \\
\text { parents in southern } \\
\text { Australia. }\end{array}$ & $\begin{array}{l}\text { Qualitative. } \\
\text { Worked with } \\
\text { focus groups to } \\
\text { discover what } \\
\text { parents and } \\
\text { children with } \\
\text { chronic illness }\end{array}$ & Adaptation & $\begin{array}{l}\text { Parents and children cope in positive manners by } \\
\text { seeking information to empower themselves in a } \\
\text { positive way through attributing meaning to the } \\
\text { disease process and also through extended social } \\
\text { and family support networks. }\end{array}$ & $\begin{array}{l}\text { Allow for earlier support and education as } \\
\text { well as opportunities to share or express } \\
\text { feelings regarding the disease and its } \\
\text { consequences both individually and in small } \\
\text { groups or family sessions. }\end{array}$ \\
\hline
\end{tabular}




\begin{tabular}{|c|c|c|c|c|c|}
\hline Author/ Year & Participants & $\begin{array}{l}\text { Study Design } \\
\text { felt would be } \\
\text { most beneficial } \\
\text { in helping them } \\
\text { adapt to their } \\
\text { diagnosis. }\end{array}$ & $\begin{array}{l}\text { Concept } \\
\text { Area }\end{array}$ & Results & Recommendations \\
\hline $\begin{array}{l}\text { Grootenhuis and } \\
\text { Last (1997) }\end{array}$ & $\begin{array}{l}84 \text { children with } \\
\text { cancer and } 84 \text { of } \\
\text { their mothers and } \\
79 \text { of their fathers } \\
\text { in Amsterdam. }\end{array}$ & $\begin{array}{l}\text { Qualitative } \\
\text { interviews with } \\
\text { each person } \\
\text { (child, mother, } \\
\text { father). } \\
\text { Descriptive } \\
\text { and Predictive: } \\
\text { Questionnaires } \\
\text { from each } \\
\text { person. } \\
\text { Questionnaires: } \\
\text { Depression } \\
\text { Questionnaire } \\
\text { for Children, } \\
\text { Control } \\
\text { Strategy Scale, } \\
\text { Beck } \\
\text { Depression } \\
\text { Inventory, } \\
\text { Trait Anxiety } \\
\text { Inventory, } \\
\text { Situation } \\
\text { Specific } \\
\text { Emotional } \\
\text { Reaction } \\
\text { Questionnaire }\end{array}$ & $\begin{array}{l}\text { Adaptation, } \\
\text { Adjustment }\end{array}$ & $\begin{array}{l}\text { Parents with children whose cancer had relapsed } \\
\text { were predictive of symptoms of depression, } \\
\text { anxiety, uncertainty and helplessness. Negative } \\
\text { expectations (lack of a positive attitude) also } \\
\text { predicted higher levels of uncertainty and } \\
\text { helplessness. However, parents generally have } \\
\text { positive expectations of the treatment regimen. } \\
\text { Positive expectations help parents feel more } \\
\text { control over the situation. Mothers show more } \\
\text { feelings of loneliness and depression further from } \\
\text { the diagnosis and they feel no one understands } \\
\text { what they are going through. }\end{array}$ & $\begin{array}{l}\text { No specific recommendations for nursing } \\
\text { care. }\end{array}$ \\
\hline Hinds et al. (1996) & $\begin{array}{l}33 \text { guardians }(27 \\
\text { mothers, } 5 \text { fathers, } \\
\text { and } 1 \\
\text { grandmother) of } \\
\text { children with } \\
\text { cancer recurrence. }\end{array}$ & $\begin{array}{l}\text { Qualitative, } \\
\text { Grounded } \\
\text { theory, } \\
\text { interviews, } \\
\text { observations, } \\
\text { and medical }\end{array}$ & $\begin{array}{l}\text { Coming to } \\
\text { terms, } \\
\text { uncertainty, } \\
\text { shock at } \\
\text { recurrence } \\
\text { diagnosis. }\end{array}$ & $\begin{array}{l}\text { Parents described the second diagnosis as shock } \\
\text { and immense grief followed by rapid turn-around } \\
\text { toward seeking out options for additional } \\
\text { treatment. Knowing the steps that needed to be } \\
\text { taken, but doubting their ability to make the right } \\
\text { decision based on the failure of prior treatment. }\end{array}$ & \\
\hline
\end{tabular}




\begin{tabular}{|c|c|c|c|c|c|}
\hline Author/ Year & Participants & $\begin{array}{l}\text { Study Design } \\
\text { record review. }\end{array}$ & $\begin{array}{l}\text { Concept } \\
\text { Area }\end{array}$ & $\begin{array}{l}\text { Results } \\
\text { Demonstrated more security with the team due to } \\
\text { prior experiences with the team and the } \\
\text { relationship built from the prior treatment's } \\
\text { interactions. Parents began preparing for the loss } \\
\text { of their child....just in case in order to help them } \\
\text { not be so shocked. }\end{array}$ & Recommendations \\
\hline Horner (1997) & $\begin{array}{l}12 \text { mothers of } 15 \\
\text { school-age } \\
\text { children with } \\
\text { asthma }\end{array}$ & $\begin{array}{l}\text { Grounded } \\
\text { Theory, } \\
\text { Qualitative }\end{array}$ & Uncertainty & $\begin{array}{l}\text { Uncertainty related to what was causing the } \\
\text { continuing illness, dissatisfaction with answers } \\
\text { given. Parents sought out information and } \\
\text { demanded variations in care. }\end{array}$ & $\begin{array}{l}\text { Suggest earlier referral to specialists. } \\
\text { Understanding and listening to the families' } \\
\text { concerns is of great importance in providing } \\
\text { sound care. Supporting families' access to } \\
\text { care. }\end{array}$ \\
\hline Hovey (2005) & $\begin{array}{l}48 \text { Fathers of } \\
\text { children with } \\
\text { chronic illnesses } \\
\text { ages } 20-60 \text { years } \\
\text { living in the mid- } \\
\text { west US }\end{array}$ & $\begin{array}{l}\text { Descriptive, } \\
\text { Utilized the } \\
\text { Family } \\
\text { Perception } \\
\text { Inventory } 1 .\end{array}$ & $\begin{array}{l}\text { Coping, } \\
\text { adaptation to } \\
\text { chronic } \\
\text { illness }\end{array}$ & $\begin{array}{l}\text { Father's concerns were mostly about children's } \\
\text { health but also about lack of family time, their } \\
\text { spouse's fatigue related to care of child. } 100 \% \text { of } \\
\text { fathers used information seeking, figuring out } \\
\text { what to do, looking at options and weighing } \\
\text { choices as coping mechanisms. }\end{array}$ & $\begin{array}{l}\text { Early intervention to guide families while } \\
\text { fathers are available before returning to work } \\
\text { in support networking (extended family } \\
\text { availability), information sharing, external } \\
\text { support help about things like equipment and } \\
\text { financial assistance. }\end{array}$ \\
\hline $\begin{array}{l}\text { Hutchinson, } \\
\text { Willard, Hardy and } \\
\text { Bonner (2009) }\end{array}$ & $\begin{array}{l}90 \text { parents of } \\
\text { childhood brain } \\
\text { cancer patients } \\
(52 \% \text { on treatment })\end{array}$ & $\begin{array}{l}\text { Descriptive. } \\
\text { Questionnaires: } \\
\text { Brief Symptom } \\
\text { Inventory, } \\
\text { Parent } \\
\text { Experience of } \\
\text { Child Illness, } \\
\text { Impact on } \\
\text { Family Scale, } \\
\text { and Caregiver } \\
\text { Strain } \\
\text { Questionnaire }\end{array}$ & $\begin{array}{l}\text { Stress and } \\
\text { illness }\end{array}$ & $\begin{array}{l}\text { Stress decreased after treatment ended, but } \\
\text { uncertainty levels remained high as well as } \\
\text { caregiving burden related to their child's illness }\end{array}$ & $\begin{array}{l}\text { Continue to provide support for caregiving } \\
\text { burden well after treatment is finished. Use } \\
\text { measures designed specifically to evaluate } \\
\text { illness related psycho social functioning like } \\
\text { the Parent experience of child illness and } \\
\text { impact on family scale. }\end{array}$ \\
\hline $\begin{array}{l}\text { Kästel, Ensär, \& } \\
\text { Björk (2011) }\end{array}$ & $\begin{array}{l}8 \text { families of a } \\
\text { child diagnosed } \\
\text { with cancer } \\
\text { receiving treatment }\end{array}$ & $\begin{array}{l}\text { Qualitative } \\
\text { interviews, } 5 \\
\text { interviews with } \\
\text { each of the } \\
\text { eight families }\end{array}$ & $\begin{array}{l}\text { Information } \\
\text { Education }\end{array}$ & $\begin{array}{l}\text { Found that not only what information is given } \\
\text { after diagnosis is important, but also who, when, } \\
\text { how information is given is of importance in } \\
\text { internalization of this material. Transitions from } \\
\text { inpatient to outpatient are especially stressful }\end{array}$ & $\begin{array}{l}\text { Suggest a more structured format for } \\
\text { education delivery. Large health care teams } \\
\text { should coordinate information delivery to } \\
\text { optimize retention and integration of the } \\
\text { parents into the child's care. Continuation of }\end{array}$ \\
\hline
\end{tabular}




\begin{tabular}{|c|c|c|c|c|c|}
\hline Author/ Year & $\begin{array}{l}\text { Participants } \\
\text { at a Swedish } \\
\text { pediatric cancer } \\
\text { ward }\end{array}$ & $\begin{array}{l}\text { Study Design } \\
\text { over the first } \\
\text { year of } \\
\text { treatment for } \\
\text { cancer }\end{array}$ & $\begin{array}{l}\text { Concept } \\
\text { Area }\end{array}$ & $\begin{array}{l}\text { Results } \\
\text { related to information sharing. }\end{array}$ & $\begin{array}{l}\text { Recommendations } \\
\text { information sharing after the original } \\
\text { diagnosis is difficult and new models should } \\
\text { be tried. Working on communication styles } \\
\text { and coordination of care models will help } \\
\text { improve family centered care and make it } \\
\text { more of a reality. }\end{array}$ \\
\hline $\begin{array}{l}\text { Kerr, Harrison, } \\
\text { Medves, Tranmer, } \\
\& \text { Fitch (2007). }\end{array}$ & $\begin{array}{l}15 \text { Parents of } \\
\text { children diagnosed } \\
\text { with cancer more } \\
\text { than } 4 \text { weeks ago } \\
\text { and less than } 2 \\
\text { years ago. }\end{array}$ & $\begin{array}{l}\text { Qualitative and } \\
\text { descriptive. } \\
\text { Cancer Patient } \\
\text { Needs } \\
\text { Questionnaire }\end{array}$ & Support & $\begin{array}{l}24 \text { concepts identified into five themes: Need for } \\
\text { information, Concept of giving information with } \\
\text { or without child present, Financial needs, Need } \\
\text { for emotional support, Need for support from } \\
\text { coworkers. Parents reported the need for more } \\
\text { information and time to talk with health care team } \\
\text { members. Need for emotional support. Felt } \\
\text { distrust from their employer. }\end{array}$ & $\begin{array}{l}\text { Recommend one coordinating person to help } \\
\text { deliver information to patients and families. } \\
\text { Communication between team members } \\
\text { should be improved. } \\
\text { Easier access for contact to healthcare } \\
\text { providers should be addressed. } \\
\text { Creation of an assessment checklist during } \\
\text { the diagnostic phase to help identify areas of } \\
\text { concerns related to psychosocial support and } \\
\text { distress. }\end{array}$ \\
\hline $\begin{array}{l}\text { Lee, Cohen, Edgar, } \\
\text { Laizner, \& Gagnon } \\
(2006) \text {. }\end{array}$ & $\begin{array}{l}18 \text { newly } \\
\text { diagnosed adult } \\
\text { cancer patients. }\end{array}$ & $\begin{array}{l}\text { Quasi- } \\
\text { experimental, } \\
\text { pre and post- } \\
\text { test with } \\
\text { interviews. }\end{array}$ & $\begin{array}{l}\text { Coping, } \\
\text { Uncertainty }\end{array}$ & $\begin{array}{l}\text { Meaning making intervention showed decrease in } \\
\text { uncertainty and improved sense of self-esteem } \\
\text { and a greater sense of security. }\end{array}$ & $\begin{array}{l}\text { MMI is a way to address existential issues in } \\
\text { cancer care. More research is needed in this } \\
\text { area to help increase coping skills and } \\
\text { decrease uncertainty. }\end{array}$ \\
\hline $\begin{array}{l}\text { Lee, Santacroce, \& } \\
\text { Sadler (2007). }\end{array}$ & $\begin{array}{l}46 \text { childhood } \\
\text { cancer survivors }\end{array}$ & $\begin{array}{l}\text { Cross-sectional } \\
\text { correlational } \\
\text { design. } \\
\text { Utilized the } \\
\text { Health } \\
\text { Promoting } \\
\text { Lifestyle } \\
\text { Profile, Mishel } \\
\text { Uncertainty in } \\
\text { Illness Scale- } \\
\text { Community } \\
\text { form, and }\end{array}$ & $\begin{array}{l}\text { Stress and } \\
\text { PTSD }\end{array}$ & $\begin{array}{l}\text { Symptoms of stress and PTSD might be the cause } \\
\text { of some developmental delays during transition to } \\
\text { young adulthood. Increased interactions with the } \\
\text { health care team and primary care provider show } \\
\text { increased rates of healthy behavior choices during } \\
\text { this transition period. History of spec. ed } \\
\text { coursework predicted delays in healthy behavior } \\
\text { choices and adaptation. }\end{array}$ & $\begin{array}{l}\text { Consider improving relationships with these } \\
\text { patients to improve long term health choices } \\
\text { Long term care clinic follow up } \\
\text { Special attention to those receiving special } \\
\text { education. } \\
\text { More developmental screenings during } \\
\text { childhood treatment and follow up. }\end{array}$ \\
\hline
\end{tabular}




\begin{tabular}{|c|c|c|c|c|c|}
\hline Author/ Year & Participants & $\begin{array}{l}\text { Study Design } \\
\text { Post-Traumatic } \\
\text { Stress Disorder } \\
\text { Index, }\end{array}$ & $\begin{array}{c}\text { Concept } \\
\text { Area }\end{array}$ & Results & Recommendations \\
\hline $\begin{array}{l}\text { Lounsberry, } \\
\text { MacRae, Angen, } \\
\text { Hoeber, \& Carlson } \\
\text { (2010) }\end{array}$ & $\begin{array}{l}19 \text { survivors } 1-3 \\
\text { years post } \\
\text { allogeneic stem } \\
\text { cell transplant aged } \\
19-66 \text {, avg. age } \\
\text { was } 45.8 \text { years, } \\
63 \% \text { were female. }\end{array}$ & $\begin{array}{l}\text { Pre and post- } \\
\text { test educational } \\
\text { intervention, } \\
\text { Questionnaires: } \\
\text { Functional } \\
\text { Assessment of } \\
\text { Cancer } \\
\text { Therapy-Bone } \\
\text { Marrow } \\
\text { Transplant, } \\
\text { Functional } \\
\text { Assessment of } \\
\text { Chronic Illness } \\
\text { Therapy- } \\
\text { Spiritual, } \\
\text { Impact of } \\
\text { Event Scale- } \\
\text { Revised, Post- } \\
\text { Traumatic } \\
\text { Growth } \\
\text { Inventory }\end{array}$ & $\begin{array}{l}\text { Education, } \\
\text { Support }\end{array}$ & $\begin{array}{l}\text { Difficulty with tele-health implementation due to } \\
\text { accessibility of sites with all necessary } \\
\text { functioning equipment. Felt the education } \\
\text { component was helpful to them as it addressed the } \\
\text { most common concerns of HST patients. Even } \\
\text { when not participating fully the participants still } \\
\text { confirmed they found the intervention helpful and } \\
\text { would like to continue. }\end{array}$ & $\begin{array}{l}\text { Continue more research in tele-health } \\
\text { implementation for support especially in rural } \\
\text { areas where traveling to the treatment center } \\
\text { outside of appointments could be difficult. }\end{array}$ \\
\hline Mawn (1999) & $\begin{array}{l}13 \text { parents ( } 1 \text { man } \\
\text { and } 12 \text { women) of } \\
\text { children with HIV } \\
\text { all treated a center } \\
\text { on the east coast of } \\
\text { the US. Aged } 30- \\
39 \text { years. }\end{array}$ & $\begin{array}{l}\text { Qualitative, } \\
\text { phenomenologi } \\
\text { cal, } 5 \text { year } \\
\text { longitudinal }\end{array}$ & Adaptation & $\begin{array}{l}\text { At diagnosis similar feelings to that of cancer } \\
4 \text { themes toward adaptation: strong tendency } \\
\text { toward normalization, a focus on a positive } \\
\text { attitude, spirituality as a source of strength, family } \\
\text { support. }\end{array}$ & $\begin{array}{l}\text { Tell them in an appropriate setting, provide } \\
\text { support with others going through the same } \\
\text { thing, treat them like normal, and help them } \\
\text { to act that way, help them tap into family } \\
\text { support and talk about ways to talk with } \\
\text { others. Address long term care concerns for } \\
\text { children...growing up, adolescence, } \\
\text { independence, and transitions to adulthood, } \\
\text { loss of their infected caregiver. }\end{array}$ \\
\hline Neville (1998) & $\begin{array}{l}60 \text { adolescents } \\
\text { aged } 14-22 \text { years } \\
\text { old diagnosed with }\end{array}$ & $\begin{array}{l}\text { Descriptive, } \\
\text { Questionnaires: } \\
\text { Mishel }\end{array}$ & $\begin{array}{l}\text { Uncertainty, } \\
\text { Support and } \\
\text { Distress }\end{array}$ & $\begin{array}{l}\text { Confirmation of Mishel's model as appropriate in } \\
\text { showing how adolescents process the diagnosis } \\
\text { and appraise uncertainty as negative. Reported }\end{array}$ & $\begin{array}{l}\text { Promotion of an atmosphere of trust and } \\
\text { sharing of information related to the } \\
\text { treatment and its side effects. Promote an }\end{array}$ \\
\hline
\end{tabular}




\begin{tabular}{|c|c|c|c|c|c|}
\hline Author/ Year & $\begin{array}{l}\text { Participants } \\
\text { cancer (40 male } \\
\text { and } 20 \text { female), } \\
\text { northeast USA. }\end{array}$ & $\begin{array}{l}\text { Study Design } \\
\text { Uncertainty in } \\
\text { Illness Scale, } \\
\text { Brief Symptom } \\
\text { Inventory, } \\
\text { Personal } \\
\text { Resource } \\
\text { Questionnaire- } \\
\text { 84-Part Two }\end{array}$ & $\begin{array}{l}\text { Concept } \\
\text { Area }\end{array}$ & $\begin{array}{l}\text { Results } \\
\text { that low levels of perceived support and high } \\
\text { levels of uncertainty led to increased levels of } \\
\text { distress. }\end{array}$ & $\begin{array}{l}\text { Recommendations } \\
\text { environment of social support. }\end{array}$ \\
\hline $\begin{array}{l}\text { Nolbris, } \\
\text { Abrahamsson, } \\
\text { Hellström, } \\
\text { Olofsson, Enskär } \\
\text { (2010) }\end{array}$ & $\begin{array}{l}15 \text { siblings of } \\
\text { children with } \\
\text { cancer, ages } 8-19 \\
\text { years old, five } \\
\text { boys and } 10 \text { girls. }\end{array}$ & $\begin{array}{l}\text { Support group } \\
\text { intervention, } \\
\text { then qualitative } \\
\text { interviews }\end{array}$ & Support & $\begin{array}{l}\text { Siblings enjoyed sharing their story. Felt it was } \\
\text { good to talk with other siblings going through the } \\
\text { same thing as them. Support group meetings } \\
\text { helped them recall and define their relationship } \\
\text { and memories with their ill sibling. }\end{array}$ & $\begin{array}{l}\text { Recommend support group for siblings of } \\
\text { children with cancer throughout the } \\
\text { treatment. Recommend more studies on } \\
\text { support for siblings. }\end{array}$ \\
\hline $\begin{array}{l}\text { Novakovic et al. } \\
\text { (1996) }\end{array}$ & $\begin{array}{l}85 \text { survivors of } \\
\text { Ewing Sarcoma. } \\
\text { At least } 3 \text { years } \\
\text { after diagnosis. } \\
\text { Average age of } \\
15.8 \text { at diagnosis, } \\
\text { average of } 13.6 \\
\text { years since } \\
\text { diagnosis. }\end{array}$ & $\begin{array}{l}\text { Qualitative } \\
\text { interviews }\end{array}$ & Coping & $\begin{array}{l}\text { Frustration with delayed independence from } \\
\text { families and also in disability associated with } \\
\text { work, school, and social activities. Uncertainty } \\
\text { regarding relapse (immediately and years later) } \\
\text { remains. } \\
\text { Participants suggested maintaining a positive } \\
\text { outlook, seeking out information to become more } \\
\text { informed, using family and support networks } \\
\text { (especially sharing with other cancer patients) to } \\
\text { help get through the cancer treatment. }\end{array}$ & $\begin{array}{l}\text { Better prepare patients (especially } \\
\text { adolescents) about their peers' possible } \\
\text { reactions to their treatment as well as } \\
\text { difficulty maintaining school performance. }\end{array}$ \\
\hline $\begin{array}{l}\text { Patiño-Fernández } \\
\text { et al., } 2008\end{array}$ & $\begin{array}{l}\text { Their sample } \\
\text { included mostly } \\
\text { two-caregiver } \\
\text { families ( } 80 \%) \text { of } \\
\text { children with } \\
\text { cancer with } \\
\text { average ages of } \\
\text { late thirties to early } \\
\text { forties. } 129 \\
\text { mothers and } 71 \\
\text { fathers. Seventy- } \\
\text { eight percent of the } \\
\text { participants } \\
\text { identified }\end{array}$ & $\begin{array}{l}\text { Examined } \\
\text { acute stress in } \\
\text { parents of } \\
\text { newly } \\
\text { diagnosed } \\
\text { childhood } \\
\text { cancer patients } \\
\text { through a } \\
\text { descriptive } \\
\text { design using } \\
\text { Acute Stress } \\
\text { Disorder Scale, } \\
\text { Family } \\
\text { Environment } \\
\end{array}$ & Acute Stress & $\begin{array}{l}\text { Over } 50 \% \text { of mothers and } 40 \% \text { of fathers met the } \\
\text { Diagnostic and Statistical Manual-Fourth Edition } \\
\text { Text Revision (DSM-IV) criteria for acute stress } \\
\text { disorder secondary to their high anxiety scores. } \\
\text { They showed that socioeconomic status, } \\
\text { relationship status, family cohesion and conflict } \\
\text { as well as the level of general anxiety correlated } \\
\text { with acute stress disorder. }\end{array}$ & $\begin{array}{l}\text { The authors suggest that delivery of } \\
\text { psychosocial support during and immediately } \\
\text { after the diagnosis period is crucial toward } \\
\text { successful adaption. }\end{array}$ \\
\hline
\end{tabular}




\begin{tabular}{|c|c|c|c|c|c|}
\hline Author/ Year & \begin{tabular}{l}
\multicolumn{1}{c}{ Participants } \\
themselves as \\
Caucasian. All \\
were located in the \\
northeast United \\
States area.
\end{tabular} & $\begin{array}{l}\text { Study Design } \\
\text { Scale, and the } \\
\text { State-Trait } \\
\text { Anxiety } \\
\text { Inventory } \\
\text { Scale. }\end{array}$ & $\begin{array}{l}\text { Concept } \\
\text { Area }\end{array}$ & Results & Recommendations \\
\hline $\begin{array}{l}\text { Ramfelt and } \\
\text { Lützén (2005) }\end{array}$ & $\begin{array}{l}10 \text { colorectal } \\
\text { patients }(2 \text { women, } \\
8 \text { men) } 61-76 \text { years } \\
\text { old }\end{array}$ & $\begin{array}{l}\text { Grounded } \\
\text { theory, } \\
\text { qualitative }\end{array}$ & $\begin{array}{l}\text { Adaptation, } \\
\text { participation, } \\
\text { uncertainty }\end{array}$ & $\begin{array}{l}\text { Patients felt they were rushed into decisions, loss } \\
\text { of control regarding their care versus having the } \\
\text { decision left to them and being informed and } \\
\text { feeling they made the right decision. }\end{array}$ & $\begin{array}{l}\text { Use supportive communication techniques to } \\
\text { ensure patient understanding of the illness } \\
\text { immediately after the diagnosis to ensure the } \\
\text { optimum level of patient autonomy, } \\
\text { empowerment and inclusion in their health } \\
\text { care decisions. Develop ways to build more } \\
\text { trusting relationships between providers and } \\
\text { the patient/family unit. }\end{array}$ \\
\hline $\begin{array}{l}\text { Samarel, Fawcett, } \\
\text { Tulman (1997) }\end{array}$ & $\begin{array}{l}181 \text { women who } \\
\text { had surgery for } \\
\text { breast cancer } \\
\text { within the previous } \\
\text { four months aged } \\
28-86 \text { years old. }\end{array}$ & $\begin{array}{l}\text { Experimental: } \\
\text { Cancer Support } \\
\text { Group } \\
\text { intervention, } \\
\text { Questionnaires, } \\
\text { Symptom } \\
\text { Distress Scale, } \\
\text { The Profile of } \\
\text { Mood States- } \\
\text { Linear Analog } \\
\text { Self } \\
\text { Assessment, } \\
\text { Inventory of } \\
\text { Functional } \\
\text { Status, } \\
\text { Relationship } \\
\text { Change Scale }\end{array}$ & $\begin{array}{l}\text { Support, } \\
\text { Coping, } \\
\text { Adaptation }\end{array}$ & $\begin{array}{l}\text { Experimental group showed no less symptom } \\
\text { distress and emotional distress or greater } \\
\text { functional status. The intervention did have an } \\
\text { effect on the status of relationships with } \\
\text { significant others. Roy Adaptation Model may not } \\
\text { be the best fit for social support and adaptation } \\
\text { research in cancer. Did not show significant } \\
\text { differences over time. }\end{array}$ & $\begin{array}{l}\text { Continue social support research earlier, } \\
\text { immediately after diagnosis and continue } \\
\text { until at least one year post diagnosis. }\end{array}$ \\
\hline Santacroce (2000) & $\begin{array}{l}25 \text { mothers of } \\
\text { children being } \\
\text { diagnosed with } \\
\text { HIV at a clinic in } \\
\text { the northeast US, }\end{array}$ & $\begin{array}{l}\text { Descriptive, } \\
\text { Questionnaires } \\
\text { Staff } \\
\text { Relationship } \\
\text { Subscale of the }\end{array}$ & Uncertainty & $\begin{array}{l}\text { Support from the health care provider/team } \\
\text { significantly decreased uncertainty related to the } \\
\text { mother's illness. Increased uncertainty about her } \\
\text { own illness also produced increased uncertainty } \\
\text { about her child's illness. }\end{array}$ & $\begin{array}{l}\text { Increased work to provide appropriate } \\
\text { support to mothers of children with HIV to } \\
\text { reduce uncertainty related to their own illness } \\
\text { so that it will also reduce uncertainty } \\
\text { regarding their child's illness. }\end{array}$ \\
\hline
\end{tabular}




\begin{tabular}{|c|c|c|c|c|c|}
\hline Author/Year & \begin{tabular}{l}
\multicolumn{1}{c}{ Participants } \\
average age was \\
30 years old.
\end{tabular} & $\begin{array}{l}\text { Study Design } \\
\text { Parental } \\
\text { Stressor Scale, } \\
\text { Mishel } \\
\text { Uncertainty in } \\
\text { Illness Scale- } \\
\text { Community } \\
\text { Form, Parent } \\
\text { Perception of } \\
\text { Uncertainty } \\
\text { Scale, Parent } \\
\text { Perception of } \\
\text { Uncertainty- } \\
\text { Diagnosis }\end{array}$ & $\begin{array}{c}\text { Concept } \\
\text { Area }\end{array}$ & Results & $\begin{array}{l}\text { Recommendations } \\
\text { Nurses should be aware of the factors that } \\
\text { cause increase in uncertainty related to the } \\
\text { child's diagnosis and care and specifically } \\
\text { work to address those concerns through } \\
\text { education and support. } \\
\text { Work to provide assessment and education } \\
\text { regarding the parent's own health and illness } \\
\text { status in order to promote the best care for } \\
\text { the child as well. }\end{array}$ \\
\hline Santacroce (2002) & $\begin{array}{l}\text { The sample } \\
\text { included } 15 \\
\text { parents of children } \\
\text { with cancer with } \\
\text { an average age of } \\
37 \text { years old and } \\
\text { two thirds } \\
\text { considered } \\
\text { themselves } \\
\text { Caucasian, the } \\
\text { others as African- } \\
\text { American. }\end{array}$ & $\begin{array}{l}\text { Correlational } \\
\text { Design } \\
\text { Utilized } \\
\text { Mishel's } \\
\text { Parental } \\
\text { Perception of } \\
\text { Uncertainty } \\
\text { Scale (PPUS) } \\
\text { to measure } \\
\text { uncertainty and } \\
\text { the State-Trait } \\
\text { Anxiety } \\
\text { Inventory } \\
\text { (STAI) to } \\
\text { measure } \\
\text { anxiety. } \\
\text { Investigated } \\
\text { uncertainty and } \\
\text { anxiety in } \\
\text { sixteen parents } \\
\text { of children } \\
\text { diagnosed with } \\
\text { cancer within } \\
\text { the previous } 8 \\
\text { weeks. }\end{array}$ & Stress & $\begin{array}{l}\text { Uncertainty, stress, and anxiety left unchecked } \\
\text { can lead to development of PTSD. }\end{array}$ & $\begin{array}{l}\text { Foremost, the uncertainty related to the } \\
\text { diagnosis of pediatric cancer does exist and } \\
\text { parents will experience it differently. Nurses } \\
\text { must take care to make interventions } \\
\text { individualized as needed. High levels of } \\
\text { anxiety are of concern as well. }\end{array}$ \\
\hline
\end{tabular}




\begin{tabular}{|c|c|c|c|c|c|}
\hline Author/ Year & Participants & Study Design & $\begin{array}{l}\text { Concept } \\
\text { Area }\end{array}$ & Results & Recommendations \\
\hline Santacroce (2003) & No sample. & $\begin{array}{l}\text { Review of } \\
\text { Uncertainty } \\
\text { and its } \\
\text { relationship to } \\
\text { PTSD. }\end{array}$ & $\begin{array}{l}\text { Uncertainty } \\
\text { Stress and } \\
\text { PTSD }\end{array}$ & $\begin{array}{l}\text { Uncertainty, stress, and anxiety left unchecked } \\
\text { can lead to development of PTSD. }\end{array}$ & $\begin{array}{l}\text { Suggest interventions should be aimed at } \\
\text { preventing full scale development of PTSD } \\
\text { through early recognition of risk factors and } \\
\text { symptoms and the use of a cognitive } \\
\text { behavioral therapy program for those at risk. } \\
\text { This program is best utilized as preparation } \\
\text { for changes in the treatment and care plan } \\
\text { and on a regular basis throughout the } \\
\text { treatment regimen. }\end{array}$ \\
\hline $\begin{array}{l}\text { Soanes, Hargrave, } \\
\text { Smith and Gibson } \\
(2009)\end{array}$ & $\begin{array}{l}\text { Their sample } \\
\text { included ten } \\
\text { children with brain } \\
\text { tumors, nine } \\
\text { mothers and nine } \\
\text { fathers. Seventy \% } \\
\text { of the participants } \\
\text { identified } \\
\text { themselves as } \\
\text { Caucasian. }\end{array}$ & $\begin{array}{l}\text { Qualitative } \\
\text { Interviews. }\end{array}$ & Uncertainty & $\begin{array}{l}\text { Feelings at diagnosis included devastation, shock, } \\
\text { anger, and stress. The stress continued to increase } \\
\text { as the financial and physical burdens of caring for } \\
\text { a child with cancer increased. frustration in } \\
\text { coordination of care, the feeling of being } \\
\text { overwhelmed by all the information and new } \\
\text { people who are members of the health care team } \\
\text { as well as the fear of the unknown regarding the } \\
\text { prognosis and the treatment process, especially } \\
\text { related to whether the treatment was effective or } \\
\text { not. }\end{array}$ & $\begin{array}{l}\text { Suggest that more standardized and } \\
\text { structured formats be used for information } \\
\text { delivery so as not to overwhelm families and } \\
\text { insure the maximum amount of information } \\
\text { is received. They also suggest that } \\
\text { individualized pathways be used to help } \\
\text { guide parents through the initial interactions } \\
\text { with the health care system. }\end{array}$ \\
\hline Sterken (1996) & $\begin{array}{l}31 \text { male primary } \\
\text { caregivers of } \\
\text { children with } \\
\text { cancer at any stage } \\
\text { of treatment in the } \\
\text { southeast US. }\end{array}$ & $\begin{array}{l}\text { Descriptive, } \\
\text { Questionnaires, } \\
\text { Parent } \\
\text { Perception of } \\
\text { Uncertainty } \\
\text { Scale and the } \\
\text { Jalowiec } \\
\text { Coping Scale }\end{array}$ & $\begin{array}{l}\text { Uncertainty, } \\
\text { Coping }\end{array}$ & $\begin{array}{l}\text { Age of the father figure is related to level of } \\
\text { uncertainty and coping. Younger fathers had more } \\
\text { difficulty with the information and teaching } \\
\text { provided. Common coping mechanisms for } \\
\text { younger fathers included avoidance activities. } \\
\text { Having a younger child with cancer showed more } \\
\text { evasive and emotive coping styles to help deal } \\
\text { with the lack of meaning related to the } \\
\text { information provided and the disease itself. } \\
\text { Uncertainty is highest immediately after } \\
\text { diagnosis. }\end{array}$ & $\begin{array}{l}\text { Work to improve support systems specific to } \\
\text { fathers' needs during the diagnostic phase as } \\
\text { they often must quickly transition into the } \\
\text { only financial caregiver and feel they can no } \\
\text { longer grieve. }\end{array}$ \\
\hline $\begin{array}{l}\text { Stewart and } \\
\text { Mishel. (2000) }\end{array}$ & $\begin{array}{l}56 \text { papers on } 34 \\
\text { empirical studies, } \\
4 \text { literature reviews }\end{array}$ & $\begin{array}{l}\text { Literature } \\
\text { Review }\end{array}$ & Uncertainty & $\begin{array}{l}\text { Uniqueness of the cancer diagnosis experience is } \\
\text { shocking to parents and leads to uncertainty. } \\
\text { External environment includes social support } \\
\text { from family, friends, and the health care team. } \\
\text { Uncertainty can lead to psychological distress. }\end{array}$ & $\begin{array}{l}\text { More studies should be done on childhood } \\
\text { uncertainty in illness especially related to the } \\
\text { use of the PPUS and other questionnaires. } \\
\text { More family based research including the } \\
\text { parent/child unit together is warranted. More }\end{array}$ \\
\hline
\end{tabular}




\begin{tabular}{|c|c|c|c|c|c|}
\hline Author/ Year & Participants & Study Design & $\begin{array}{l}\text { Concept } \\
\text { Area }\end{array}$ & $\begin{array}{l}\text { Results } \\
\text { Uncertainty leads to challenges in the } \\
\text { parent/family roles and dynamics. Lack of } \\
\text { literature on interventions related to reducing } \\
\text { uncertainty. Children also have uncertainty } \\
\text { related to their disease and changes in their family } \\
\text { roles. }\end{array}$ & $\begin{array}{c}\text { Recommendations } \\
\text { diverse population research is warranted. }\end{array}$ \\
\hline $\begin{array}{l}\text { Vrijmoer-Wiersma, } \\
\text { Klink, Kolk, } \\
\text { Koopman, Ball, } \\
\text { and Egeler (2008) }\end{array}$ & $\begin{array}{l}67 \text { articles all } \\
\text { published between } \\
1997-2007 \text { on } \\
\text { parental strain, } \\
\text { stress and } \\
\text { adaptation to a } \\
\text { child with cancer }\end{array}$ & $\begin{array}{l}\text { Literature } \\
\text { review }\end{array}$ & $\begin{array}{l}\text { Uncertainty, } \\
\text { stress, } \\
\text { adaptation, } \\
\text { coping }\end{array}$ & $\begin{array}{l}\text { Uncertainty: articles showed high levels that were } \\
\text { pervasive and could lead to PTSD, Anxiety is } \\
\text { highest right after diagnosis and decreases with } \\
\text { time, Over half of parents of children in active } \\
\text { treatment report signs qualifying for PTSD, } \\
\text { Primary caregivers seem to have higher levels of } \\
\text { stress and anxiety than the second parent. Higher } \\
\text { levels of social support lead to lower levels of } \\
\text { anxiety and stress and depression. }\end{array}$ & $\begin{array}{l}\text { Early identification, early intervention, } \\
\text { continued follow up, more longitudinal } \\
\text { studies on this topic, gender differences } \\
\text { versus primary caregiver differences in } \\
\text { uncertainty }\end{array}$ \\
\hline $\begin{array}{l}\text { Williams et al. } \\
\text { (2003). }\end{array}$ & $\begin{array}{l}252 \text { couplets } \\
\text { parent-siblings of } \\
\text { children with } \\
\text { chronic }\end{array}$ & $\begin{array}{l}\text { Experimental } \\
\text { intervention } \\
\text { was two } 2 \text { hour } \\
\text { education } \\
\text { sessions and } \\
\text { two } 2 \text { hour } \\
\text { psychosocial } \\
\text { sessions. } 2 \\
\text { hour parent } \\
\text { session. Two } \\
\text { booster } \\
\text { sessions for } \\
\text { both parents } \\
\text { and siblings at } \\
4 \text { and } 9 \\
\text { months. } \\
\text { Questionnaires: } \\
\text { A Knowledge } \\
\text { test, Social } \\
\text { Support Scale } \\
\text { for Children, } \\
\text { Self-Percpetion }\end{array}$ & $\begin{array}{l}\text { Support, } \\
\text { Education }\end{array}$ & $\begin{array}{l}\text { The full intervention groups had the highest } \\
\text { significant changes. Improvements were sustained } \\
\text { through the entire one year period. Attitudes } \\
\text { toward the illness and sibling improved in all } \\
\text { groups. Improved communication came from } \\
\text { simply allowing the travel time between sites. } \\
\text { Camp experience showed improvement in social } \\
\text { support and feelings of self-esteem. }\end{array}$ & $\begin{array}{l}\text { More intervention based studies on } \\
\text { improving support for families and siblings. }\end{array}$ \\
\hline
\end{tabular}




\begin{tabular}{|c|c|c|c|c|c|}
\hline Author/ Year & Participants & $\begin{array}{l}\text { Study Design } \\
\text { Profile for } \\
\text { Children, } \\
\text { Sibling } \\
\text { Perception } \\
\text { Questionnaire, } \\
\text { Revised-Mood } \\
\text { Scale, Eyberg } \\
\text { Child Behavior } \\
\text { Inventory, } \\
\text { Sibling } \\
\text { Percpetion } \\
\text { Questionnaire- } \\
\text { Attitude Scale, } \\
\text { Family } \\
\text { Adaptability } \\
\text { and Cohesion } \\
\text { Scales II, } \\
\text { Profiles of } \\
\text { Mood States- } \\
\text { Short Form }\end{array}$ & $\begin{array}{c}\text { Concept } \\
\text { Area }\end{array}$ & Results & Recommendations \\
\hline $\begin{array}{l}\text { Wong and Chan } \\
\text { (2006) }\end{array}$ & $\begin{array}{l}\text { One father and } \\
\text { eight mothers of } \\
\text { children } \\
\text { undergoing active } \\
\text { treatment for } \\
\text { cancer; all of } \\
\text { which were middle } \\
\text { class and had } \\
\text { completed average } \\
\text { levels of education } \\
\text { for that area of } \\
\text { China. }\end{array}$ & $\begin{array}{l}\text { Completed a } \\
\text { phenomenologi } \\
\text { cal qualitative } \\
\text { study of } \\
\text { Chinese } \\
\text { parents of } \\
\text { children with } \\
\text { cancer and } \\
\text { focused on } \\
\text { their coping } \\
\text { after diagnosis. }\end{array}$ & Adaptation & $\begin{array}{l}\text { Found that coping could be split into four themes: } \\
\text { shock and denial, establishing meaning, } \\
\text { confronting reality, and establishing a new } \\
\text { perspective. }\end{array}$ & $\begin{array}{l}\text { Offer opportunities for parents to share their } \\
\text { experiences. Provide teaching and } \\
\text { information to meet the individualized } \\
\text { patient/family needs. }\end{array}$ \\
\hline
\end{tabular}




\section{Uncertainty, Stress, and Anxiety During the Diagnostic Phase}

Uncertainty leading up to and immediately after diagnosis. For purposes of discussion the diagnostic phase includes the period of time leading up to diagnosis, the delivery of the diagnosis, and the first two to three weeks afterwards while treatment is being planned or started. Prior to diagnosis mothers of children who were chronically ill had increased levels of stress and uncertainty (Horner, 1997; Grootenhuis \& Last, 1997; Patiño-Fernández et al., 2008; Stewart \& Mishel, 2000). Evidence shows not knowing a cause related to the child's illness can lead to uncertainty (Horner, 1997). The period leading up to the diagnosis can contain high levels of stress and uncertainty. Parents described their feelings during this period to include devastation, shock, anger, and stress (Hinds et al. 1996; Soanes, Hargrave, Smith, \& Gibson, 2009). Once a diagnosis was confirmed some parents felt the awareness of a treatment plan helped reduce their uncertainty (Grootenhuis \& Last, 1997; Horner, 1997; Stewart and Mishel, 2000).

Psychological distress is the most common symptom related to uncertainty in adults following diagnosis (Patiño-Fernández et al., 2008; Santacroce, 2002; 2003). Parents of children with cancer understandably have higher levels of stress and anxiety. Moderately high to severe levels of uncertainty and stress were common in approximately half of participants (Boman, Lindahl, \& Björk, 2003; Fuemmeler, Mullins, \& Marx, 2001). Soanes et al (2009), Mawn (1999), and Stewart and Mishel (2000) describe the shock at diagnosis and frustration in coordination of care, the feeling of being overwhelmed by all the information and the new people who are members of the health care team, and fear of the unknown regarding the prognosis and the treatment process, especially related to the potential effectiveness of treatment. VrijmoetWiersma et al. (2008) found that primary caregivers tended to demonstrate higher levels of stress than their second parent peers. Over $50 \%$ of mothers and $40 \%$ of fathers met the Diagnostic and Statistical Manual-Fourth Edition Text Revision (DSM-IV) criteria for acute stress disorder secondary to their high anxiety scores. Socioeconomic status, relationship status, family cohesion 
and conflict as well as the level of general anxiety correlated with acute stress disorder. This was significantly higher in parents who identified themselves as a racial minority (Patiño-Fernández et al., 2008; Santacroce, 2002).

Ramfelt and Lützén (2005) found that patients' uncertainty and stress was related to their understanding and participation in the decisions related to their treatment path. This was most evident in the weeks following diagnosis. For example, patients felt that the information they received from the health care team was helpful and inclusive of their opinions and lead them toward making the right decision for their treatment, or they felt the opposite. When parents perceived that the information was very overwhelming and they felt rushed by the health care team to make a decision, they felt less in control. Rather than feeling empowered, they felt alone and unsupported and that the consequences of their decision would fall on them rather than on the health care team. This increased the stress level and uncertainty felt by these patients (Ramfelt \& Lützén, 2005).

Stress and post-traumatic stress. When parents are not supported by a positive structural framework, they are likely to feel isolated and can view uncertainty in a negative light. Santacroce (2002) found that parents of children diagnosed with cancer in the previous four to eight week period met the DSM-IV criteria for diagnosis of PTSD and had moderate to severe stress levels based on their Basic Stress Index (BSI) scores. Higher PTSD scores and higher uncertainty scores were significantly correlated. Although full scale PTSD in childhood cancer diagnosis is not very common, various symptoms of PTSD are found to be more common among parents of children with cancer (Fuemmeler et al., 2001; Lee et al., 2007; Santacroce, 2002).

Timeframe for uncertainty. Uncertainty and stress correlated with the elapsed time since diagnosis (Boman et al., 2003; Hutchinson et al., 2009; Vrijmoet-Wiersma et al., 2008). Both stress and anxiety are highest in the first few weeks following the diagnosis (Stewart \& Mishel, 2000). Five weeks after diagnosis two thirds of participants demonstrated moderate to severe levels of anxiety similar to post-traumatic stress disorder (PTSD) and that the anxiety scores were 
similar to those of hospitalized psychiatric patients diagnosed with depression and anxiety related illnesses (Santacroce, 2002). Emotion-focused coping combined with higher levels of uncertainty for longer periods of time led to higher levels of PTSD (Fuemmeler et al., 2001).

Three areas of concern were identified in the two to three week period after diagnosis: communication, access to services, and information (Ramfelt \& Lützén 2005; Soanes et al., 2009). Although the authors did not specifically use the term uncertainty they described the common attributes for uncertainty: parental loss of control, ambiguity toward the future, and difficulty understanding all the information provided to them. The findings reflected that participants exhibited what are known to be common traits of uncertainty, and were overwhelmed by the vast amount of information given. How they interpreted the volume of information provided, the change in locus of control from internal (parental) to external (the health care team's treatment plan), and the education assistance they were provided affected how they adapted in the first few weeks (Ramfelt \& Lützén 2005; Soanes et al., 2009).

\section{Healthy Adaptation to Diagnosis of Cancer and Chronic Illness}

Healthy adaptation to a chronic illness, especially a childhood cancer diagnosis, is crucial in order to reduce uncertainty and return the family unit back to normalcy as quickly as possible. Adaptation includes development of positive coping mechanisms. Coping can be split into four themes: shock and denial, establishing meaning, confronting reality, and establishing a new perspective (Wong \& Chan, 2006). This is similar to the concepts of uncertainty: stimuli, structural framework and the ability to process information (Wong \& Chan, 2006). Gannoni and Shute (2010) found both positive and negative coping skills leading to adaptation. They reported positive coping skills such as the use of anticipatory coping skills. These skills included seeking information from outside sources, such as their care providers or others who have experienced a similar situation and have beneficial information to share.

Self-education to facilitate adaptation. Many parents sought out more information that led them to feel empowered and knowledgeable even if they tended to assume things could be 
worse medically (Gannoni \& Shute, 2010; Hovey, 2005). Hinds et al. (1996) reported that parents may be overwhelmed by the diagnosis which causes them to shift almost immediately into efforts to gain information about possible treatment options. This knowledge helped them to be prepared and able to cope when things did not go as well as anticipated. Fathers tended to rate four areas of coping higher than all others: information seeking, figuring out what to do, looking at options and weighing choices. If not provided information during this time, fathers tended to have more stress and anxiety later because, although they want to be available to the spouse, child, and the rest of the family, they often must return to work (Hovey, 2005).

After moving past the initial shock, parents spent time reorganizing the information they were provided into smaller pieces that were easier to understand (Wong \& Chan, 2006). As they began to understand more of that information given to them, the parents shifted toward acceptance and began adapting their behaviors and home life to focus on the health and care of the ill child. During this period most parents stated they continually sought out more information both from their health care team and from outside resources, such as books and the internet in order to increase their understanding and ability to manage what would be necessary for their child (Hovey, 2005; Wong \& Chan, 2006).

Boyd and Hunsberger (1998) and Novakovic et al. (1996) found that even children and adolescents prepare themselves by learning about their disease and treatment. Their studies demonstrated that chronically ill children and adolescents use information seeking as a coping mechanism and feel distrust, frustration, and anxiety when information is withheld. Knowing when to share disease and treatment information with the child was difficult, especially in regards to the long term consequences. Wanting to ensure understanding conflicted with desire not to instill fear in the child. Trying to return to and maintain normalcy was a central theme for chronically ill children and their families (Mawn, 1999).

Personal relationships to facilitate healthy adaptation. Personal relationships that are important to the family play a large part in facilitating healthy adaptation. In chronic illness, 
parents tended to rely more on their close family than on outside support (Mawn, 1999).

However, the recognition and use of external support systems was recognized as vital as a way to share with people who understand what it is like (Gannoni \& Shute, 2010; Novakovic et al., 1996; Stewart and Mishel, 2000; Vrijmoet-Wiersma et al., 2008; Wong \& Chan, 2006).

It is important to facilitate the expansion of these external resources through providing opportunities for parents to visit with others going through similar circumstances, whether through targeted therapeutic support groups or family activity times. Parents found emotional support from their health care team, from other family members and friends, and also from other parents on the cancer unit very helpful to them (Flury et al., 2011; Wong \& Chan, 2006). The sharing of experiences and support between parents and also between patients, especially for adolescents, on the unit was reported as one of the most helpful ways to cope (Flury et al., 2011; Nolbris, Abrahamsson, Hellström, Olofsson, \& Enskär, 2010; Wong \& Chan, 2006).

Maintaining a positive outlook. Parents felt it was important for the child and the family to remain positive and hopeful because they recognized that hopelessness would not be helpful. Parents and adolescents undergoing active cancer treatment recognized that maintaining a positive outlook helped them to cope with the rigor of the treatment and loss of control (Corey, Haase, Azzouz Monahan, 2008; Gannoni and Shute, 2010; Grootenhuis \& Last, 1997; Mawn, 1999; Novokavic et al., 1996). Attributing meaning to the diagnosis and treatment of childhood cancer helped parents to remain positive and focus on what needed to happen day by day (Lee et al., 2006).

\section{Barriers to Healthy Adaptation to Diagnosis of Cancer and Chronic Illness}

The manner in which parents appraise uncertainty may be manifested as a negative emotion and cause the parents to not seek information to empower themselves. As a result they may withdraw to avoid the stressful worries about the future (Santacroce, 2002, 2003). This is

considered to be a poor adaptation method since the parent experiences continued exposure and constant reminders of the traumatic event of childhood cancer and does not learn to use coping 
behaviors appropriately (Santacroce, 2002, 2003). Withdrawal happens in two primary ways: 1) withdrawal into previously unhealthy coping behaviors such as increased alcohol intake and avoiding interactions with members of the health care team and extended family, or 2) restricting of their child's activities in an over-protective fashion, which can hinder the child's normal development (Santacroce, 2003). Strong and positive relationships with the healthcare team were helpful in decreasing withdrawal, but often families felt information was withheld and they were not treated with respect (Boyd \& Hunsberger, 1998; Novakovic et al., 1996). This caused frustrations and a lack of trust. It is important to be truthful and open when communicating with families in order to facilitate a trusting relationship and decrease the chance of a parent withdrawing rather than becoming more empowered (Mawn, 1999).

Caring for a child with cancer required a significant change to the family's daily routine that can hinder healthy adaptation. Parental employment was a major challenge because of the need for a parent, if not both, to participate in the child's care and fulfill other home responsibilities. Reduction or discontinuation of employment for at least one parent was needed at times, and this caused strain on their financial resources during a time when their child required a special and more expensive diet and also frequent and high medical costs. Additional stress such as this can cause increased uncertainty (Flury et al., 2011; Gannoni \& Shute, 2010; Stewart \& Mishel, 2000).

Managing care at home. Flury et al. (2011) discussed the changes families undergo as they transition from the inpatient hospital unit to home after their cancer diagnosis. Parents reported easily becoming overwhelmed with the management of the child's care combined with managing the lives of the rest of the family and the home environment. This transition forces families to provide around the clock medical care for their child and causes a huge shift in their family dynamics. Parents feared making a mistake or missing something crucial to the child's care, leaving them feeling as though they lived in a "permanent state of emergency" (Flury et al, 2011, p. 147). They equated home care for a child with cancer to a full time, 24-7 type job. Flury 
et al. (2011) found that as the first discharge approached, parents reported increased uncertainty that likely resulted from a combination of the overwhelming information provided about the cancer diagnosis, the fear related to that diagnosis, and the unknown success of the treatment regimen. Although they were happy about being discharged home, they also felt fear and uncertainty regarding the eminent responsibility of caring for their child post-discharge. Parents had to adjust the daily routine with the ill child and siblings to reduce the infection risk due to immunosuppression. This made routine activities like grocery shopping and attending school functions difficult. The authors report that knowing these changes would be necessary but difficult would help prepare and empower families to adapt successfully by addressing what is unknown, a critical concept in the theoretical framework.

\section{Interventions to Reduce Uncertainty Through Education and Psychosocial Support}

Parental uncertainty can be minimized by addressing the fear of the unknown and ambiguity that oftentimes results in the stress, anxiety, and isolation that are commonly experienced by parents of children with cancer. Education may be the key to empowering patients to successfully adapt and develop positive coping mechanisms through providing individualized educational interventions. Psychosocial supportive measures such as formal support groups and the use of counselors have been shown to be effective in adult populations (Lee et al., 2006; Samarel, Fawcett \& Tulman, 1997). They are recommended for parents of children with cancer, but there is little evidence demonstrating their success.

Education. Providing specific types of education at transitional periods of cancer treatment, especially at diagnosis can make a significant impact on uncertainty and facilitating adaptation (Kästel, Ensär, \& Björk, 2011). Gannoni and Shute (2010) and Flury et al. (2011) found that parents wanted more information and education, especially at transitional periods. They also identified that education regarding the diagnosis and steps of treatment was crucial during the diagnosis period and this information should be repeated often throughout that period. Kerr, Harrison, Medves, Tranmer, and Fitch (2007) found that most parents wanted complete 
explanations of treatments, drugs, and procedures as a way to empower themselves as advocates and aids for their children. They also noted this information is very helpful prior to the experience and repeating it would be an effective learning tool for parents. Many parents expressed that information and education should be shared in the presence of an identified support person, such as a spouse or family member. This helps in solidifying information so it can be recalled later as they reinforce what they heard together as well as providing emotional support to the caregiver (Kästel et al., 2011; Kerr et al., 2007).

Kästel et al. (2011) found that not only was providing accurate information crucial, but also the context in which it was delivered was important. Physicians tend to provide the original diagnosis and treatment related information, but in the subsequent days and weeks that role primarily fell to the nursing staff. If follow up conversations were needed they were often held in suboptimal environments and timeframes. The lack of physician availability for further detailed discussion left some parents feeling very frustrated and caused some distrust in their care as well. At this time, most information is shared at the bedside by a provider or nurse using written materials, pictures, and videos (Kerr et al., 2007). Kerr et al., (2007) also reported that parents felt one primary contact person for information delivery and teaching during the diagnostic phase would improve information retention and understanding.

Psycho-social support for parents and family members. While there is not a lot of evidence detailing the provision of psychosocial support interventions for parents of children with cancer, some articles identified the importance of reducing stress and enhancing coping skills in the patient (child/adolescent) and siblings. Providing support to the family as a whole rather than just simply to the parents could enhance the coping skills of the family as a unit and help them adapt more quickly. Corey et al. (2008) reported that perceived support from family, friends and the health care team helped to decrease symptoms of stress, anxiety, and improved mental health in parents of children with cancer. Novakovic (1996) found that many adolescents and young adults dealing with cancer preferred to share with other patients rather than with counselors. 
Neville (1998) reported that adolescents would benefit greatly and have less distress and uncertainty when provided with improved communication and strong social support from their family, friends and the health care team. Lounsberry, McRae, Angen, Hoeber, and Carlson (2010) introduced a supportive and educational intervention through a tele-health program. They found this to be helpful in rural areas because it allowed patients to participate without traveling to the treatment center several hours from their homes. However, Sameral, Fawcett, and Tulman (1997) found that support groups do not affect the overall effects of the disease treatment such as side effects from chemotherapy or psychological distress and did not show any long-term effects in childhood cancer. They are aimed at providing opportunities to share information with others that have gone through similar circumstances.

Sibling support. Nolbris et al. (2010) reported that a therapeutic support group for siblings helped them reflect on both the positive and negative memories associated with their sibling's illness. Their participants found it helpful to talk with others going through similar things and felt that sharing their thoughts within the group was helpful to them. Williams et al. (2003) also found that structured psychosocial support and education interventions delivered in an informal setting (family activities and summer camp) were helpful to siblings of children with chronic illnesses in developing self-esteem and positive attitudes towards the chronically ill child and the illness itself. The intervention also helped reduce behavior concerns in the well sibling who attended, and facilitated better communication between the parent and child. Branstetter, Domian, Williams, Graff, and Piamjariyakul (2008) did a follow up study to that of Williams et al. (2003) addressing familial communication themes and identified several themes: communication reflecting relationships within the family unit, siblings can be empowered to speak up, connectedness, and struggling for normalcy (Branstetter et al., p. 176). They recommended addressing concerns from these themes through family based support and education as a crucial step toward facilitating normalcy and communication, and also reducing uncertainty as they learned to adapt to the chronic illness. 
Multiple studies have similar recommendations for parents of children with chronic illnesses (Boyd \& Hundsberger, 2008, Hovey, 2005; Kästel et al., 2011; Lee et al., 2007; Mawn, 1999; Santacroce, 2000). Sterken (1996) suggested support directed specifically for fathers of children with cancer in the diagnostic period to help them cope and adapt to their role as both father of a chronically ill child and also often the primary provider for the family. Wong and Chan (2006) recommended specifically providing opportunities for parents to share with other parents.

\section{Discussion and Implications for Practice}

Recommendations from this review focused on four main areas: stress and uncertainty, facilitators and barriers to adaptation, education, and early and continued psychosocial supportive interventions. Implications for practice are not just focused on nursing interventions. They also include the multidisciplinary team, including physicians, counselors, child life therapists, social workers and case managers.

\section{Stress and Uncertainty}

Parental stress after diagnosis of childhood cancer is inevitable, but if not handled effectively, prolonged stress and uncertainty can lead to complications such as post-traumatic stress disorder (Fuemmeler et al., 2001; Santacroce, 2002). Positive adaptation by parents is difficult when they are faced with such traumatic events because their uncertainty creates fear about the future, and they worry about how they will protect themselves and their child from these future events when they cannot understand them. Reduction of stress related symptoms in both patients and caregivers should be of utmost concern to the health care team. They must be knowledgeable about and consistently assess for symptoms of unhealthy coping and adaptation so that early interventions can be introduced (Boman et al., 2003). If not, parents and patients can have difficulty coping and retaining information throughout the treatment and even well after treatment has completed. Additional stress can come from concerns regarding familial adjustment to the hospital setting and frequent visits to the clinic, changes in financial security, as well as 
changes in household roles and responsibilities. The stress can continue to increase as the financial and physical burdens of caring for a child with cancer increase. An interdisciplinary team focus is necessary to address any knowledge deficits or clarification of information as well as the need for psychological support through counseling and small group gatherings. The health care team has the opportunity to intervene and promote positive coping mechanisms. This includes referrals for case management and social work, child life, and spiritual/religious support. A team approach supporting the family in this way will help address some of the stress and anxiety parents are going through during the diagnostic phase.

\section{Facilitators and Barriers to Adaptation}

Evidence has demonstrated that some parents adapt easier and more readily than others. For example, those with increased levels of uncertainty, stress, depression or PTSD have more difficulty in doing so (Fuemmeler et al., 2001; Lee et al., 2007; Santacroce, 2002). Increased stress may come from lacking understanding of the disease and treatment or the unpredictability of the situation (Boyd \& Hunsberger, 1998; Santacroce, 2002; Stewart \& Mishel, 2000). Stress may also increase due to the financial and physical burdens of caring for the sick child begin to take a toll (Soanes et al., 2009). The stress of work and finances can be a distraction to the parents and cause them to lose focus on the child's needs as can additional familial relationship stress at home (Boyd \& Hunsberger, 1998; Kerr et al., 2007; Stewart \& Mishel, 2000). If the parent does not feel the child is receiving optimum care and they are not receiving the support they need, it might cause some distrust between the parent and the health care team. Lack of trust hinders communication and increases uncertainty and stress (Boyd \& Hunsberger, 1998; Corey et al., 2008; Novakovic et al.,1996; Penrod, 2001; Ramfelt \& Lutzen, 2005). The health care team should focus on these areas in order to reduce external factors and allow the parents to adapt more easily (Soanes et al., 2009; Vrijmoer-Wiersma et al., 2008).

Other barriers to healthy adaptation include unhealthy behaviors such as increased alcohol intake or chemical dependency. Withdrawal from the support system and family unit can 
also be considered an unhealthy response to uncertainty and increased stress. Sometimes parents will isolate their child as well, and this hinders normal growth and development responses (Santacroce, 2000; 2002; 2003).

Factors that help facilitate adaptation include a strong external support network both personally and from the health care team (Corey et al., 2008; Fiese \& Wamboldt, 2003; Neville, 1998; Santacroce, 2000). Parental empowerment through information seeking and education can also facilitate adaptation (Gannoni \& Shute, 2010). If a parent maintains a positive outlook and seeks out information and education about the child's disease and treatment they will have less uncertainty and stress (Gannoni \& Shute, 2010; Grootenhuis \& Last, 1997). Empowered and positive parents appraise uncertainty in a positive light. They regain some control over the situation and are able to utilize coping mechanisms that are helpful in adapting to life with childhood cancer quicker (Grootenhuis \& Last, 1997; Mishel, 1983; 1988; Novakovic et al., 1996).

\section{Education}

Communication of information focuses on the education and information needed during the illness diagnostic phase and throughout the treatment thereafter. Several interventions were suggested in the literature. First, members of the health care team must address how they communicate together, across the interdisciplinary team, and between the team members and the parent and patient. Effective communication builds trust and improves continuity in the care provided (Boyd \& Hunsberger, 1998; Corey et al., 2008; Novakovic et al., 1996; Penrod, 2001; Ramfelt \& Lutzen, 2005).

Education should be provided as soon as the diagnosis is made and should continue throughout the treatment (Kästel et al., 2011; Kerr et al., 2007). The use of a single person or small group of people to serve as coordinators of education and communication could help to regulate how parents absorb and understand information (Kerr et al., 2007). Having a person or department devoted to coordinating education would also reduce the discrepancy and variation in 
delivery. This helps to ensure information is delivered in a more structured format that is not overwhelming to parents, and that it is provided at timeframes shown to be most beneficial and individualized to the parents' needs (Kästel et al., 2011). Structured classes are another way to continue education to parents, patients, and siblings after the initial diagnosis. They have been successful in some adult populations and also demonstrated with parent-sibling couplets (Williams et al., 2003). Provision of education materials and sessions should be through nonrushed, short, frequent sessions to build parent confidence in the skills required for home care and should be done in a timely manner and not rushed immediately prior to discharge (Kästel et al., 2011). In many areas, patients do not live close to their urban treatment center. Education and information sharing can be provided in non-traditional ways such as by using tele-health interventions to teach patients and family members in rural areas. This allows them to receive the same education and ask questions as needed without traveling from their homes to the distant treatment center (Lounsberry et al., 2010).

Parents are in need of more transitional assistance (Flury et al., 2011; Gannoni \& Shute, 2010; Kästel et al., 2011). This includes education and support related to moving from the hospital environment back into the outside world, school re-entry programs, managing the longterm clinic appointments, and learning about the differences between stages of treatment. Parents suggested a liaison or education person be the point of contact for needed support during transitional periods (Kerr et al., 2007). This person could help facilitate what would be the next step for the family, or what support might be available and beneficial. Gannoni and Shute (2010) recommended that interventions should be strongly emphasized during specific transitional periods during the cancer treatment regimen such as throughout the diagnostic period (the first month), between phases of treatment, when families are moving from primarily acute care within the hospital to mostly outpatient care, when children are re-entering the mainstream school system, during periods of relapse, and when necessary the shift towards end of life care. 


\section{Early and Continued Psychosocial Support}

Early assessment of psychosocial needs related to stress, depression, and anxiety should be included in the care of every family adapting to life with childhood cancer (Boman et al., 2003; Gannoni \& Shute, 2010; Kerr et al., 2007). This will allow for early interventions related to counseling and social support needed for both mothers and fathers. Psychosocial support must be tailored to both parents' needs. Formal support groups and classes have been shown to be effective, but are often difficult to maintain and coordinate and are also difficult for participants to attend on a regular basis (Gannoni \& Shute, 2010; Horner, 1997; Mawn, 1999; Nolbris et al., 2010; Patiño-Fernández et al., 2008). In order to address this tele-health and online interventions might be a better option especially for treatment centers that have patients living great distances from the hospital (Lounsberry et al., 2010).

Other types of familial support might be better suited to the situation and show stronger results. Social support through formal support groups has long been a staple of psycho-social support for patients in a variety of situations and environments. It is a highly recommended technique, but the implementation and sustainment of such measures in childhood cancer remains to be identified in the literature. What is well documented is what types of topics should be included to help parents and children adapt and develop positive coping mechanisms. Offering opportunities for parents, patients, and siblings to share their experiences and learn from others going through similar situations is important (Flury et al., 2011; Gannoni \& Shute, 2010; Wong $\&$ Chan, 2006). This can be done in both formal and informal environments such as in camp settings, family dinners, and fun activities on the unit or clinic areas (Williams et al., 2003). It should address how other family and peers might react to the diagnosis and side effects of treatment. This is best introduced approximately one to two months after the diagnosis when the initial shock has reduced. Assisting families in identifying their own support resources early, such as extended family and social networks is an important step in this process (Boyd \& Hunsberger, 
1998; Corey et al., 2008). This will help the family adapt and change their routine to a new "normal" so they are prepared for the long term care needed in childhood cancer.

\section{Theoretical Implications}

An integrative literature review should guide researchers toward advancing the theoretical model (Torraco, 2005). Mishel's Theory of Uncertainty in Illness focuses on the patient's uncertainty (Mishel, 1981) and his/her appraisal of uncertainty in either a positive or negative manner. The theory was expanded to include parents' perception of uncertainty regarding their ill child (Mishel, 1983), but the model was the same. The only difference is that parental uncertainty is derived from their fear and the unpredictability related to their child's

illness. Stewart, Mishel, Lynn, \& Terhorst (2010) began expanding the theory to also include children with cancer. They discussed how the volume of the ill child's uncertainty is affected by the level of parental uncertainty. Thus far no one has attempted to expand the model to include the opposite: how uncertainty in children may affect parental uncertainty. Based on the literature presented here, it is possible that interventions addressing uncertainty in the ill child and siblings could have a positive feedback effect on parental uncertainty. It is also possible that family based interventions (structure providers) aimed at reducing uncertainty in various members of the family together could accelerate adaptation.

\section{Future Research}

This review indicates that interventions are necessary in the childhood cancer population, and they should be delivered through a combination of education and psycho-supportive measures. Future research should avoid testing the effectiveness of formal education sessions. Instead, how diagnosis and treatment information is delivered should be more fully explored in order to help minimize parental uncertainty. Studies that test for pre and post-test comprehension of education, and the effect on uncertainty may be helpful to the childhood cancer and chronic illness community as a whole. 
The implementation and maintenance of an active support group model still remains an important priority for research. More research into distance support and education programs should be a focus in the future. Research involving support of both childhood cancer patients and their siblings is an important focus. Of special concern is the adolescent and young adult cancer population as they are transitioning not only through their treatment regimen, but also from adolescence into adulthood. Future research should be aimed at more family-based support and structured education interventions to reduce uncertainty, identify coping mechanisms, and facilitate adaptation.

\section{Study Limitations}

Limitations of this study include the possibility of inadvertently overlooking relevant articles, and the lack of availability of interventional studies. The majority of articles identified in the literature search were of descriptive or qualitative design. This is problematic because the same limitation is repeated in many of these studies, but the number of interventional studies still remains small. The small number of articles limits the potential applicability of this review toward future research endeavors. Another limitation to consider is the lack of diversity in sample populations. Most of the samples included a majority of Caucasian mothers as participants. This also limits the applicability to other populations and regions.

\section{Summary}

As the primary contact for most patients, nurses are in the forefront of their care. As trusted caregivers, interventions aimed toward helping the parent and patient develop coping mechanisms and decrease uncertainty can be easily implemented. Nurses could help develop interventions that would meet the needs of their regional populations and tailor them specifically to each area. By ensuring patients and parents are educated about their treatment regimen and the

care that goes along with it, nurses help improve patient outcomes related to physical care of their illness, reduction in uncertainty, and facilitation of healthy adaptation. They help patients 
transition successfully from each stage of their treatment and help maintain family normalcy. This is true family-centered care.

This article reviews relevant research over the last two decades in order to synthesize data related to uncertainty, education and psychosocial support, all of which are areas of concern for pediatric oncology nurses and other health care providers who work with this special population. It helps to identify nursing and multi-disciplinary interventions that can be implemented in a variety of ways to address uncertainty and increase adaptation of the family unit to the diagnosis of childhood cancer and to the long term treatment regimen. Future research should be aimed toward promoting healthy adaptation through successful interventions to meet the needs of a variety of family types and diverse populations. 


\section{References}

American Cancer Society. (2014). Cancer facts \& figures 2014. American Cancer Society. Retrieved from:

http://www.cancer.org/acs/groups/content/@ research/documents/webcontent/acspc042151.pdf

Boman, K., Lindahl, A., \& Björk, O. (2003). Disease-related distress in parents of children with cancer at various stages after the time of diagnosis. Acta Oncologica, 42(2), 137-146.

Boyd, J.R. \& Hunsberger, M. (1998). Chronically ill children coping with repeated hospitalizations: Their perceptions and suggested interventions. Journal of Pediatric Nursing, 13(6), 330-342.

Branstetter, J.E., Domian, E.W., Williams, P.D., Graff, J.C., \& Piamjariyakul, U. (2008). Communication themes in families of children with chronic conditions. Issues in Comprehensive Pediatric Nursing, 31, 171-184. doi: 10.1080/01460860802475184

Brashers, D. E., Neidig, J. L., Cardillo, L. W., Dobbs, L. K., Russell, J. A., \& Haas, S. M. (1999). 'In an important way, I did die': Uncertainty and revival in persons living with HIV or AIDS. AIDS Care, 11(2), 201-219.

Comer, J. S., Roy, A. K., Furr, J. M., Gotimer, K., Beidas, R. S., Dugas, M. J., \& Kendall, P. C. (2009). The intolerance of uncertainty scale for children: A psychometric evaluation. Psychological Assessment, 21(3), 402-411.

Corey, A.L., Haase, J.E., Azzouz, F., Monahan, P.O. (2008). Social support and symptom distress in adolescents/young adults with cancer. Journal of Pediatric Oncology Nursing, 25(5), $275-284$

Fiese, B. H. \& Wamboldt, F. S. (2003). Coherent accounts of coping with a chronic illness: Convergences and divergences in family measurement using a narrative analysis. Family Process, 42(4), 439-451.

Flury, M., Caflisch, U., Ullmann-Bremi, A., Spichiger, E. (2011). Experiences of parents with caring for their child after a cancer diagnosis. Journal of Pediatric Oncology Nursing, 28(3), 143-153.

Fuemmeler, B.F., Mullins, L.L., Marx, B.P. (2001). Posttraumatic stress and general distress among parents of children surviving a brain tumor. Children's Health Care, 20(3), 169182.

Gannoni, A.F. \& Shute, R. H. (2010). Parental and child perspectives on adaptation to childhood chronic illness: A qualitative study. Clinical Child Psychology and Psychiatry, 15(1), 39-53. doi : 10.1177/1359104509338432

Grootenhuis, M.A., \& Last, B.F. (1997). Predictors of parental emotional adjustment to childhood cancer. Pyscho-Oncology, 6, 115-128. 
Hinds, P.S., Birenbaum, L.K., Clarke-Steffen, L., Quargnenti, A., Kreissman, S., Kazak, A. ...Wilimas, J. (1996). Coming to terms: Parents' response to a first cancer recurrence in their child. Nursing Research, 45(3), 148-153.

Holm, K. E., Patterson, J. M., Rueter, M. A., \& Wamboldt, F. (2008). Impact of uncertainty associated with a child's chronic health condition on parents' health. Families, Systems \& Health: The Journal of Collaborative Family HealthCare, 26(3), 282-295.

Holopainen, A., Hakulinen-Viitanen, T., Tossavainen, K. (2008). Systematic review: A method for nursing research. Nurse Researcher, 16(1), 72-83.

Horner, S. D. (1997). Uncertainty in mothers' care for their ill children. Journal of Advanced Nursing, 26(4), 658-663.

Hovey, J. K. (2005). Fathers parenting chronically ill children: Concerns and coping strategies. Issues in Comprehensive Pediatric Nursing , 28, 83-95.

Hutchinson, K. C., Willard, V. W., Hardy, K. K., \& Bonner, M. J. (2009). Adjustment of caregivers of pediatric patients with brain tumors: A cross-sectional analysis. PsychoOncology, 18(5), 515-523.

Jackson, A., Enderby, K., O'Toole, M., Thomas, S., Ashley, D., Rosenfeld, J.,...Gedye, R. (2009). The role of social support in families coping with childhood brain tumor. Journal of Psychosocial Oncology, 27(1), 1-24.

Kästel, A., Ensär, K., \& Björk, O. (2011). Parents' views on information in childhood cancer. European Journal of Oncology Nursing, 15, 290-295. doi: 10.1016/j.ejon.2010.10.007

Katz, S. (2002). When the child's illness is life threatening: Impact on the parents. Pediatric Nursing, 28(5), 453.

Kerr, L.M.J., Harrison, M.B., Medves, J., Tranmer, J.E., \& Fitch, M. (2007). Understanding the supportive care needs of parents of children with cancer: An approach to local needs assessment. Journal of Pediatric Oncology Nursing, 4(5), 279-294.

Lee, V.N., Cohen, S.R., Edgar, L.N., Laizner, A.M. \& Gagnon, A.J. (2006). Meaning making and psychologic adjustment to cancer: Development of an intervention and pilot results. Oncology Nursing Forum, 33(2), 291-302.

Lee, Y.L., Santacroce, S.J., Sadler, L. (2007). Predictors of healthy behavior in long-term survivors of childhood cancer. Journal of Nursing and Healthcare of Chronic Illness, 16(11c), 285-295.

Lounsberry, J.L., McRae, H., Angen, M., Hoeber, M., \& Carlson, L.E. (2010). Feasibility study of a telehealth delivered, psychoeducational support group for allogeneic hematopoietic stem cell transplant patients. Psycho-Oncology, 19, 777-781. doi: 10.1002/pon.1617

Mawn, B. (1999). Raising a child with HIV: An emerging phenomenon. Families, Systems, \& Health, 17(2), 197-215. 
McGrath, P., \& Phillips, E. (2008). "It is very hard": Treatment for childhood lymphoma from the parents' perspective. Issues in Comprehensive Pediatric Nursing, 31(1), 37-54.

Mishel, M. H. (1981). The measurement of uncertainty in illness. Nursing Research, 30, 258-263.

Mishel, M.H. (1983). Parent's perception of uncertainty concerning their hospitalized child. Nursing Research, 32(6), 324-330.

Mishel, M. H. (1988). Uncertainty in illness. Image: Journal of Nursing Scholarship, 20(4), 225232.

Neville, K. (1998). The relationships among uncertainty, social support, and psychological distress in adolescents recently diagnosed with cancer. Journal of Pediatric Oncology Nursing, 15(1), 37-46.

Nolbris, M., Abrahamsson, J., Hellström, A., Olofsson, L., \& Enskär, K. (2010). The experience of therapeutic support groups by siblings of children with cancer. Pediatric Nursing, 36(6), 298-304.

Novakovic, B., Fears, T., Wexler, L., McClure, L., Wilson, D., McCalla, J., Tucker, M., (1996). Experiences of cancer in children and adolescents. Cancer Nursing, 19(1), 54-59.

Patiño-Fernández, A.M., Pai, A.L.H., Alderfer, M., Hwang, W.T., Reilly, A., \& Kazak, A.E. (2008). Acute stress in parents of children with newly diagnosed cancer. Pediatric Cancer Blood, 50, 289-292. doi: 10.1002/pbc.21262

Penrod, J. (2001). Refinement of the concept of uncertainty. Journal of Advanced Nursing, 34(2), 238-245.

Polit, D.F. \& Beck, C.T. (2012). Literature reviews: Finding and critiquing evidence. In NursingResearch: Generating and Assessing Evidence for Nursing Practice (pp. 94-125). Philadelphia, Pennsylvania: Lippincott, Williams, \& Wilkins.

Ramfelt, E. \& Lützén, K. (2005). Patients with cancer: Their approaches to participation in treatment plan decisions. Nursing Ethics, 12(2), 143-155.

Samarel, N., Fawcett, J., \& Tulman, L. (1997). Effect with support groups with coaching on adaptation to early stage breast cancer. Research in Nursing and Health, 20, 15-26.

Santacroce, S. J. (2000). Support from health care providers and parental uncertainty during the diagnosis phase of perinatally acquired HIV infection. Journal of the Association of Nurses in AIDS Care, 11(2), 63-75.

Santacroce, S. J. (2002). Uncertainty, anxiety, and symptoms of post-traumatic stress in parents of children recently diagnosed with cancer. Journal of Pediatric Oncology Nursing, 19(3), 104-111. doi: 10.1177/104345420201900305

Santacroce, S. J. (2003). Parental uncertainty and posttraumatic stress in serious childhood illness. Journal of Nursing Scholarship, 35(1), 45-51. 
Soanes, L., Hargrave, D., Smith, L., \& Gibson, F. (2009). What are the experiences of the child with a brain tumour and their parents? European Journal of Oncology Nursing, 13, 255261. doi: 10.1016/j.ejon.2009.03.009

St. Jude's Children's Research Hospital. (2014). Five year cancer survival rates 1962 vs. present. Facts and Figures: Cancer Survival Rates. Retrieved from: http://www.stjude.org/stjude/v/index.jsp?vgnextoid=5b25e64c5b470110VgnVC M1000001e0215acRCRD\&vgnextchannel=4bbafe08dc835110VgnVCM1000001 e0215acRCRD

Sterken, D. J. (1996). Uncertainty and coping in fathers of children with cancer. Journal of Pediatric Oncology Nursing, 13(2), 81-88.

Stewart, J.L. \& Mishel, M., (2000). Uncertainty in childhood illness: A synthesis of the parent and child literature. Scholarly Inquiry for Nursing Practice, 14(4), 299-313, 321-326.

Stewart, J.L., Mishel, M. H., Lynn, M.R., Terhorst, L. (2010). Test of a conceptual model of uncertainty in children and adolescents with cancer. Research in Nursing and Health, 33(3), 179-191. doi: 10.1002/nur.20374

Torraco, R.J. (2005). Writing integrative literature reviews: Guidelines and examples. Human Resource Development Review, 4(3), 356-367. doi: 10.1177/1534484305278283

Vrijmoet-Wiersma, C., van Klink, J., Kolk, A. M., Koopman, H. M., Ball, L. M., \& Egeler, R. M. (2008). Assessment of parental psychological stress in pediatric cancer: A review. Journal of Pediatric Psychology, 33(7), 694-706.

Williams, P.D., Williams, A.R., Graff, J.C., Hanson, S., Stanton, A., Hafeman, C.,...Sanders, S. (2003). A community-based intervention for siblings and parents of children with chronic illness or disability: The ISEE study. The Journal of Pediatrics, 143, 386-393. doi: 10.1067/S0022-3476(03)00391-3

Wong, M.Y.F. \& Chan, S.W.C. (2006). The qualitative experience of chinese parents with children diagnosed of cancer. Journal of Clinical Nursing, 15, 710-117. doi: 10.1111/j.1365-2702.2006.01297.x 


\title{
Chapter 3
}

Social Support to Reduce Uncertainty in Childhood Cancer in South Texas:

A Case Study

M. Danielle Gunter, MSN, RN, CPN

\begin{abstract}
Problem: Supportive measures for families facing a new diagnosis of childhood cancer are needed to address uncertainty and adaptive behaviors. Previous evidence suggests support groups are effective in adaptation; however, implementation is difficult.

Objectives: Determine the types of supportive measures found to be most helpful and feasible for families of pediatric oncology patients during the first three months after diagnosis.

Propositions: Traditional methods of psychosocial support do not meet the needs of parents and families in this situation. Participants prefer more informal meetings and gatherings that are more social in nature.

Methods: A descriptive single embedded (i.e. multiple informants) case study was used to study uncertainty and social support for families with children treated at an inpatient, pediatric oncology department in south Texas. The sample included members of the health care team in a pediatric cancer/bone marrow transplant unit and parents of children diagnosed with cancer. Data was gathered through interviews and observation of various family activities on the cancer unit. Data was analyzed through thematic content analyses and pattern matching.
\end{abstract}

Keywords: uncertainty, adaptation, childhood cancer, parent, support 
Approximately 924 new cases of childhood cancer (ages 0-14 years) were diagnosed in Texas between the years 2005-2009 (Texas Department of State Health Services, 2014). The number of new cases in one south Texas county totaled 914 (ages 0-19 years) between 2001 and 2010 (Texas Department of State Health Services, 2014). These patients and their families require a tremendous amount of resources from the health care team. Support groups and information sharing meetings have the potential to enhance the way resources are shared with this population. However, the structure, time commitment, and sensitive nature of topics to be shared can make this method of support unreasonable (Gannoni \& Shute, 2010; Kaufman, Harbeck, Olson, Nitschke, 1992; Kerr, Harrison, Medves, Tranmer, \& Fitch, 2007).

Studies have demonstrated that after learning a child has cancer, parents go through a range of emotions. Parents are concerned about the possibility of the child's death, a future disability, side effects of treatment, loss of income, and provisions for the child's siblings (Boman, Lindahl, \& Björk, 2003; Harrington, Kimball, \& Bean, 2009; Hutchinson, Willard, Hardy, \& Bonner, 2009). Parents feel anxiety, depression, uncertainty, anger, and guilt (Boman et al., 2003; Dolbeault, Boistard, Meuric, Copel, \& Bre'dart, 2011; Holm, Patterson, Rueter, \& Wamboldt, 2008; Kerr et al., 2007; Patiño-Fernández et al., 2008). Some parents have even been diagnosed with post-traumatic stress disorder (Boman, et al., 2003; Kazak \& Baxt, 2007). Uncertainties can prevent parents from successful adaptation when their child is diagnosed with cancer (Boman et al., 2003; Hutchinson et al., 2009). These products of uncertainty can lead to increased familial stress or even complete family breakdown resulting in divorce (Kalnins, 1983).

By addressing uncertainty one can regain control of the situation and begin the adaptive process (Mishel, 1981, 1988). Increased symptoms of depression and anxiety can also occur (Vrijmoet-Wiersma et al. (2008), and may negatively impact the family's functional ability to cope and tap into support networks (Hutchinson et al., 2009). If uncertainty is not addressed it can become pervasive and persist throughout the treatment plan or even become a lifelong concern (Hutchinson et al., 2009; Mishel, 1988). Despite generalized recognition of these problems in 
this population, little has been done to explore best practices in addressing them. Stewart, Mishel, Lynn, and Terhorst (2010) suggested that research be aimed at interventions to reduce parental uncertainty. Research investigating practice in addressing uncertainty and enhancing adaptive behaviors can help nurses and health care providers plan standardized interventions into their programs which can lead families toward development of increased adaptive mechanisms, recognition of social support networks, and more positive outcomes. However, an attempt to follow through on the recommendations to test an intervention of a standard support group failed. In spite of provider encouragement, flexible scheduling, and provision of child care, no parents elected to participate. The standard intervention recommended in the literature did not appear to meet the needs of families in south Texas. The purpose of this study is to determine the types of supportive measures found to be most helpful and realistic for families of children with cancer during the first three months after diagnosis. This preliminary study will lead to future development of testable interventions for improved nursing practice in this area.

\section{Literature Review}

\section{Uncertainty}

Within the realm of nursing care, uncertainty pertains to the period of time during an illness experience when a patient or family member is unsure of what the outcome of a procedure or disease process will entail (Penrod, 2001). Mishel (1988) defines uncertainty as a state when a stressful event cannot be organized due to lack of information or knowledge. The feeling of uncertainty can be quite distressing, and in fact, can be debilitating on both physical and mental health levels (Holm et al., 2008). Feelings of uncertainty can vary in length and last for a short period until diagnostic test results are known, or it can persist for years after completion of a cancer therapy regimen (Brashers et al., 1999; Clayton, Mishel, \& Belyea, 2006; Horner, 1997; Llewellyn, McGurk, \& Weinman, 2005; Roberts \& Clarke, 2009). Often associated with it are feelings of loss of control and fear of the unknown, and it has a direct link to increased familial stress patterns (Brashers et al., 1999, Dolbeault et al., 2011; Holm et al., 2008; Patiño-Fernández 
et al., 2008). Typically the most distressing period of time is the initial diagnosis period through the first few months (Brashers et al., 1999; Patiño-Fernández et al., 2008; Santacroce, 2002; 2003). By approximately six months after diagnosis families have usually developed either healthy or unhealthy coping mechanisms.

Hutchinson et al. (2009) reported parents of children who were currently receiving cancer treatment demonstrated significantly higher levels of anxiety and greater symptoms of depression than parents of children who had completed treatment. Those in active treatment also rated the impact of the illness on the family much higher than those already having completed therapy. The authors noted a significantly high level of uncertainty in both groups, those on treatment and those post-treatment, even after treatment had long since ended. A few studies have demonstrated gender differences in rates of uncertainty and its side effects (Hoekstra-Weebers, Jaspers, Kamps, \& Klip, 1998, 2001; Vrijmoet-Wiersma et al., 2008), but most studies have been populated primarily only by middle class, Caucasian women. This is not reflective of the typical population in south Texas. Comparisons of demographic factors as variables within these studies were not available (Boman et al., 2003; Clayton et al., 2006; Llewellyn et al., 2005; Hoekstra-Weebers, et al., 2001).

Boman et al. (2003), Clayton et al. (2006), and Llewellyn et al. (2005) investigated disease-related stress and time elapsed since diagnosis to examine if the amount of stress and uncertainty felt by parents decreased with time. They noted that feelings related to loss of control, anxiety, and physical signs and symptoms of stress, such as headaches and fatigue, all decreased with time. However, parents and patients who had large amounts of uncertainty continued to demonstrate these higher levels of uncertainty throughout the treatment period and often for years afterwards. Uncertainty must be addressed from the beginning of treatment so that coping mechanisms and adaptive behaviors can be identified and honed early and the family can return 
to normalcy (Brashers et al., 1999; Clayton et al., 2006; Kästel, Ensär, \& Björk, 2011; Roberts \& Clark, 2009).

Stewart et al. (2010) adapted Mishel's $(1981,1988)$ original model to apply to pediatric and adolescent patients with cancer and developed a tool with which to measure uncertainty in children, the Uncertainty in Kids Scale (UKS). They found a significant positive correlation between the amount of parental uncertainty and the amount of child uncertainty, and that child uncertainty had a significant positive correlation on the amount of child anxiety and depressive symptoms. Due to the strong correlation between the parents and children, future research aimed toward reducing parental uncertainty while measuring both parental and child uncertainty was recommended (Stewart et al., 2010). Mishel $(1981,1988)$ believed that parental adaptation was key to family and child adaptation.

Uncertainty leaves the family unable to predict outcomes. A primary role of nursing is to facilitate the shift from illness to optimum health by assisting in adaptation to new roles through therapeutic interventions. Research suggests that interventions aimed at reducing uncertainty soon after diagnosis should increase adaptation in the chronically ill and their families (Brashers at al., 1999; Clayton et al., 2006; Comer et al., 2009; Dolbeault et al., 2011; Holm et al., 2008; Mishel et al., 2005; Soanes, Hargrave, Smith, \& Gibson, 2009). Mishel et al. (2005) studied an intervention aimed at reducing uncertainty in long-term breast cancer survivors, and measured uncertainty by measuring cancer knowledge, patient-provider communication, social support satisfaction, and problem solving. They found significant differences between the control and intervention group overall, as well as significant differences on the specific measures: problem solving cancer knowledge, patient-provider communication by ethnicity, and social support satisfaction. Further evidence suggests that levels and types of uncertainty change over time and the earlier the intervention the better the outcome (Brashers et al., 1999; Clayton et al., 2006; Roberts \& Clark, 2009). It is not known if these findings in a sample of adult women with breast cancer can be generalized to parents of children with cancer. In order to provide interventions aimed at reducing 
uncertainty and promoting adaptation among parents, nurses must understand the attributes of uncertainty so that appropriate interventions can be planned. These attributes include ambiguity, loss of control, fear of the unknown, multiple meanings, unpredictability, and psychological distress (Brashers et al., 1999; Clayton et al., 2006; Holm et al., 2008; Horner, 1997; Llewellyn et al., 2005; Mishel, 1983; 1988; Roberts \& Clarke, 2009).

\section{Adaptation}

Adaptation, the process by which a patient or family member adjusts to the cancer diagnosis, is linked with uncertainty (Comer et al., 2009; Gannoni and Shute, 2010; Holm et al., 2008; Hutchinson et al., 2009; Katz, 2002; McGrath \& Phillips, 2008; Mishel, 1983; Santacroce, 2002; Vrijmoet-Wiersma et al, 2008). Vrijmoet-Wiersma et al (2008) conducted a descriptive literature review that focused on parental strain, reactions to stress and the adjustment period that followed diagnosis of a catastrophic illness. The authors included only articles with standardized measures of psychometric quality and statistical analysis. They found that anxiety and depression are very common traits and are worse immediately after diagnosis. These rates showed statistically significant differences between mothers and fathers, especially in mothers already diagnosed with depression prior to the child's cancer diagnosis.

One would anticipate that with the reduction of uncertainty, one would adapt more readily, and outcomes would begin to improve (Clayton et al., 2006; Llewellyn et al., 2005; Mishel, 1981, 1983, 1988). Patients, parents, siblings, the extended family, and the social support network go through a process of adaptation to living with a child diagnosed with cancer or blood disorder. Gannoni \& Shute (2010) found that parents of children with chronic illnesses believed they had trouble communicating with the health care team and were inundated with information they were expected to rapidly process. Parents and child both learn about the disease process, how to care for the child, how to monitor for signs and symptoms of the disease, types of medications, dosages and administration techniques. Families adjust their schedules and routines, and are often hindered from participating in normal activities secondary to the adaptations 
required for their disease process (Gannoni \& Shute, 2010; Machado da Silva, Jacob, \& Nascimento, 2010). Parents also adapt to a loss of income and managing the household while establishing a routine of medical office visits and days in infusion clinics while still attempting to maintain some sense of normalcy (Gannoni \& Shute, 2010; Soanes et al., 2009).

\section{Psychosocial and Education Interventions}

Psychosocial interventions, such as support groups and consultations by psychologists, have been recommended in adult populations, and more research is needed in working with family units (Chien, Wang, Chien, \& Hwang, 2011; Coleman et al., 2005; Nolbriss, Abrahamsson, Hellstrom, Olafsson, \& Enskar, 2010; Zabalegui, Sanchez, Sanchez \& Juando, 2005). Many centers in the United States offer regularly scheduled on-site support groups for parents of children with cancer as well as immediate social work consultations after diagnosis. These support groups have been helpful in developing internal familial coping strategies, which leads to quicker adaptation to the culture of childhood cancer (Jackson et al., 2009). Early implementation of psycho-social interventions, such as support groups directed at management of stress-related symptoms without the use of medications, can enhance coping behaviors (Chien et al., 2011; Coleman et al., 2005; Kaufman et al., 1992; Nolbriss et al., 2010). In their study of parents of childhood cancer survivors, McGrath and Phillips (2008) suggest inviting parents of children who are further along in the treatment regimen to support groups because they would be helpful in providing an overall picture of the treatment process. Continuing the availability of support groups long after treatment is completed has been recommended in order to facilitate adaptation back to normal family life without the continued regular influence of the health care team (Boman et al., 2003; Harrington et al., 2009; Hutchinson et al., 2009). Boman et al. (2003) and Kwok and Ho (2011) go on to suggest that support groups should be focused on emotional vulnerability and discussing past experiences that might help facilitate adaptation to this stressful event. Limitations of these interventional studies include lack of variance in the study participant groups and small sample sizes. This has limited the generalizability of the results to a broader 
population (Boman et al., 2003; Clayton et al., 2006; Llewellyn et al., 2005; Hoekstra-Weebers et al., 2001), such as that found in south Texas.

A qualitative study reported that both parents and children prefer having psychosocial interventions for ease of transition from one stage to another (Gannoni and Shute, 2010). What remains unknown is how best to implement the support group interventions, and which demographic variables predict higher or lower adaptation and uncertainty scores. Bragadóttir (2008) and Lounsberry, McRae, Angen, Hoeber, and Carlson (2010) utilized long-distance support group interventions through teleconferencing and online chat rooms. Both studies showed marginal success and recommendations were offered regarding further research in these areas for patients and families unable to participate in on-site support interventions.

The immediate need for family support and education following the diagnosis of childhood cancer is strongly reflected in the literature. However, minimal evidence exists that demonstrates an effective program of psychosocial and educational support that is easily implemented and inexpensive. Very little evidence exists in populations outside of the middle class Caucasian mother figure. The population of south Texas is rich in cultural diversity and is in need of interventions of this nature, but due to variances in language, family dynamics, and cancer diagnoses, interventions have been difficult to implement and sustain. At this time, in the hematology/oncology/bone marrow transplant unit of one south Texas children's hospital there are no support groups or interventions aimed at reducing uncertainty in this population. Attempts to implement a support group in this population have been unsuccessful. It is expected that implementing specific types of support resources will help parents learn from others, discover they are not alone in this process, and also to build a community within the unit. A preliminary study is necessary to determine what types of services would be most helpful to these families so that specific educational meetings and support measures aimed at reducing uncertainty could effectively facilitate adaptation in this population. 


\section{Theoretical Model}

Mishel's Theory of Uncertainty in Illness (Mishel, 1981, 1988) defines perceived uncertainty as a concept rooted in a person's evaluation and judgment of an event, situation, or illness. Uncertainty may be decreased if parents whose children are diagnosed with cancer are able to cope, leading to smoother adaptation to life when a life-threatening condition exists. Effective coping and adaptation can potentially increase positive patient outcomes both early in treatment and after therapy completion.

Mishel's Model of Uncertainty (Mishel, 1981, 1988) demonstrates that uncertainty exists when a traumatic event occurs, in this case the diagnosis of cancer in a child. The way an event is interpreted depends upon one's internal cognitive capabilities and influence of external support. The traumatic event prompts one to feel a loss of control leading to uncertainty regarding future events. When uncertainty is present, a person cannot categorize or process events in a systematic fashion due to factors such as ambiguity, unpredictability, loss of control, and knowledge deficits (Mishel, 1981, 1988). This breakdown in processing or lack of cognitive schema leads to a decreased ability to adequately develop coping mechanisms and adapt to the new situation. Interventions that reflect various types of support can help parents begin forming adaptive coping mechanisms which will decrease anxiety and address knowledge deficits. Figure 1 describes an adapted variation of Mishel's model which includes an intervention phase to help decrease uncertainty and increase adaptive behaviors through developing stronger coping mechanisms. 


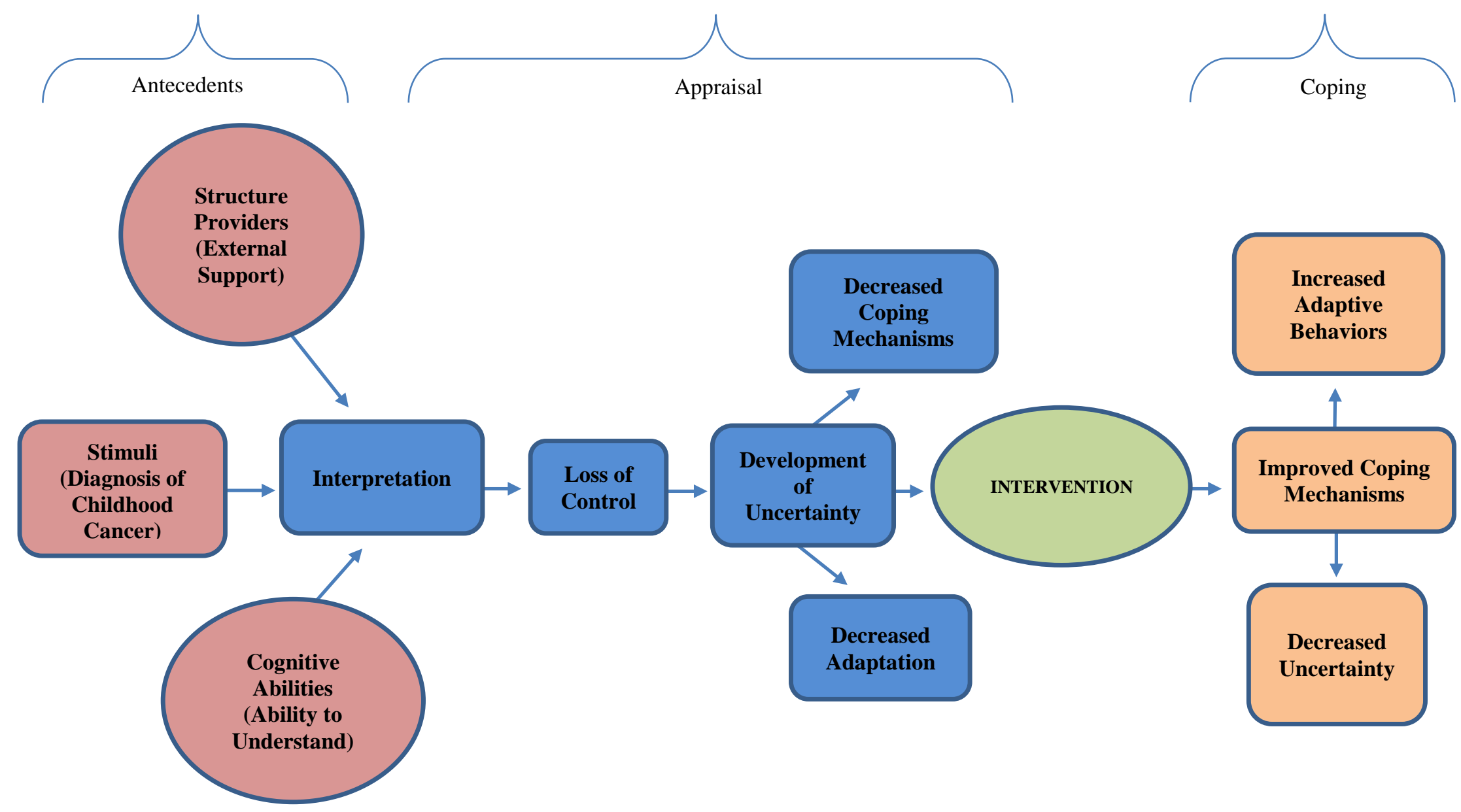

Figure 1. Model of Perceived Uncertainty in Illness Adapted from Mishel's Model of Uncertainty in Illness Theory (Mishel, 1988). A visual description of the conceptual model of perceived uncertainty derived from Mishel's Theory of Uncertainty. A causal event leads recognition of an experience framework (cognitive understanding and external support) followed by development of uncertainty. Administration of the intervention and the result of decreased uncertainty and increased adaptive behaviors are shown at the right. Derived from Mishel (1988). 


\section{Study Design}

A descriptive single embedded case study design with multiple informants guided this study. The single embedded case study included examining the views regarding uncertainty and support mechanisms of parents of children with cancer and their health care team members. According to Yin (2013), a case study is defined as "an empirical inquiry that investigates a contemporary phenomenon (the "case") in depth and within its real world context especially when the boundaries between phenomenon and context may not be clearly evident" (p. 16). Case studies are used in most social science disciplines to help understand complex social interactions and concerns. They are best used to answer the "how and why" types of research questions, and can be used as an alternative to more descriptive models of research in nursing. Case studies, as opposed to descriptive research, emphasize the constructivist approach to the participant's real experiences and provide a clearer picture to the investigator (Baxter \& Jack, 2008; Zucker, 2001). Case study research does not require control over or manipulation of events. It is used simply to answer the question of why an event occurred or how it has affected a certain group or an environment (Yin, 2013). Case studies can be done as single or multiple case research studies. Single case studies tend to focus on contemporary events rather than historical ones, especially when behaviors related to that event cannot be manipulated by research. The researchers gather a thorough and complete picture of one phenomenon from various view points and data sources (Yin, 2013). Yin (2013) notes that embedded single case studies include separate units of analysis. The examination of an organization or program includes the views of multiple informants such as employees, clients, the socioeconomic structure of the community the organization serves, men compared to women, and various ethnic and cultural influences.

Case studies are ideal when multiple variables are possible causes of or contributors to the phenomenon. Yin (2013) and Baxter and Jack (2008) state that in order to discover these variables, multiple sources of evidence may be used, unlike other methods of research such as written surveys and observations that are limited in scope. Yin (2013) also states case study 
research proposals are ideal when guided by a theoretical model. The use of Mishel's Uncertainty in Illness Model $(1981 ; 1983 ; 1988)$ helped to guide the study inquiry. It is known that an intervention is necessary, but how best to do so is a gap in the collective research knowledge. A comprehensive, scientific approach to analyzing the concern was recommended before attempting another quantitative research study (Casey \& Houghton, 2010, Koch, 1994, Yin, 2013; Zucker, 2001).

Previous attempts of this pediatric cancer program to include social support and formal education for patients and parents have been unsuccessful. Since the literature review demonstrates that this technique is highly recommended, the principal investigator wanted to discover more context-rich information related to why these interventions were unsuccessful by examining the attitudes and feelings of the health care team members and parents within this hospital program regarding psychosocial and educational support. The descriptive single embedded case study design was chosen because the context of the phenomenon in question, uncertainty, would contribute essential knowledge for future intervention-based research for parents of children with cancer. This was done by examining the thoughts and feelings towards uncertainty, coping mechanisms, and support provided and/or needed from various data points (the embedded units of analysis) (Yin, 2013). The case study design is a more comprehensive approach towards a successful research program (Baxter \& Jack, 2008; Price, 2000; Richards \& Morse, 2013; Yin, 2013; Zucker, 2001).

\section{Philosophical Underpinnings}

Case study research as a qualitative research method is based in the realm of constructivism (Yin, 2013). Constructivism means that through knowing and understanding the human mind gives meaning and order to its own reality (Balbi, 2008). In this case that reality is uncertainty and the lack of adaptive behaviors. Constructivist approaches have long been used in therapy to help the patient gain meaning from their own version of reality, and the practitioner's role is to help enhance or expand that version of reality (Balbi, 2008). Completing in depth 
observations and interviews, as well as collecting data from multiple sources allows the participants to share their version of reality. Because understanding their vision of reality is crucial to addressing their concerns and the phenomenon in question, it is important for the investigator to allow this process to occur (Yin, 2013; Zucker, 2001). In order to understand what the reality of uncertainty is and what assistance is needed to adapt appropriately, research was needed that allows the participant to elaborate on their version of reality.

\section{Methods}

\section{Research Questions and Propositions}

Research questions were: (1) How do parents of children with cancer and members of their health care team identify and describe feelings of uncertainty? (2) How do parents currently adapt and use coping skills to deal with uncertainty? (3) What types of support are available and which are most helpful to parents caring for a child recently diagnosed with cancer in south Texas? (4) Why is implementation and sustainment of more traditional methods of psychosocial support (formal support groups) so difficult in a south Texas clinical setting?

Proposition (1): Traditional methods of psychosocial support, such as therapy groups, meetings, and classes do not meet the current needs of parents and families in this situation due to the strict structure and nature of their delivery. Proposition (2): Parents and families prefer more informal meetings and gatherings that are more social and familial in nature to help decrease their uncertainty and develop positive coping mechanisms.

\section{Setting}

In this case study design, the PI examined a south Texas pediatric 17-bed cancer unit, seven of which are usually devoted to bone marrow transplant patients. This treatment facility has approximately 60-70 new patients diagnosed with a childhood cancer each year. The treatment center includes an inpatient unit and an outpatient clinic owned and operated by one of six hospital systems in the county. It is housed within the children's hospital of the health care system, but is on a shared campus with one of the system's adult hospitals. 


\section{Sample}

Convenience, purposive selection of health care team members $(n=15)$ and parent participants $(n=6)$ was done from the childhood cancer center to gather the perspectives desired. Data from both parents of children with cancer and members of the health care team are considered embedded unit of analysis within the single case study. All views related to what type of support is needed and why it has not been successful are helpful toward a full analysis within the single case study. Therefore both were recruited as part of the sample for this study. Together they served as the primary source of information for the case study. By seeking information from a broader demographic than previous studies of social support, it is hoped that the views from this sample of health care providers and parents in south Texas will be generalizable to the broader population of parents of children with cancer across the United States, and even to parents of children dealing with other chronic illnesses such as juvenile rheumatoid arthritis, cystic fibrosis, multiple sclerosis, cerebral palsy, diabetes, and HIV/AIDS.

Administrative approval from the unit nursing director was granted and formal recruitment began after institutional review board approval was received. The unit health care team includes bedside nurses, patient care assistants, a nurse educator, a nurse director over both areas, a nurse manager over the outpatient clinic, a case manager, a social worker, an art therapist, a child life therapist, a nutritionist, a physical and occupational therapist, three transplant physicians, four oncology physicians (two of whom are in private practice), and two nurse practitioners. In addition to representatives of the health care team, parents of patients diagnosed within the previous year were included to get a fuller understanding of the case.

A specific sample number is not calculated for case study research because the goal is concept saturation and a comprehensive analysis of the entire case (Casey \& Houghton, 2010; Miles \& Huberman, 1994; Richards \& Morse, 2013; Yin, 2013). However, it was estimated that a minimum of 10-15 participants would provide the data required. This case study actually had a total of 21 participants. 


\section{Inclusion and Exclusion Criteria}

Parent participants. Any parent of a child or adolescent age 0-19 years was eligible to participate provided the child/adolescent was diagnosed within the previous year, the parent could speak and read/write English, and was willing to spend approximately 45-60 minutes in an audio recorded interview with the PI. Parental inclusion criteria included any age, ethnicity or race (if able to read and speak English), education, socioeconomic background, marital status, or immigration status. If both parents of a child with cancer wanted to participate, they were offered the choice to complete the interview session alone or together.

Health care professional participants. Professional participants from the unit health care team must have been currently employed full time within the childhood cancer center, work with these patients/families on a frequent/daily basis, and must have done so for at least six months prior to the interview. Racial diversity in this region of south Texas shows that over $60 \%$ of the population identifies itself as Hispanic (City-Data, 2009). It was reported by the unit director and assistant manager that the unit staff and typical patient population is approximately 40\% Hispanic. An attempt was made to recruit a sample from both parent and health care professional participants that was equal to this diversity so that the sample was representative of the general population in this geographic area.

\section{Recruitment}

A verbal announcement by the unit director about the study was made at the weekly clinical rounds meeting which includes all of the pediatric oncology health care team. A separate email and phone call was made by the PI to the health care team members to recruit interest in their participation. Professional participants were also identified through referral by the nurse director and approached directly for their participation by the PI. Once confirmation of their wish to participate was received, an appointment was scheduled to complete the informed consent and the demographic questionnaire, and to record the interview. There were a total of 21 participants: 15 members of the health care team and 6 parents of children with cancer. Health care team 
participants were all women and included two unit administrators, two nurse practitioners, one staff educator, two staff nurses, one case manager, and one physician. In addition to these, a group interview of the psychosocial support team that included the social worker, the BMT counselor, the child life therapist and director, the art therapist, and a staff educator was done. The chaplain participated in this session, but did not wish to have her comments included in the study, so her input was removed from the data.

Recruitment of parent participants was conducted on the inpatient units and outpatient clinic with assistance from the clinical providers such as nursing staff, nurse practitioners, and the medical providers. Flyers were posted around the family areas in the inpatient unit and outpatient clinic and also given to all oncology providers for distribution at the cancer center. Possible parent participants were identified by the nurse practitioners and nursing staff and recommended as possible participants. Those recommended were given a copy of the recruitment flyer. Potential parent participants were asked to contact the PI using the information provided on the flyer. Possible parent participants were also identified through referral by the nurse director or nursing staff and approached directly for their participation by the PI. Parent participants included one father and mother married couple, and four other mothers.

Once a participant contacted the PI, the PI met with them to review the study requirements, risks and benefits. If the potential candidate was agreeable, the PI obtained informed consent. This meeting was held at the participant's convenience, either in the hospital, clinic, or at his/her home. Following consent signatures, participant identification numbers were assigned, and consents were stored in a locked cabinet in the PI's office separate from the list of research identification numbers and all survey results.

Recruitment continued until a diverse sample of health care providers and parents were interviewed and data saturation was achieved. Yin (2013) suggests doing this as a way to ensure the completeness of the case study rather than limiting the number of participants based on presumed boundaries in numbers of participants. An attempt was made to ensure the sample is 
representative of the cultural diversity in south Texas by seeking out a sample group similar to the demographic numbers represented on the unit which includes approximately $40 \%$ Hispanic patients, families, and health care team members. Participants' average age, education, race/ethnicity, and other demographic data are summarized in Table 1

Table 1

Demographic Data

\begin{tabular}{|c|c|c|}
\hline & $\begin{array}{l}\text { Health Care Team } \\
\text { Participants }(n=15)\end{array}$ & $\begin{array}{l}\text { Parent Participants } \\
(\mathrm{n}=6)\end{array}$ \\
\hline Ethnicity & $\begin{array}{l}\text { 33.3\% Hispanic } \\
66.6 \% \text { White, Non-Hispanic } \\
0.06 \% \text { Multi-racial }\end{array}$ & $\begin{array}{l}33.3 \% \text { Hispanic } \\
66.7 \% \text { White, Non-Hispanic }\end{array}$ \\
\hline Religion & $\begin{array}{l}\text { 73.3\% Christian } \\
13 \% \text { None } \\
0.6 \% \text { Buddhist } \\
0.06 \% \text { Other }\end{array}$ & 100\% Christian \\
\hline Age & $\begin{array}{l}31-55 \text { years } \\
\text { Average age of } 39.6 \text { years }\end{array}$ & $\begin{array}{l}30-41 \text { years } \\
\text { Average age of } 34.6 \text { years }\end{array}$ \\
\hline Education Level & $\begin{array}{l}100 \% \text { completed college } \\
20 \% \text { completed some } \\
\text { graduate school } \\
46.6 \% \text { completed graduate } \\
\text { school }\end{array}$ & $\begin{array}{l}50 \% \text { finished college } \\
33.3 \% \text { finished some college } \\
16.6 \% \text { finished high school }\end{array}$ \\
\hline Professional license & $86.6 \%$ & $33.3 \%$ \\
\hline $\begin{array}{c}\text { Average Years of } \\
\text { Experience }\end{array}$ & 12.8 years & Not Applicable \\
\hline $\begin{array}{c}\text { Average Years at This } \\
\text { Program }\end{array}$ & 4.63 years & Not Applicable \\
\hline Child's Diagnosis & Not Applicable & $\begin{array}{ll}33 \% & \text { Leukemia } \\
33 \% & \text { Neuroblastoma } \\
16.6 \% & \text { Brain tumor } \\
16.6 \% & \text { Wilms } \\
\end{array}$ \\
\hline Time since Diagnosis & Not Applicable & $\begin{array}{l}50 \% \quad<3 \mathrm{mos} \\
16.6 \% \\
3-6 \mathrm{mos} \\
33 \% \quad>6 \mathrm{mos}\end{array}$ \\
\hline Average Age of Child & Not Applicable & $\begin{array}{l}4.25 \text { years } \\
\text { Range: } 6 \text { mos to } 8.5 \text { years }\end{array}$ \\
\hline Marital Status & Not Applicable & $\begin{array}{l}50 \% \text { Married } \\
33 \% \text { Divorced } \\
16.6 \% \text { Single }\end{array}$ \\
\hline Preferred Language in Home & Not Applicable & 100\% English \\
\hline
\end{tabular}




\section{Instruments and Measures}

Separate demographic instruments were developed for parent and health care team participants. The parental demographic instrument was used to gather information on participant age, race/ethnicity, education level, and members of the household. In addition to the usual questions on age, race/ethnicity, religion and education, the health care provider demographic questions obtained data about length of experience in this role and at this facility. This information was used to describe and facilitate identification of the population to whom results can be generalized. Separate interview guides and questions for parents and health care team members were developed by the principal investigator.

\section{Procedures}

\section{Data Collection}

Yin (2013) recommends the collection of data from multiple sources, which can be considered embedded units of analysis. Beyond traditional interviews as units of analysis, the principal investigator visited and observed several art therapy sessions on the inpatient and outpatient units to note any specific interactions between parents, patients, and family members that might provide insight to supportive measures taking place at these sessions. These observations served as another embedded unit of analysis for the single case study. Field journal notes from these observations also included information regarding setting, context, approximate number of attendees, and tone of each gathering. This is in an effort to obtain as comprehensive an analysis of the entire case as possible. Multiple sources of data are encouraged in case study research (Miles \& Huberman, 1994; Richards \& Morse, 2013; Yin, 2013). No interviews or recordings took place during these observations. Notes were taken by the investigator regarding the context (location, purpose of event, persons present), tone of the environment, and verbal and non-verbal communications.

The principal investigator made an appointment with each participant at a time and place convenient to the participant. The informed consent was signed and the demographic form 
completed. Then the principal investigator proceeded with the 45-60 minute audio recorded interview. According to Yin (2013) targeted interviews are a way to focus directly on the topic of the case study, but must be specific and questions must be formatted well before starting. The same pattern should be repeated and the interviewer must be conscious of his/her demeanor so as not to influence the interviewee's responses. Specific questions with appropriate probing were asked of each participant. Separate interview questions were asked of parent participants and professional participants and all interviews were conducted by the principal investigator to ensure the same process and tone was used for each one.

Interviews were conducted and audio-recorded at a location convenient to the participant. This could be in the clinic/hospital office, the unit conference room, their home, hospital room or any other location the participant preferred. The only requirements were that it be fairly quiet where interruptions could be minimized and that the participant and principal investigator had a comfortable sitting area so that a casual conversation could occur. This minimized the possible influence of researcher over participant and made the environment more informal. Snacks and beverages were allowed if the participant liked and the room temperature was maintained at a comfortable level to the participant.

Prior to beginning the actual interview question guide, the principal investigator engaged in social conversation to demonstrate respect and increase the comfort level of the participant. This is customary in many social situations in south Texas and thus more culturally sensitive. This helped build rapport between the participant and the investigator. The investigator also offered to the participant a choice of using a pseudo-name or their first name. Then the investigator spent a few minutes just helping the participant become more comfortable with what would happen during the interview by explaining the topics to be discussed again, encouraging any questions the participant might have, and when the recording would be started and stopped. The investigator also explained that written notes would be taken during the interview simply to help add to the transcription and data analysis later. The investigator emphasized that the 
interview was a time to be open and transparent about feelings and concerns related to the questions and at any time the interview could be stopped. At the end of each interview all participants were offered the opportunity to share more later if something else came to mind. They were also asked if it was acceptable for the principal investigator to follow up with the participant if further clarification was needed. Finally the principal investigator ensured they understood that no quotes from their interview would be shared or included in publications without their express permission and the opportunity to review it first for validation of their meaning and intent. The digital recordings were transcribed by the investigator and by a transcriptionist who acknowledged the importance of confidentiality.

During each observation period and interview the principal investigator kept notes regarding observations and the decision making process in a field journal. Time was taken by the PI immediately after each interaction for observational reflection on the experience. These field journal notes included details regarding the setting, the emotional tone, body language, expressions, and possibly direct quotes, how participants were dressed, and how they interacted with the investigator and others. It also included notes from the investigator's behavior, feelings, and actions because this too can affect the contextual environment (Williams, 2011; Yin, 2013). Reflective notes included investigator thoughts regarding the process and changes that might need to occur prior to the following participant's interview. Occasionally these notes led to further questions for follow up. This helped to demonstrate the thought process of the investigator and provide a decision and audit trail for concerns regarding rigor and transferability (Casey \& Houghton, 2010; Koch, 1994; Yin, 2013). Interviews and observations continued until data saturation was noted when no new themes or concepts began to emerge (Houghton, Casey, Shaw $\&$ Murphy, 2013). Interviews continued until at least one nurse, administrator, social worker, case manager, and physician were included and the participants were self-identified as approximately $40 \%$ Hispanic so that the case study was as comprehensive and generalizable as possible. 


\section{Data Management}

Digital and hard copy files identifying the names of participants and their assigned number along with copies of all consents and demographic surveys were maintained for clarification purposes only and were secured in a locked cabinet within the principal investigator's office. A Microsoft Excel file was created and maintained by the principal investigator. All files were locked with a password. Only the principal investigator entered data as it was received. All copies will be destroyed once the write up is completed, and only a back-up digital copy of the excel and transcription files will be maintained.

\section{Data Analysis}

Demographic information was placed in an Excel spreadsheet so that generalizations about the case could be made. In order to analyze the interview data, each one was transcribed into a word processing document. Transcription and interview notes both reflected the emotional context and voice inflection. After transcripts were verified for accuracy, they were entered into the qualitative analysis software program (N-Vivo 9). Searches for word patterns in each interview were conducted and placed into codes, which N-Vivo 9 refers to as "nodes", then crossmatched with other interviews from all the participants. This helped identify how often certain concepts and language phrases were used and in what context they occurred. Pattern matching was completed to compare results from within each participant's interview, and also compare across all participants' interviews (Miles \& Huberman, 1994; Yin, 2013). These patterns were grouped into themes. Field notes from the observations of art therapy sessions were considered contextual evidence and were included in the analysis as such. These codes and themes were tied back to the original research questions and propositions, thus permitting the principal investigator to examine how these concepts fit into Mishel's Model of Uncertainty (Mishel, 1988).

\section{Rigor}

Yin (2013) states that the four areas to ensure rigor within quantitative studies still apply within case study research: construct validity, internal and external validity, and reliability. 
Construct validity was addressed through the use of multiple sources of evidence and creating a chain of evidence. This included the purposeful selection of members of the health care team and parents that were representative of the program's population. Credibility was maintained by triangulation through extensive interviews and repeated observations leading to data saturation (Houghton et al., 2013; Miles \& Huberman, 1994; Richards \& Morse, 2013; Ryan-Nicholls \& Will, 2009). These were done during the data collection phase. Yin (2013) states that internal validity addresses accuracy of causal relationships, and is more important in causal studies and not in exploratory and descriptive case studies. It is addressed during data analysis through inferences in "pattern matching, explanation building, addressing rival explanations and using logic models" (Yin, 2013, p. 48). Since this case study is descriptive, internal validity was not addressed. External validity is concerned more with the generalizability of the study to other populations and areas and is typically addressed through the wording in research question design and the purposeful selection of a diverse and representative sample. Yin (2013) suggests the use of how and why questions in descriptive and exploratory designs because this allows for a broader understanding and should be addressed at the start of the study design. This was done through the interview guides and approved prior to the start of the study. Lastly, reliability minimizes errors and biases within a study by ensuring later "researchers can conduct the same research again and come to the same conclusions" (Yin, 2013,p. 48). This is done in case study research through the development of a specific case study protocol and database.

An experienced, expert qualitative researcher assisted in demonstrating agreement between labeling and coding and the decision tree process. This helps to improve credibility in a qualitative research design (Houghton et al., 2013; Ryan-Nicholls \& Will, 2009). Ensuring that participants have the opportunity to review transcripts of their interviews prior to analyzing the data also helps clarify if the data is accurate. This helped reinforce the validity and strength of suggestions prior to development of interventions aimed at reducing uncertainty and also identify any rival interpretations (Richards \& Morse, 2013; Ryan-Nicholls \& Will, 2009). Finally, a 
description of social and educational support plans thought to be most helpful was derived for future research implementation.

\section{Results}

Results showed that health care team members and parents of children with cancer had many of the same concerns regarding uncertainty and similar thoughts on how to best help families adapt to the diagnosis of childhood cancer. After data coding was completed the data was grouped into five themes: meaning of uncertainty, facilitators of parental adaptation, education and psychosocial support, patient/family obstacles and breaking through the institutional culture. Each theme also had subthemes, which are shown in Table 2. The themes and subthemes are discussed in this section when addressing each of the four research questions. Pieces of participants' transcribed interviews are reported in this section to help illustrate the development of these themes and subthemes. 
Table 2

Research Results: Themes and Subthemes

\begin{tabular}{|c|c|c|}
\hline $\begin{array}{l}\text { Research } \\
\text { Question }\end{array}$ & Themes & Subthemes \\
\hline $\begin{array}{l}\text { How do } \\
\text { parents of } \\
\text { children with } \\
\text { cancer and } \\
\text { members of } \\
\text { their health } \\
\text { care team } \\
\text { identify and } \\
\text { describe } \\
\text { feelings of } \\
\text { uncertainty? }\end{array}$ & $\begin{array}{l}\text { Meaning of } \\
\text { Uncertainty In } \\
\text { Parents and } \\
\text { Members of the } \\
\text { Health Care } \\
\text { Team }\end{array}$ & $\begin{array}{l}\text { Shock and subsequent barrage of negative emotions } \\
\text { Health care provider (physician) uncertainty in guiding the } \\
\text { steps of treatment } \\
\text { Looking through the black tunnel } \\
\text { Burden of parental ambiguity and decision making }\end{array}$ \\
\hline $\begin{array}{l}\text { How do } \\
\text { parents } \\
\text { currently adapt } \\
\text { and use coping } \\
\text { skills to deal } \\
\text { with } \\
\text { uncertainty? }\end{array}$ & $\begin{array}{l}\text { Facilitators of } \\
\text { Parental } \\
\text { Adaptation }\end{array}$ & $\begin{array}{l}\text { Extended network support } \\
\text { Socioeconomic } \\
\text { Empowerment }\end{array}$ \\
\hline $\begin{array}{l}\text { What types of } \\
\text { support are } \\
\text { available and } \\
\text { which are most } \\
\text { helpful to } \\
\text { parents caring } \\
\text { for a child } \\
\text { recently } \\
\text { diagnosed with } \\
\text { cancer in south } \\
\text { Texas? }\end{array}$ & $\begin{array}{l}\text { Education and } \\
\text { Psychosocial } \\
\text { Support }\end{array}$ & $\begin{array}{l}\text { Communication } \\
\text { Providing information and sharing support }\end{array}$ \\
\hline \multirow{2}{*}{$\begin{array}{l}\text { Why is } \\
\text { implementation } \\
\text { and } \\
\text { sustainment of } \\
\text { more } \\
\text { traditional } \\
\text { methods of } \\
\text { psychosocial } \\
\text { support (formal } \\
\text { support } \\
\text { groups) so } \\
\text { difficult in a } \\
\text { south Texas } \\
\text { clinical } \\
\text { setting? }\end{array}$} & $\begin{array}{l}\text { Patient/Family } \\
\text { Obstacles }\end{array}$ & $\begin{array}{l}\text { Family stress at home } \\
\text { Financial instability } \\
\text { Disconnectedness, Entrapment, and Isolation } \\
\text { Lack of meaningfulness of social service provision } \\
\text { Stigmatization of "Support" } \\
\text { Cultural Barriers }\end{array}$ \\
\hline & $\begin{array}{l}\text { Breaking } \\
\text { Through } \\
\text { Institutional } \\
\text { Culture }\end{array}$ & $\begin{array}{l}\text { Policy and institutional culture } \\
\text { Home-grown management experience } \\
\text { Lack of trust } \\
\text { Interdisciplinary collaboration: An evolving model }\end{array}$ \\
\hline
\end{tabular}




\section{Meaning of Uncertainty in Parents and Members of the Health Care Team}

In order to address the first research question, which explored how parents of children with cancer and members of their health care team identify and describe feelings of uncertainty, each participant was asked what the term uncertainty meant to them. Parent participants described what uncertainty in childhood cancer meant to them. Health care team participants described their perspective on parental uncertainty. Both groups described this in similar terms. Comments were grouped into four subtheme areas: shock and subsequent barrage of negative emotions, health care provider (physician) uncertainty in guiding the steps of treatment, looking through the black tunnel, and burden of parental ambiguity and decision making. Each subtheme will be discussed separately.

Shock and subsequent barrage of negative emotions. Emotions experienced by parents were described by both health care team participants and by parents. Responses from both parent and health care team member participants revealed that emotions focused on negative connotations in the diagnostic phase (two the three weeks after diagnosis). They included feelings of shock, guilt, fear, anger, loss of control, and grief. Initially shock and disbelief were very common emotions expressed. Parental informants shared the following: "Shock is the first one (emotion) that comes to my mind"; "Shock, sadness, fear...;" "I was just shocked...," "For me...disbelief." Guilt was also of concern due to the feeling that parents may perceive they missed some key piece of information or symptom, did not take their child to the doctor soon enough, or may not have advocated for them as strongly as they felt they should have. Health care team participants shared, "I think there is some guilt...have been these vague symptoms that they've put off for a little bit...(or)...what if I had recognized it sooner?" Another said, "I think the first thing most parents feel is guilt. What did I do to cause my kids to have cancer?" Persistent and repetitive anxiety and loss of control were other common emotions described by several participants, as demonstrated in these phrases, "A sense of losing control of the care of their child, and... (the) daily anxiety to not know what each hour is going to bring, or each day a 
new catastrophic diagnosis.” A few participants described anger rather than anxiety as a way to express frustration with the loss of control parents feel when forced to face the overwhelming consequences of a childhood cancer diagnosis. For example, one participant said, "Anger. Some people are so angry! Why me? Why my family? So angry." Another parent participant shared that anger was a reflection not only of loss of control, but of the guilt she was feeling, "You get angry. I started getting angry at myself mostly because I was like 'why didn't I take her in sooner'? These types of comments were fairly common among parent participants.

\section{Health care provider/physician uncertainty in guiding the steps of treatment.}

Uncertainty was not a parental concept alone. It was also described by parents as something their oncology providers demonstrated. This was discussed in the context of a poor prognosis or in disease relapse. Physicians did not always know the best way to move forward or what steps should come next. After relaying positive biopsy results to a parent, the physician walked out of the room indicating the need to talk with the tumor board, giving the parent the impression the physician did not know what to do. Another physician was not able to guide a parent in making treatment decisions because of how rare her tumor was. There was very little research available about successful treatment options and that appeared to frustrate the physician as much as the parent. This could cause concerns regarding lack of trust should statements like these be interpreted as lack of knowledge and experience on the part of the provider. It could also be interpreted as leaving the major decisions up to parents which puts the burden of responsibility related to treatment success or failure on parents rather than on the physician.

Looking through the black tunnel. Health care members described parental uncertainty as searching through the darkness, "like a black tunnel in front of them." They felt that parents were lost and overwhelmed and did not know what to expect regarding treatment and what would happen to their child. Parents had lost control of the day to day happenings in their lives. One participant said, “... there's all this unknown. They don't have a schedule anymore. Their life is up in the air,...whatever happens, happens." Parents have uncertainty both about their child's 
prognosis, and also how to adapt to the lifestyle changes required. It invades every point of their lives. A participant shared,

They are uncertain about their own lives. A lot of the first few days we've heard parents say, 'Can I work? What will my work say? What am I going to do with the other kid?' I can see that the word uncertainty is huge....they can't even think. They are flabbergasted and their world is turned upside down ... are really uncertain just about everything.

Members of the health care team also noted that some uncertainty can come from simply adjusting to the hospital environment. One participant said, "What are the visitation rules? What are the rules about how I talk with people? Can I tell people not to come into the room? What are the rules about me walking away to get food? Where is the food? Are there people I can ask? What are the resources?"

Burden of ambiguity and decision making. Parents reported similarities in the meaning of the concept uncertainty. The heightened fear of what is unknown and unpredictable is considered ambiguity (Mishel, 1983; 1988). Parents feared whether or not their child would die from cancer or from the surgery required to remove a tumor. One parent stated: "The very first thing that comes to my mind is how long is my kid going to live?" Another parent shared that the immediacy and urgency to start treatment affected the level and type of uncertainty because there was no time allowed for questions or addressing her concerns. The surgeons felt death was imminent if surgery to relieve the pressure was not initiated immediately. One minute her child was only complaining of a headache and playing with her siblings and suddenly, her daughter was at imminent risk of dying. The shock and not knowing what the outcome of surgery increased the mother's uncertainty.

The doctor said she had to go into surgery pretty quick, and that the tumor was in a tough spot. The doctor didn't know if they were going to be able to do it. So the uncertainty at first for me was 'My child is going to die from this?' Because I thought he was telling me he was not going to be able to do anything.

Parents felt a loss of control and a need to know what would happen, what was expected for treatment, and how that plan would be provided. A parent shared, "Well like in the beginning, it's not knowing what's going on.” Another parent said, 
There wasn't any definite answer for me. ...I got here and it was like I'm sorry because her protocol is so different we can't really give you a calendar. We're just going day by day.

Understanding and having a plan of action was crucial to help parents adapt, decrease their uncertainty and then make decisions that would impact the situation in a positive manner.

Sometimes these were decisions based on financial concerns at home, living arrangements, and employment. Other times these decisions impacted the child's treatment. The parents felt they had to make decisions that could impact the success of that treatment with little information. Their uncertainty stemmed from the weight of that decision. One parent voiced this concern in the context of an upcoming decision related to moving to another city for a specific type of radiation therapy not available at this treatment center. She said, "The uncertainty is, okay, do I go forward with more treatment or do I wait and see what happens and hope that it doesn't come back?"

Of importance to note is that health care team participants felt that uncertainty was a concept faced in the period after diagnosis, and again perhaps when a child might relapse or move to transplant. Parents agreed with a few distinct differences. They reported more uncertainty in the period leading up to the confirmed diagnosis, often reporting being in limbo between several diagnostic possibilities. Sometimes they were not even being told yet that there was a chance their child's symptom were from cancer. For example, when describing uncertainty one parent said,

Not knowing, and (the physician) was just (saying), 'Well, it could just be a tumor of some kind; it doesn't mean it could be cancer. It could be.' Just that not knowing what it is and then how it's going to affect your child.

Another parent shared her experience while going through diagnostic scans. She reported how things had been fairly innocuous until that point and relayed the shock she felt at recognizing how serious the situation was with no one there to explain the implications.

When the (radiology technician) came back in she was like, 'Well now they want me to take her chest and her head and her neck to see if it spread anywhere.' Well, nobody had told me anything up to that point...I was like what are you talking about?

Several parents shared that their uncertainty was actually reduced once they had a definitive diagnosis and a treatment plan because the waiting was over. One parent shared, "I think the 
uncertainty....it was a relief to find something out because we had been in the hospital for two weeks, not knowing anything and then it wasn't like, 'Oh she has cancer, great!', but we had a plan of attack."

In addition, parent participants reported that although it was difficult at diagnosis, uncertainty persisted throughout the entire treatment and was especially troublesome as they transitioned between phases of treatment. One parent felt that uncertainty was fairly low in the earlier phases of treatment because they were surrounded by providers, but this changed as they progressed and became more independent: “...it's when they're like 'you are on your own'. Your child is getting better. Because now I'm in panic mode wondering what if this happens or this happens." Clearly this parent fears the return of her child's cancer and was struggling with the change in the frequency of monitoring for relapse. She reported a heightened sense of uncertainty related to that transition.

\section{Facilitators of Parental Adaptation}

The second research question, how parents currently adapt and use coping skills to deal with uncertainty, was addressed by asking participants to identify factors that assist parents with children recently diagnosed adapt better to the situation. On this topic parents and health care team members all suggested factors that fall into three subthemes: extended network support, socioeconomic, and empowerment. All three are described separately here.

Extended network support. Participants all described the importance of trusted family and friends in assisting parental adaptation through providing emotional support, monetary support, transportation, babysitting for their other children relief at the hospital to give parents a break, and assistance with chores around the house. One health care team participant described the importance of extended family presence through the treatment, "When extended family is involved, it can make a large difference." One parent specifically mentioned how much she has relied on the availability of her siblings for emotional support. Extended family support also helps in coordinating and meeting the needs of the affected family, such as helping to coordinate offers 
of assistance from others, such as food deliveries. Other parents described how their family and church groups supported them by bringing food to their home on a regular basis, and by coordinating fund raisers and networking to complete work on the house so that it was safe for their daughter to come home. One parent said, "...the whole church came together and had meals for months and we had help and we had fund raising stuff, and people coming over to visit the girls, and blood drives ...."

Several parents described how extended network support was strongest at diagnosis and then tended to taper off after a month or two. Perhaps this is typical as those not affected by the diagnosis daily recover from the shock and return to their own lives. However, this leaves the family feeling somewhat deserted just when they are starting to understand the significance of all that they are going through. One parent shared: "You have everybody at immediate crisis... and then six months down the road everyone goes back to their own lives." Health care team participants also mentioned how a strong faith system was important for many families. A participant shared, "I've definitely seen folks that have a strong faith system that can help guide them during those difficult times." However, this was not mentioned specifically by any parent participant in this study.

Socioeconomic. Factors related to education level and socioeconomic status were mentioned by both health care team participants and parents as key to their adaptation after diagnosis. Health care team participants put emphasis on professional and higher education as a factor for better understanding and ability to learn and therefore adapt. The level of family income was another factor stressed because it is key to locating resources as well as having the flexibility to take off work to care for the child. Higher levels of income allow for some financial stability should one parent have to leave work. This allows the parents to focus on caring for the child and the rest of the household without the increased stress of loss of income. One participant shared, "Financial means reduces the stress. Our families that come in and make a hundred thousand dollars a year, they may be shocked, but they recover quickly.” Regarding the same 
context, another provider participant said, "They may have other external things going on in their family that impact the family and the child, but money won't be the issue."

Empowerment. Some participants felt that more important than education level and socioeconomic status was the concept of empowerment. If the parent's personality was to assume responsibility and take charge of the situation, then the parent tended to adapt quickly and sought out learning opportunities in order to do so. One participant said, "I think another huge impact is their personalities. Some might be more proactive and have more initiative." Other parental statements included: "I read everything, even if it didn’t make sense," and "You don't have to have a great educational background to be that proactive empowered person... it is the type of person; that they are the seeker." One parent went so far as to say she could not just be told her daughter's treatment plan. She needed to be involved in the process and know it all in order to understand it. She said, “It's just I don't want to be told her treatment plan, I want to be in her treatment plan. I want to be a part of it." For these parents, gathering information to improve understanding and taking ownership of the decision making required was a big part of their adaptation to this situation and their reduction of uncertainty.

\section{Education and Psychosocial Support}

Adaptation to life with childhood cancer is the next step after receiving the diagnosis. Interventions aimed at providing various types of support are necessary to assist families in adapting and forming a new version of normalcy as quickly as possible. Participants were asked what types of education and psychosocial support would be the most helpful to families. The responses were grouped into two subthemes: communication, and providing information and sharing support.

Communication. This subtheme focused on information sharing between parents and breaking down the isolation parents feel. One health care team participant said,

... if they talked to other parents, that helps. Because I feel like when they first get diagnosed they feel like it's a vortex. They're in the center and have no idea what's going 
on around them. In their mind this is it. This is as bad as it gets and no one else can know how they are feeling.

A parent participant stated that just knowing someone she was familiar with was in the room next door during a troublesome hospitalization was comforting, because she could go talk with someone who really did understand what she was going through. It helped her feel less isolated. She said, "If something really bad happens I have somebody that I can talk to if I need something ... if I didn't know her I would've felt really alone." One parent used the internet as a resource for sharing with others. She searched websites and met someone with whom she could communicate on an online forum. She felt this was helpful, but wished she could have utilized this resource earlier or had something similar at the treatment facility. Some parents felt that just sharing with other parents was helpful no matter the type of cancer diagnosis, but a few mentioned that talking with those of the same would be most helpful. This example describes one such request: “... it would have been nice to talk ...somebody that has the same diagnosis as your child. 'We've been there; we've done that. You know? Like a go to person?" Another parent described a craving to have an opportunity to ask questions of other parents, but was torn with caring for her ill child and unable to leave. The timing and context when offered were inappropriate for her and she was very conflicted about that. She struggled between the desperate need to speak with someone who had gone through something similar and the need to stay at her child's bedside. The type of information requested to be shared included suggestions of basic hospitalization survival tips, what things to bring, what helped the most while inpatient. Parents also wanted to know of any problems or complications from treatment that other families had dealt with so that they could possibly be more proactive and prepared to deal with them.

These statements of preferring sharing with others informally support avoidance of offering formal support. Two different parents suggested that just having the name and number of someone willing to talk would be ideal because they could call upon them when the timing was better and they already knew that person was willing to share. 
Providing information and sharing support. Health care team participants also recognized the need for less structured implementation of psychosocial support. They recognized the need for interdisciplinary support interventions and voiced frustration at failed attempts to sustain attendance at formal implementations. A psychosocial support team member participant described challenges with having a support program, “...it's hard to get them there, (but) families will cluster ... and there's this magic and they provide support to each other, but then there is no continuity to that. We provide groups and they don't come." Health care team participants suggested informal group gatherings where parents, patients and siblings could mingle and just be together while visiting with other families. One participant suggested those opportunities should be on a daily basis rather than one night per month and should be done in a way that was convenient to families rather than asking them to come back in the evening for a special event. Another participant reinforced this: "Informal hanging out and talking is what we should be doing and maybe you have someone from the psychosocial team sit in and just sort of clarify facts for them, but help facilitate that dynamic." Several health care team participants felt that this would be more helpful than their traditional once a month family game nights if held during normal clinic hours. Members of the health care team recognized that these types of gatherings could be used for sharing between parents and also for education information sharing. One nurse participant said she would like to see something similar to an informal group based on a physician question and answer session she had heard about at a national conference. She felt opportunities like this could be helpful to both the parents and the staff. Another participant offered this about group gatherings:

If the parents are not educated and they are not able to pass on, you know, what is actually true and correct to the patient or siblings. They can have all these misconceptions and that's part of all of our jobs, to go in and help clear up those misconceptions.

However, in order for an implementation such as this to be successful it must also be timed appropriately. Parents still adapting to the shock of the diagnosis are not able to absorb the information given them completely. Parents reported needing time to understand their diagnosis 
and treatment plan and the side effects before being ready to talk. However, starting around two to three months after the diagnosis, they are ready for more information, even seeking out that information to prepare for what will come next.

Parent/patient education. Patient education was a top priority by many members of the health care team members. It is differentiated from information sharing as described above because patient education is considered to be the required education to be provided by members of the health care team or their designee. Health care team participants felt that their role as members of the pediatric cancer team was to facilitate parents' adaptation through education. One participant said, "Our job is to keep them informed about what is about to happen today and tomorrow and next week. Our goal is to educate, educate, educate." However, participants did not feel patient education was an area of strength of the program. Health care team members described a lack of coordination and ownership regarding how and what education is provided. They believed a more structured format for education delivery throughout the program is needed so that each member of the team would be aware of who was responsible and what had been done. One parent said, "This nurse said this and this nurse said this, so which is the right?" When asked specifically if there was a lot of variation between what each nurse was teaching one health care team member responded, "Yes, and that to me is a reflection of (the nurses') clinical knowledge and experience."

Timeframes and delivery of information. Parents reported readiness to share information approximately two to three months after receiving the diagnosis, and this also applies to their readiness for education. One health care team participant said, "It takes about three months for people to get over it (the shock of diagnosis) and start focusing again." One health care team participant hoped to see changes for improvement within their program: “... it (the content) should be broken up, and we aren't doing a great job of that." Participants also reported a perception of secrecy related to the diagnosis. Cancer is suspected, but never spoken of until the physician has documentation. One health care team participant described her frustration with this 
lack of honesty as getting the standard acute lymphocytic leukemia workup and explaining the hospitalization and work up as problems with the child's blood and the parents have no idea a possible cause is cancer. Then when the diagnosis shows up a couple of days later the parents are shocked. She described this experience as utterly horrifying to parents. However, too much information can be the opposite and equate to overload. Another health care team participant shared that regardless of how you deliver the diagnosis it's going to be a shock. So health care team members had to be careful not to give too much information too quickly because it is just overwhelming until the parent is ready to accept it and learn about it. There must be a fine balance between keeping secrets from families and overloading them with information at the time of diagnosis. One health care team participant recommended something more structured and limiting about what is shared to five things parents needed to know to go home and be safe.

Education was described by parents as often rushed and left until discharge. At that point their retention was minimal and their feeling of being overwhelmed increased. Although they felt it should be a priority both parents and health care team members felt it was not weighed as strongly in the scope of all the responsibilities of the nursing staff. One parent said, "We didn't get information until we were leaving, that day. We got handed a big binder. She brought it to us as she was discharging us."

Addressing individual patient needs with appropriate materials. Problems with outdated and overwhelming materials and how they were delivered were common in the participants' responses. Some participants felt that parents never even opened the reading materials due to the large volume of them, as one reported, "We do give them a lot of stuff to read...but then maybe only half the people even open it." Other parents avidly read all the material given to them, as one parent reported, "I got one binder on the oncology side and another binder on this (BMT) side.... I know on the BMT side like it came with tables like for your labs, for your treatments, I love that". Another parent found outside reading material was most helpful and shared this comment regarding how helpful a book for parents of children with leukemia was, "(I) was just like, 'Okay. 
We have a plan for me to figure out.., that helped me." Materials provided should benefit the individual patient.

Classes. Another suggestion from health care team participants was holding formal classes on various topics for parents to attend. This option provides a standardized format for information delivery that can be offered on a regular basis or with a rotating group of topics. This was something offered within this program at some point before, but has since been discontinued for various reasons as described by one health care team participant, "I think we have tried in the recent past to do more structured education once a week, but (the) big groups didn't work and some of this has been lost. We really should try it again.” Despite the difficulties described by this participant, the reactions of other health care team member participants to having structured learning opportunities such as classes were very positive. One participant said, "I think that when we had the classes it was such a big patient satisfier. They loved it, because they not only loved the education, but they loved the interaction with each other."

However, the parents noted that not everyone comes from the same background and learns the same way. Instead, education plans should be individualized just as care plans are. One participant described this " ... if we provide the same education it just seems like sometimes it just doesn't work...everybody is coming from a different place and has different resources... have a different walk in life and it's hard to sometimes put that together." Assessments to find out in what way each parent or patient learns should be completed at different timeframes as their learning continues.

Earlier discharge from inpatient services. Also mentioned was the tendency toward earlier discharge. Participants reported discharges scheduled prior to day seven after starting chemotherapy. This minimizes time for inpatient staff to provide education, so this responsibility has shifted to outpatient clinics. This means that health care team expectations of knowledge attainment and understanding should be changed and that the resources for follow up education and coordination must be done through outpatient services. This was identified as a gap earlier in 
the reported results. This issue also came up in regards to coordinating follow up care between the inpatient unit and the private physician clinics. After discharge the psychosocial team does not follow up with patients seen at the private clinics because they are not employed by the clinic. They must wait until the patient is readmitted or until they are contacted by someone at the clinic for assistance. The psychosocial support team does not purposely ignore the patients seen at the non-hospital-based clinics, but they do not currently have the resources and have not been invited to follow up with those patients.

Psycho-spiritual support. If psychosocial and educational interventions are to be provided, appropriate timeframes, contexts, and priority needs must be acknowledged. One area noted was the lack of appropriate pastoral support. Both members of the health care team and parents recognized the gap in provision of Catholic care at this institution. A parent participant shared that she is accustomed to talking to a priest and that it was "weird" that the person providing spiritual care was not a priest. It was mentioned that a priest is always available to parents, but not always on site, and rarely makes rounds to check on patients as do the other pastoral care representatives.

The need for a professional and non-biased person to talk to and to provide counseling was expressed by participants. One parent described her unsuccessful visits to a counselor outside the program when she needed to talk with someone. She was frustrated with the lack of support or progress she was making and felt a strong need to seek counseling services which were not helpful because the counselor lacked the skills to help a parent of a child diagnosed with cancer. She stated: “All she could say was, 'I could only imagine', and you can only hear that so many times. I was like 'You can't get me anywhere. 'One health care team participant commented on how a recently hired psychologist for the bone marrow transplant program has improved the quality of care and how members of the health care team are now able to better focus on their specific support roles instead. 
Facilitating proactive behaviors through support. Interventions aimed at addressing the questions parents and family members have regarding the future, to help parents prepare and adapt appropriately could reduce their uncertainty. For example, re-entering school, working with peers and addressing long term side effects of the cancer and its treatment were mentioned as areas of future concern. One participant member of the health care team specifically mentioned school re-entry as especially difficult with the potential of patients falling behind due to a lack of resources. She expressed the need for school-based teachers who could work in the acute care setting. Parents voiced concern regarding long term effects of the cancer and its treatment. One parent expressed concerns about her daughter 's future and her need to plan for undue consequences: “They're saying there's a chance she can't have kids. If they did, you know, are the kids okay? ... I'm a planner I like to know ahead... a chance she could even develop breast cancer.

\section{Patient and Family Obstacles Hindering Successful Adaptation}

In addressing the research question regarding why implementation and sustainment of more traditional methods of psychosocial support (formal support groups) is so difficult in this setting, all participants were asked what kind of obstacles hindered successful adaptation in families dealing with a childhood cancer. Responses ranged from stress at home, divorce or single parenting, to language barriers. They were grouped into six total subthemes: family stress at home, financial instability, disconnectedness/entrapment/isolation, lack of meaningfulness of social service provisions, stigmatization of "support", and cultural barriers. Each of these is described separately here.

Family stress at home. Marital status can affect the care provided by parents to the ill child and family. Participants shared that single parenting and divorced families have more stress and difficulty adapting due to lack of resources and support at home. One participant said, "Mom and dad are going through a divorce... It just adds to the stress.... They can't focus on this (the child with cancer) because of outside things." Another participant agreed when she described how 
psychosocial factors contribute to the stress: “... if there is a recent divorce or separation, any kind of other psychosocial stressors that exist before the diagnosis are going to be amplified."

Financial instability. Participants described how financial instability influenced increased stress for the families and how this can be a barrier for their successful adaptation. The immediate effects come from the day to day expenses such as food and parking for the parent. One participant said, "The out of pocket expenses and the fact that they have to be at the institution for several months ...can provide a lot of stress. Someone might be out of work to be a primary caregiver and that is a big deal."

Both health care team participants and parents mentioned the lower the financial status the more governmental assistance resources were available. This means that those middle class families with incomes between the poverty line and $\$ 100,000 /$ year are at risk for greater financial instability. For these families, when one parent quits working to care for the child, the impact is significant because they likely required two incomes to manage, yet they make too much to qualify for more government assistance. This was summarized by one health care team participant, “...the social middle class, they have more stress because they don't qualify for Medicaid. So they don't get help for copays. They have to work things out like getting prescriptions two weeks in advance." One parent described how important it was to consider what would be needed in the months following the initial diagnosis, perhaps even six months later as she struggled with needing to return to work after using up her employment leave. There was only so much flexibility she could have at work, but after that assistance and flexibility ran out and the other support from her external network decreased, she had to once again adapt because the financial resources were much lower. She said, "I did use up a lot of my time... When I got all the help I technically didn't need it as much. It wasn't until after I ran out that I really needed help."

Disconnectedness, entrapment, and isolation. Parent participants described feeling very isolated in that no one else was sharing in their own experiences and no one else could 
understand what they were going through. Parents shared that they were forced to make decisions regarding medical care alone either because they were a single parent or emotionally disconnected from their co-parent. This was demonstrated in the following examples from two parent participants: "Parents feel alone in this sea about nobody else's kid has cancer;" "They (child's grandparents) would just handle outside stuff. I felt really alone on making decisions. I would rely on his doctor".

Parents voiced feeling trapped and isolated from those around them. Even with visits from the support staff or nursing, parents reported feeling that in the end it was just them and their child. They can never escape their child's cancer or treatment. One parent said, "You know you try to keep yourself busy, but really there's nobody else here. It's just you and maybe the nurse every once in a while, and they come in and then it's just you and your child." Another parent specifically voiced not being able to escape: “There's no getting away from here. ...constantly on my mind...there's no out... no distraction here." Parents perceive the nursing staff are not available and not engaged in the education process during transitions because they are required to do other nursing care that is more important. This increases the isolation parents feel. One parent said,

You have a nurse, who's on her twelve hour shift and has three other patients. So I think it's harder when you don't have that person (an educator) and you have a rushed nurse instead, someone who's trying to get through this book and tell you all this information so she can tell her next shift person she did the education.

Lack of meaningfulness of social service provision. This subtheme focuses on the lack of availability and recognition of the assistance members of the psychosocial team provide. One participant described this as focusing on "the minutia" and not the more meaningful interventions they do. Minutia was described by a health care team participant, "Where are your meal tickets? Did you fill out the forms for your work and insurance?" However, a parent perceived the importance of this differently: "The parking thing was one thing and the meals were another... the meals were the most expensive parts of our stays. It may seem like simple things, but it's 
every day." The work provided by the social workers especially is perceived as only during the initial diagnosis and not ongoing as described by one parent participant, "In the beginning I feel like they kind of get you started, but then it's just you have to fight for your own." Another health care team participant said, "If a social worker gets word they need something then we address it, but it's like putting out fires more sometimes than being able to help maintain..."

There is a perception of inequity of resource provision between families. This makes parents that may not have gotten the level of support they perceive as necessary offered to them feel they are being ignored or treated unfairly. One parent overheard that a family was receiving multiple benefits and was defensive: "I was wondering why they didn't do that for us?... Why weren't we asked if we needed hotel accommodations...(and) given free food vouchers, and free parking?" Another parent shared, “That's just the thing. No one told us or tells the office, and we didn't know. We only saw our social worker one time."

Stigmatization of "support." Both parents and health care team participants voiced that some parents will not take advantage of support services offered because they do not want the stigma of accepting support. They view it as a crutch. One participant said, "You know we're lucky enough to have people help us, but some people don't like asking for help. They just don't." One thought shared by several different participants is that the term "support" is just too formal, and that people do not like to go to support groups or group therapy sessions due to the negative connotations that they have. One parent believed if a different word, other than "meeting" or "support" was used it may be helpful. This stigma related to support is a barrier that will be hard to overcome for the program.

Cultural barriers. Members of the psychosocial team mentioned the concern related to immigration status and the availability of resources for those children and families that are pending citizenship, particularly the extended wait list for health insurance for these children. In addition to access to health care, the psychosocial team felt that language barriers affected the care patients received. They felt the translation services via phone were helpful in the inpatient 
and clinic areas, but when parents call in and could not get a Spanish-speaking nurse on the phone to help answer their question, that was a huge safety concern.

Differences in participation in the health care team. Another barrier of concern is one of cultural roles and trust in the health care team. One health care team participant described this as a barrier for their patient population. She said,

I think that for the most part, their view, maybe their culture, that they are more comfortable with letting the doctor make decisions. I think a lot of our Hispanic families are very trusting of us and most of them try to go with the flow of the treatment and just sort of trust us blindly. That may be even more frustrating because you want them to be more engaged.

This disconnect between expectations for active information seeking (empowerment) and inclusion in the plan of care with the cultural tendency to leave decision making up to the health care team can cause frustrations and miscommunications regarding the care provided.

\section{Breaking Through Institutional Culture}

This last theme also addresses research question four, exploring barriers regarding implementation and sustainment of support and education interventions. While the previous theme, patient and family obstacles, focused on patient specific obstacles, this theme focuses on obstacles controlled by the hospital system and program. Throughout the discussions the participants mentioned factors that were less about specific types of psychosocial interventions and more about barriers related to the implementation of those supportive interventions. These included things like financial restraints and policies that affect patient outcomes and satisfaction. These results were split into five subthemes: financial constraints, policy and institutional culture, home-grown management experiences, lack of trust, and interdisciplinary collaboration: An evolving model.

Policies and institutional culture. This childhood hematology, oncology and bone marrow transplant treatment program includes an inpatient hospital unit, an outpatient hospitalbased hematology/oncology clinic, an outpatient bone marrow transplant clinic which is housed by the hospital but run by a separate transplant program, a hospital-based infusion clinic, and at 
least one private practice hematology/oncology physician clinic. All of these areas have different administrative teams and functions, but they must work and collaborate together to provide services as patients flow from one to the other. Funding and resources for each of these areas comes from different sources and is not always equally distributed. This means that certain allocations are supposed to be limited to one practice area or another. For example, the current psychologist on the support team was brought to the program as a way to meet accreditation standards for the bone marrow transplant program, but because that program is funded separately from the hospital based hematology/oncology program the psychologist is limited to primarily seeing patients who are being seen for a bone marrow transplant. The psychology and counseling services for the hematology/oncology program are left to other members of the psychosocial support team hired by the hospital rather than the BMT program. Many of the other members of the team are not solely devoted to covering only this program. They must cover other areas of the children's hospital as well. One provider participant described this process, "I think it's time and money to be honest with you... They're funded by this program so they will only see these patients." Certainly the team works together to help ensure that patients still are able to access counseling services if needed through other members of the team, but the disconnect between the two programs causes gaps in the care provided.

Lack of accreditation standards and advocacy. In addition to the divisions between service area administrations, guidelines exist for each practice area. The bone marrow program is accredited by a national foundation, and without this designation, the bone marrow program could not function and the hospital system could no longer offer this service. Maintaining accreditation forces the BMT program to keep up with evidence based practice and to revise policies based on the foundation's current guidelines. However, inconsistencies in standards of practice exist because there are no accreditation guidelines for the hematology/oncology unit. 
One participant said,

It is true that the bone marrow program has more support, but that is really only because ...We have to maintain our accreditation.... Unfortunately, there is no accrediting body for Hem/Onc programs.

Because of the lack of accreditation standards, the hematology/oncology program is listed as National Cancer Institute designated center and this allows them to provide services and to conduct research protocols.

Patient education is not a priority. Although patient education is a measure of quality and safety it often falls second to other responsibilities because it can be passed on from shift to shift, and this was reflected in this study. As a result, the provider participants reported a lack of consistency and ownership for completion of patient education. One participant said, "You know nurses are so busy and they're so rushed... lot of variations that can slow them down. It (referring to education) just doesn't happen, or at least doesn't happen thoroughly." Another said, "The nurse says I don't have to do it because the BMT coordinator did it. Then when the coordinator doesn't do that job it's the day the patient is leaving and there's no education that's done."

Inhibition of family centered care. Participants reported challenges with family-centered care in the hematology/oncology unit. At the core of this is basic inclusion of materials, activities, and service that promotes the patient and family's well-being. One health care team participant commented on the "task driven" focus of the unit, and that providers were "...using all the right buzz words like we are family-centered, but the action hasn't been there...not focused on the other stuff that can be so crucial to patient success."

There were some concerns related to services connected to family-centered care such as the provision of enough child life therapists. Participants felt that child life was under-utilized and under-appreciated in the program. One provider participant said, "Child life is lacking. Like our child life specialist is separated between inpatient and outpatient...." Another said, "We need someone who is more consistently on the floor providing more than just videos or play therapy, but also doing assessments on their (patients') growth and development." 
Visitation policies. Other concerns included the lack of a family-centered visitation policy especially regarding siblings. Infection control is of concern regarding visitors and the Center for Disease Control and Infection Prevention Department have guidelines in place to both protect the patient and protect visitors from the spread of infection. However, when providing services to chronically ill children the impact of long-term isolation from the family unit must also be considered. One parent participant shared the difficulty with the visitation policy in regards to her other daughter and also her spouse. She said,

She (sibling of patient) can't be up there in there (the unit). It's very anti-family. We're (sister hospital) family-centered care; so anybody can come and go whenever they want, and we can have as many people as they want to spend the night, within safety reasons.

One parent participant described difficulties in coordinating getting meals because she could not leave her infant alone and the staff did not offer to help her while she stepped out of the room to go get something. She had to wait for her spouse to arrive and since he could not bring the sibling, he was not able to come many days.

Home-grown management experience. One barrier to effective policy changes mentioned by provider participants is that most of the unit and hospital administration for the program were local. They had never worked outside the region and many of them had only worked in administration within this hospital system. The participants felt this might be considered a bias because they had never seen how other hospitals might run a childhood hematology/oncology program or how another institution might implement policies regarding family-centered care. One participant said,

Compared with other places I have worked and spent time working with, the leadership in this hospital system is the same people. The middle folks, like the charge nurses, the directors. They don't have a view of what it could be like if they worked elsewhere. They only have the perspective of what they've been taught here.

Lack of trust. Inconsistencies in care led to a sense of mistrust of providers. One participant said “...It was scary...depending on what nurse you got; you know the ones you could trust and the ones you couldn't." One participant described how parents felt the need to verify all 
the teaching they received with the physicians because they felt the information varied so much they could not tell what was true and not true. Another health care team participant shared that bias related to parenting styles and cultural differences also hindered care effectiveness. Due to "human nature" there was a tendency to judge parenting styles, but they also recognize these behaviors are not constructive and efforts to changing them are in place.

Interdisciplinary collaboration: An evolving model. Perceptions of the impact of interdisciplinary team collaboration on the effectiveness of supportive interventions were mixed. Some providers felt it was an evolving improvement in the direction of interdisciplinary teamwork, while others voiced concern about the lack of value placed on interdisciplinary collaboration and how this affected the long term support for patients after they are discharged. One participant stated, "I would have told you three months ago, 'No our team is very broken', but what you are asking today, it's not there yet, but it will be soon... new staff ... are consistently focusing on improving... psychosocial support.” The hiring of new staff has strengthened the interdisciplinary approach, and though it is in its "infancy stages.... we are starting to see the fruition of that labor." Another participant discussed how the change in expectations regarding each team member's participation was also influencing how the team worked together. She was attempting to shift the culture to hold everyone accountable for their role on the team, and states: “... we've had a culture where that expectation was not present, but (every) member must contribute something... expectations are very high out of myself and everyone else."

Some nurses and social workers felt there were still challenges to being fully interdisciplinary. For example, one participant stated: “There's never been the support to say, even internally...to say, 'Hey, there's really a different way to do this.' Or what a big part of the team they (members of the psychosocial team)." Another health care team participant suggested that some of the gaps were a result of a cultural shift from a medical model to one that included interdisciplinary components of psychosocial and alternative therapies in a more traditional 
medical model setting. Her concern implies that as the program shifts to incorporate a more allinclusive model of care there are difficulties related to the value of care that is not based on the medical model. Even with rounds on the unit, psychosocial needs are not always addressed. This finding demonstrates concerns regarding the value of the work these members of the health care team provide.

Power differentials. The power hierarchy within a program influences the effectiveness of the team through difficulties in communication and also in the value placed on the work done by various members of the team. Perceptions were that the physicians led the decision making and in some cases other members of the team had difficulty accessing patients and families until they were given permission to do so from the physician. One participant shared the following:

The doctors do make the diagnosis and I get that, but we aren't idiots.,. We could always clarify by saying, 'They are asking a lot of questions and can I talk with them about it? I know you haven't diagnosed, but can I explain to them a little?"

The assistance they may be able to provide is placed secondary to the medical needs of the patient.

\section{Discussion}

\section{Meaning of Uncertainty in Parents and Members of the Health Care Team}

Uncertainty as described by both parents and health care team members was similar to previous research findings (Flury, Caflisch, Ullmann-Bremi, \& Spichiger, 2011; Stewart \& Mishel, 2000). Commonalities were fear of the child's death, not knowing or understanding about the diagnosis and treatment, guilt related to not seeing the symptoms sooner, and being overwhelmed with the lifestyle changes necessary especially in regards to home life, finances, and employment. Emotions described included shock, fear, grief, sadness, anger, and loss of control. This is also similar to previous findings (Boman et al., 2003; Flury et al., 2011; Hinds et al., 1996). What differed between parents' perceptions of uncertainty and health care team

members' perceptions of parental uncertainty is the timeframe in which uncertainty was highest. Health care team members described uncertainty being the highest during the diagnostic phase 
(the two to three weeks following diagnosis). Although parents agreed that uncertainty does exist during this period, they expanded to also include the days or weeks leading up to the diagnosis as well as throughout the cancer treatment. They emphasized how uncertainty increased during transitional phases of the treatment plan, similar to the findings in Kästel et al. (2011) and Kerr et al., (2007). Health care team members discussed the need for continued education throughout the treatment plan, but did not specifically state this was due to increased uncertainty during these transitions. Parents placed emphasis on the information they received, or lack thereof, during the period leading up to diagnosis.

\section{Facilitators of Parental Adaptation}

Both parent and health care team participants discussed the importance of utilizing the parental and family support network. This includes extended family and friends. It also could include support from the family's church, school, neighborhood, and work. Early identification of this network and resources is important in facilitating adaptation (Boyd \& Hunsberger, 1998; Corey, Haase, Azzouz, \& Monahan, 2008; Horner, 1997; Hovey, 2005). Parents recognized that this support would eventually fade as members of their external support group rallied to help at diagnosis and then returned to their normal lives after two to three months. However, the cancer treatment persists much longer and the need for additional support when resources expired was troublesome for some parents. Knowing that the level of external support provided at initial diagnosis is probably not sustainable long term would be helpful to families in order to keep them from feeling they are deserted as treatment progresses. It would perhaps reduce the feeling of isolation. This also has implications for sustainable supportive care within the hospital environment. Interventions directed at preparing families for this transition could be of great benefit.

Most interesting in the findings was parental empowerment as a strong facilitator in their adaptation. Health care team participants suggested that parents' positive attitude and proactive approach toward learning and being involved in the decision making for their child really 
improved the speed of adaptation to living with childhood cancer. Two parents suggested this as important as well in their ability to cope and maintain a positive outlook on their child's treatment. This aligns with the evidence as a strength for parents, patients, and siblings (Boyd \& Hunsberger, 1998; Gannoni \& Shute, 2010; Grootenhuis \& Last, 1997; Hovey, 2005; Mawn, 1999; Novakovic et al., 1996; Wong \& Chan, 2006).

Religious and spiritual support has been reported as an important factor in parents of children with cancer (Schneider \& Mannell, 2006). However, in this study no comments about faith were mentioned by the parent participants in this study. They all identified themselves as Christian, but they did not explicitly say their faith was something that helped them cope. One mother and father reported that their church family played a large role in their external support by providing food and helping with things around the house, but they did not mention the role of their faith in their uncertainty or coping styles. Several members of the health care team did say that for many patients their faith is something that helps. They recognized that having that support available to families was important in helping them heal and adapt. According to the Association of Religion Data Archives (2000) for this county, 65\% of the total population is associated with a religious congregation. Of that population $63 \%$ are Catholic. Once families feel ready to speak with someone it helps if they share a few similarities with that person so that the care provided is individualized to their needs. That is especially important when providing pastoral support in a community that is predominantly Catholic. Lack of availability of a pastoral care representative of their own religion hindered parents' perceptions of the value of this support intervention.

\section{Education and Psychosocial Support}

Evidence shows that parents and family members benefit from the opportunity to share with other families going through similar difficulties (Flurry, Caflisch, Ullmann-Bremi, \& Spichiger, 2011; Gannoni \& Shute, 2010; Mawn, 1999; Nolbris et al., 2010; Novakovic et al.,

1996; Wong \& Chan, 2006) and was supported by findings from this case study. Both parents and health care team members reported the benefits of allowing parents to share and gather 
information from parents in similar situations or from those that had gone through the same thing previously. Some parents preferred talking to any parent of a child with cancer; others preferred to speak with someone that had gone through the same diagnosis as their child. Informal settings for these activities were important to the participants. The health care team participants believed this would encourage attendance and participation because of their previously unsuccessful experiences with more formal and structured support groups. The two to three month mark might be the best time to invite parents to come to support interventions and introduce them to other parents with similar diagnoses. Facilitating discussion between parents of recently diagnosed children and those of long term survivors may be very difficult. However, having opportunities to address these types of questions with providers or those that care for long term survivors might also prove beneficial in alleviating some of the fear and uncertainty that lasts long past treatment completion.

Both parents and health care team participants strongly recommended the availability of a professional counselor to all patients, especially those diagnosed in the previous four to six months. When implemented internally a counselor or psychologist can be very beneficial for the well-being and adaptation of families and contribute to improved patient care outcomes. (Sekse et al., 2014). Chaplains and social workers usually shoulder this responsibility, and they do not always have the time or resources to counsel appropriately. The program counselor should be an integral part of the pediatric cancer team and be familiar with the difficulties and challenges these families undergo. Having a skilled counselor as part of the team can provide a unique and internal perspective on what is happening with the family and the stress they are experiencing, and this knowledge can be crucial to their success in helping these families (Humphris, 2008). When each member of the team is allowed to function in their full capacity it can improve patient care flow, quality and over all outcomes (Hill-Smith, Taverner, Greensmith \& Parsons, 2012).

Education delivery was also of particular concern to both parents and health care team members. Comparable to other findings, (Kästel et al., 2011; Santacroce, 2002; Soanes et al., 
2009), participants desired education delivery to be provided in a more structured format, that it be individualized and coordinated by one person or a small team of people. However, a person to coordinate these educational activities does not exist on the unit. Parents are provided handouts, and education booklets. These materials are helpful, but should be supplemented by individualized education (Boman et al., 2003; Flury et al., 2011; Kerr et al., 2007; Soanes et al., 2009). Allowing parents time to go through the grieving process and the shock before expecting them to retain more than the basics of education related to their disease, treatment, and care at home is essential (Hovey, 2005; Neville, 1998). As suggested by participants, early introduction with smaller bursts of education would be ideal because parents are ready to retain more and will be empowered to be proactive as they increase their understanding (Kästel et al., 2011).

Although parent participants stated that two to three months after diagnosis was when they were ready to talk and share with other parents, it is not ideal to wait this long to introduce education materials (Boman et al., 2003; Gannoni \& Shute, 2010; Hovey, 2005; Kästel et al., 2011). Parents must be ready to care for their child at the first discharge so education must be provided early (Flury et al, 2011). It is crucial to improve early parent and patient understanding, build trust between the family and the health care team, and also to improve patient outcomes and satisfaction (Ramfelt \& Lützén, 2005). Parents learn in different ways and should expect to receive education in that fashion at all times. If the role of the health care team is to "educate, educate, educate" as mentioned earlier, then the health care team must make allowances to ensure parents are educated in the way that meets their learning style rather than that of the health care team.

\section{Patient/Family Obstacles}

Consistent with the literature, increased stress at home can cause barriers to adaptation when caring for a chronically ill child (Santacroce, 2002; Santacroce, 2003). Intactness of the family unit is clearly a factor for increased stress. This can cause problems both within the family 
unit and also in the care provided to the child. Helping families identify sources of stress, helping them work out a communication plan, and ensuring that all members of the family receive the education needed to provide the level of care necessary for the child is crucial to helping the family adapt in a positive manner.

The change in the availability of resources was especially difficult for those who considered themselves to be single parents and for those whose spouse must leave their job to care for the ill child, as is reflected in the literature (Hovey, 2005; Kerr et al., 2007; Soanes et al., 2009). Resources related to the exorbitant expenses of immediate and long term cancer treatment and multiple hospitalizations were problematic, and those with middle incomes struggled the most because they did not qualify for additional governmental supplements. Circumstances like those described are areas in which social work could help ensure parents access what's needed and that resources are available at certain timeframes during treatment. Parents can be empowered through awareness of the treatment plan and what will be required of them so that they can plan accordingly, budget current funds, and seek community resources. This has implications for practice in that sustained supportive measures that allow for sharing and recognition that other parents are going through similar circumstances (Nolbris et al., 2010) could have a positive impact at this center as well.

Barriers related to language, cultural impressions, and access to health care are a real concern for this childhood cancer program. Providing qualified translation services is essential for appropriate teaching and communication. Different cultures may have different views regarding medicine and health care and its value to them individually. Some cultures take a more active role in their treatment, others tend to leave decisions to the health care team and trust they will make the right ones for them (Carteret, 2011). Parents may defer to the physician as an expression of respect, not because they do not wish to be involved (Carteret, 2011). This misconception can lead to poorer patient outcomes if parents and healthcare providers have different understanding regarding the monitoring and home care needed and the expectations of all parties involved. 
Health care teams in any program serving a population that has Hispanic patients will need to be aware of potential cultural differences and be prepared to communicate effectively. Culturally sensitive communication has a direct impact on the care provided and patient outcomes related to learning and empowerment. Parents and members of the healthcare team both identified that some parents or family members will not attend formal psychosocial support sessions or accept offers to speak with a counselor simply because there is a stigma related to that kind of support. It could be considered a weakness to do so, or it could be because the connotations of the word support are negative. Support groups could be considered sad, depressing, and not helpful (Gary, 2005).

\section{Breaking Through Institutional Culture}

Similar to findings in this study, financial restraints related to the availability of full time equivalent (FTE) staff to complete the supportive work required to assist parents in successful adaptation has been problematic over the last few years throughout health care (Kiselev, 2010). Participants felt this program is in need of a psychologist, additional child life therapists, and a patient education coordinator. Patient education must be placed back into the forefront of care. This can be done by either allowing the staff more time by reducing ratios when working with these patients, or providing someone who is specifically responsible for its delivery as suggested by Kerr et al., (2007) and Soanes et al. (2009).

Family-centered care was mentioned as lacking, but desired, in this study. According to the Institute for Patient-and Family-Centered Care (2010), family-centered care, which includes psycho-social and developmental support, is crucial for the promotion of health and well-being for families and patients. Policies within the hospital should be "children-friendly" and allow extended family presence. The visitation policy appeared to have a negative impact on the implementation of family-centered care. The Institute for Patient-and Family-Centered Care (2010) recommends removing visitation policies altogether and shifting the paradigm to show that members of the family are not the visitors; the visitors are the members of the health care 
team. While the need to prevent infection with immunosuppressed patients will always exist, the needs of the family and the need to promote normal development for the children must also be considered when designing visitation policies (Institute for Patient-and Family-Centered Care, 2010).

Parent participants and members of the health care team both noted difficulty regarding variations in nursing practice and education instruction; so much so that some parents felt unsafe when certain nurses cared for their child. Trust between patients, families and the health care team can be affected. Communication between members of the team and between the team and parents can be difficult and may cause misunderstandings that risk the child's health and hinder the family's adaptation. Mistrust also occurs when there is significant variation in the care they receive (Corey et al., 2008; Kästel et al., 2011; Neville, 1998). Some parents reported verifying instructions received from the nursing staff with their physician prior to implementing it. This was confirmed with the physician participant as well. Various levels of nursing experience, educational preparations, and clinical knowledge may all contribute to inconsistencies in delivery of patient information.

Roles and responsibilities of bedside nurses have changed dramatically in recent years. While hospitals are adjusting to the effects of health care law changes and requirements for reimbursement, the monitoring of implementing requirements has frequently been assigned to the bedside nurse as a means to involve nurses in quality improvement activities (Draper, Felland, Liebhaber, \& Melichar, 2008). Providers and parents believed interdisciplinary collaboration is integral to quality and patient outcomes. In order to facilitate interdisciplinary collaboration, psychosocial support team members need access to patients immediately upon arrival to the floor. Waiting for approval and invitation from the physician delays access to supportive care that is both necessary and wanted (Hill-Smith et al., 2012; Humphris, 2008). Physician members of the team would like more input on supportive care measures from other members of the team, but at this time the perceived power differentials within the unit culture prevent that from occurring. 


\section{Implications for Practice}

This study has numerous implications for practice that may facilitate a program's effectiveness in the reduction of uncertainty and facilitation of adaptation through education and support. Major implications are that of providing consistency in education and support, providing opportunities for parents and family members to share with others who have gone through similar situations, improving interdisciplinary collaboration across the program and extending support services through the entire treatment plan with special attention focused on the areas of transition between phases of care.

\section{Meaning of Uncertainty in Parents and Members of the Health Care Team}

Assessing for high levels of parental, patient, and sibling stress, anxiety, and depression should be a priority for nursing and psychosocial support team members. An assessment checklist can be developed such as suggested by Kerr et al. (2007). Providers should recognize that honest communication among the healthcare team and parents is crucial. Having time to discuss thoughts and perceptions during the pre-diagnostic period, can significantly decrease the level of uncertainty parents have. The way in which the diagnosis is initially delivered should be considered. Reducing the surprise delivery of the diagnosis and treatment plan helped reduce parental uncertainty and increased the trust in the health care team (Neville, 1998; PatiñoFernández et al., 2008; Santacroce, 2002). If cancer is suspected, parents should be informed it is a consideration being evaluated. Withholding information instills distrust between the family and the team. Also the context in which those suspicions are shared should be considered. Parents should not learn their child has cancer while standing in a hallway in the radiology department. Care should be taken to secure a private area where communication can occur and emotional support can be provided. It was recommended that the diagnosis not be given by the physician alone and that a member of the support team should be present as well to help answer questions not related to the disease and to help provide the emotional support needed after the physician 
leaves. At no time should a parent receive the diagnosis alone especially if their co-parent is available. Health care teams should ensure that the parent's support person is available prior to going in and telling one parent alone.

\section{Facilitators of Parental Adaptation}

Assessment for symptoms of uncertainty can also help family members identify external support network and resources (Boyd \& Hunsberger, 1998; Corey et al., 2008; Horner, 1997; Hovey, 2005). Early identification of these resources can help families adapt sooner (Boyd \& Hunsberger, 1998; Corey et al., 2008). Health care teams should also be cognizant of parents' learning preferences and whether or not they identify themselves as someone who is proactive and thus empowered to seek out information. Importantly, doing this as early in the process as possible can facilitate adaptation. The health care team can also promote adaptation by ensuring parents are gaining information from reputable sources and correct any misinformation early (Boyd \& Hunsberger, 1998; Gannoni \& Shute, 2010; Grootenhuis \& Last, 1997; Hovey, 2005; Mawn, 1999; Novakovic et al., 1996; Wong \& Chan, 2006).

\section{Education}

A full time patient education coordinator position or team should be considered (Kästel et al., 2011; Kerr et al., 2007; Soanes et al., 2009). This person would coordinate education delivery through individual meetings with parents and patients, designing curricula for teaching information about various diagnoses and treatment plans, and setting up structured classes where parents learn information in small, informal groups. The education coordinator should provide information delivery across all phases of treatment and would serve as a communication contact for parents with questions and concerns throughout the program of treatment. The education coordinator should be skilled in monitoring and implementing evidence-based practice to ensure consistent and accurate information is shared. The education coordinator's role should also include staff education to ensure team members are aware of evidence and guidelines for practice so that they are able to implement that practice consistently and work for changes in policies that 
would reflect best practices and improve quality (Carpenter \& Bell, 2002). Consistency and accuracy in education can improve the trust parents and families have in the care they receive and thus improve communication between them and the team (Ramfelt \& Lützén, 2005). Education plans should be tailored to the needs of the individual family (Boman et al., 2003; Flury et al., 2011; Kerr et al., 2007; Soanes et al., 2009), and the best way to do this is to have someone frequently assessing what those needs are and how they change with time. This will help identify the level of empowerment and proactive tendencies of each parent and should allow the educator to be clear about expectations of parental involvement in the treatment plan. Parents do not retain the bulk of information regarding the disease and treatment initially after receiving the child's diagnosis. Information will need to be repeated frequently over the first few months of treatment and also be provided in a format that works best for the parent and patient. This may further empower parents, reduce their uncertainty, and facilitate adaptation post-diagnosis.

\section{Psychosocial Support}

The results of this study suggest that psychosocial support is both wanted and needed in this program. Group support services should include opportunities for parents, patients, siblings, and other family members to visit with each other and share in an informal environment such as family game nights and parent afternoon tea/coffee breaks (Flury et al., 2011; Gannoni \& Shute, 2010; Wong \& Chan, 2006). These activities should be done during the day in both inpatient and outpatient areas. Invitations should be offered to all parents present, but especially inclusive of those that are two to three months post-diagnosis. Perhaps the education coordinator could invite parents willing to share their stories to come in and meet specific parents in need of someone with whom they can share (Kästel et al., 2011). In order to address parental uncertainty focus should be on empowerment and preparation for the future such as sharing how families adapted to financial changes, how they prepared for long hospitalizations, and how their child progressed with each phase of treatment. 
Early assessment and recognition of the need to talk with a professional counselor should be considered as some parents will have higher levels of stress and anxiety and will not adapt well to the new situation (Boman et al., 2003; Boyd \& Hunsberger, 1998; Gannoni \& Shute, 2010; Horner, 1997; Kerr et al., 2007). The health care team should not expect that all parents will be ready to retain information early in the process and therefore the offer should be repeated as they continue to adjust to the shock of the diagnosis. Consideration should be given to providing a psychologist who is knowledgeable about the special needs of families of children with cancer (Hill-Smith et al., 2012; Humphris, 2008). Having a professional who is aware of the common stressors for families in this situation can only help improve their adaptation by helping them recognize coping strategies earlier. Pastoral support should include readily available spiritual advisors representative of the family's faith.

Consistent social work support and services should be offered to every family (HillSmith, 2012). Identification of possible resources available should be provided early in treatment and repeated frequently as parents may not recall that certain assistance programs are available or how to apply for them. This may require expanding the social work and case management service line to allow follow up at both the hospital and private outpatient clinics. Day to day difficulties such as parking validation and meal assistance should be addressed during the initial admission. Even if governmental assistance is not available to families due to their income, a check list with services and things to consider should be provided so that parents will know what steps should be taken early in the treatment process (Kerr et al., 2007). A list of items to be considered and available services will assist them in making decisions regarding appropriate employment changes and finances.

\section{Patient/Family Obstacles}

Provisions for translation services on the inpatient unit and for handling phone calls with non-English speaking patients/families around the clock should be of immediate concern. Staff education regarding cultural differences in respect for health care team members' knowledge and 
authority should be considered so that staff members will learn to assess for families who are less likely to be informed and act proactively in their child's treatment plan (Carterer, 2011). Continuing efforts to reach out to parents and family members to attend less formal support interventions should be considered in an effort to reduce the stigma related to psychosocial support interventions. Care should also be taken to ensure that every parent has the opportunity to receive financial, governmental, and hospital-based resources at first admission with follow-up over the next two to three months (Boman et al., 2003; Flury et al., 2011; Gannoni \& Shute, 2010).

\section{Breaking Through the Institutional Culture}

Gaining financial approval for more positions is a difficult task for administration. The request must be validated by return on investment and improvement in patient care outcomes. In this study it is recommended that a position be created for a Hematology/Oncology coordinator similar to what is found in the BMT program. Evaluation of how this position improves patient satisfaction and patient outcomes will need to occur in order to validate the creation of this position. Creation of a national accrediting body for hematology/oncology programs similar to that of BMT would help to validate the request for additional funding as addition of an FTE is challenging in an era of very tight budgets, rising health care costs, and increased regulations that continue to cut reimbursement to hospital systems.

Empowering the psychosocial team to proactively participate in care when they feel that opinion is not valued may be challenging. Interventions aimed at improving communication and decreasing the power differentials between members of the health care team should be considered a top priority because if not, this perception of inequality within the team will only continue to grow (Hill-Smith, 2012). Providing for members of the team to work on projects for improvement together helps to make these power differences disappear as they get to know each other outside of a clinical context. Also allowing and encouraging members of the team to network with other programs will help to empower the necessary changes. 


\section{Strengths and Limitations}

The first limitation is that of the case study research design because many consider it a weaker research study (Miles \& Huberman,1994; Richards \& Morse, 2013; Yin, 2003). However, the case study design was chosen for this study in an effort to draw out all the complexities of social and educational support in this population and to establish a basis upon which a stronger interventional study could be designed, eventually leading to practice changes. Other limitations include sample selection as members of the health care team (physicians, therapists, nurses, etc.) or parents might have provided information based on their own experiences, both good and bad, and desire for program changes. The setting was a limitation in that the principal investigator was known to participants, which could have resulted in biased data. In order to address this concern, a second review of concept and theme identification by one who is unfamiliar with this population was sought. The study participant sample may not accurately represent healthcare providers (e.g. lack of men in the sample), so findings have limited generalizability. For a qualitative study, 21 participants is a fairly large sample. However, 15 of these were members of the health care team, and only six were parents of children with cancer. This could bias the results towards the reflections and suggestions of members of the health care team. It was also only completed at one childhood cancer site in south Texas and all parent participants were the caregivers for children under the age of 10 . Therefore, the findings may not be generalizable to parents of adolescents and young adults. Despite the purposeful inclusion of over $30 \%$ participants identifying themselves as Hispanic none of the participants were Spanish speaking only. Input from Spanish speaking only participants would likely have given a different perspective and should be sought in future studies. Because of these limitations, the results may not be generalizable to programs in other parts of the country or even to other centers in south Texas. This study will serve as a foundation for larger, future longitudinal research studies with participants randomized to control and intervention groups. 


\section{Summary}

This descriptive, single-embedded case study reflected five major themes regarding the overall perceptions of uncertainty and support mechanisms as reported by health care providers and parents of children who were patients on a hematology/oncology inpatient unit. Overall, there were more similarities than differences between the two groups regarding their perceptions of parental uncertainty, need for continued education throughout the treatment plan, and the need for informal psychosocial support opportunities. Major differences were noted in the themes regarding timeframes for parental uncertainty, need for specific assistance during transitions in phases of the treatment plan, and concerns regarding customer service and family-centered-care.

Uncertainty and problems with healthy adaptation in parents of children with cancer have been recognized. Numerous researchers (Brashers et al., 1999; Clayton et al., 2006; Holm et al., 2008; Horner, 1997; Hutchinson et al., 2009; Llewellyn et al., 2005; Roberts \& Clark, 2009; Vrijmoet-Wiersma et al., 2008) report examples of parents and families suffering from stress, depression, fatigue, anger, and even post-traumatic stress disorder from the diagnosis of a child with cancer. This study helped to add scientific knowledge addressing the barriers to implementation of educational and support programs so that successful programs may be designed. More research based on interventions reducing uncertainty and effective use of adaptive behaviors is warranted. Decreasing uncertainty and enabling adaptive behaviors could lead to positive patient outcomes, decreased hospital stays, better understanding of the disease process, and an increased likelihood that a family dealing with childhood cancer can return to relative normalcy and have a higher quality of life. 


\section{References}

Association of Religion Data Archives. (2000). Bexar county religion adherent data.

Retrieved from:

http://www.thearda.com/mapsReports/maps/map.asp?variable=3\&state=43\&variable2=

Balbi, J. (2008). Epistomological and theoretical foundations of constructivist cognitive therapies: Post rationalist developments. Dialogues in Philosophy, Mental and Neuro Sciences, 1(1), $15-27$.

Baxter, P. \& Jack, S. (2008). Qualitative case study methodology: Study design and implementation for novice researchers. The Qualitative Report, 13(4), 544-559.

Boman, K., Lindahl, A., \& Björk, O. (2003). Disease-related distress in parents of children with cancer at various stages after the time of diagnosis. Acta Oncologica, 42(2), 137-146.

Boyd, J.R. \& Hunsberger, M. (1998). Chronically ill children coping with repeated hospitalizations: Their perceptions and suggested interventions. Journal of Pediatric Nursing, 13(6), 330-342.

Bragadóttir, H. (2008). Computer mediated support group intervention for parents. Journal of Nursing Scholarship, 40(1), 32-38.

Brashers, D. E., Neidig, J. L., Cardillo, L. W., Dobbs, L. K., Russell, J. A., \& Haas, S. M. (1999). 'In an important way, I did die': Uncertainty and revival in persons living with HIV or AIDS. AIDS Care, 11(2), 201-219.

Carpenter, J.A. \& Bell, S.K. (2002). What do nurses know about teaching patients? Journal of Nurses Staff Development, 18(3), 157-161.

Carteret, M. (2011). Cultural values of latino patients and families. Dimensions of Culture: Cross Cultural Communications for Healthcare Professionals. Retrieved from:

http://www.dimensionsofculture.com/2011/03/cultural-values-of-latino-patients-andfamilies/

Casey, D. \& Houghton, C. (2010). Clarifying case study research: Examples from practice. Nurse Researcher, 17(3), 41-51.

Chien, T.W., Wang, W.C., Chien, C.C., Hwang, W.S. (2011). Rasch analysis of positive changes following adversity in cancer patients attending community support groups. PsychoOncology, 20(1), 98-105.

City Data. (2009). Races in San Antonio, Texas detailed stats: Ancestries, foreign born residents and places of birth. City Data. Retrieved from: http://www.city-data.com/races/racesSan-Antonio-Texas.html

Clayton, M. F., Mishel, M. H., \& Belyea, M. (2006). Testing a model of symptoms, communication, uncertainty, and well-being, in older breast cancer survivors. Research in Nursing \& Health, 29(1), 18-39. 
Coleman, E.A., Tulman, L., Sameral, N., Chamberlain Wilmoth, M., Rickel, L., Rickel, M., \& Stewart, C.B. (2005). The effect of telephone social support and education on adaptation to breast cancer during the year following diagnosis. Oncology Nursing Forum, 32(4), 822-829.

Comer, J. S., Roy, A. K., Furr, J. M., Gotimer, K., Beidas, R. S., Dugas, M. J., \& Kendall, P. C. (2009). The intolerance of uncertainty scale for children: A psychometric evaluation. Psychological Assessment, 21(3), 402-411.

Corey, A.L., Haase, J.E., Azzouz, F., Monahan, P.O. (2008). Social support and symptom distress in adolescents/young adults with cancer. Journal of Pediatric Oncology Nursing, 25(5), 275-284.

Dolbeault, S., Boistard, B., Meuric, J., Copel, L., \& Bre'dart, A. (2011). Screening for distress and supportive care needs during the initial phase of the care process: a qualitative description of a clinical pilot experiment in a French cancer center. Psycho-Oncology, 20, 585-593. doi: 10.1002/pon.1946

Draper, D.A., Felland, L.E., Liebhaber, A., \& Melichar, L. (2008, March). The role of nurses in hospital quality improvement. Research Brief Number 3: Findings from the Center for Studying Health System Change. Retrieved from:

www.hschange.com/CONTENT/972/972.pdf

Flury, M., Caflisch, U., Ullmann-Bremi, A., Spichiger, E. (2011). Experiences of parents with caring for their child after a cancer diagnosis. Journal of Pediatric Oncology Nursing, 28(3), 143-153.

Gannoni, A.F. \& Shute, R. H. (2010). Parental and child perspectives on adaptation to childhood chronic illness: A qualitative study. Clinical Child Psychology and Psychiatry, 15(1), 39-53. doi : 10.1177/1359104509338432

Gary, F.A. (2005). Stigma: Barrier to mental health care among ethnic minorities. Issues in Mental Health Nursing, 26, 979-999. doi: 10.1080/01612840500280638

Grootenhuis, M.A., \& Last, B.F. (1997). Predictors of parental emotional adjustment to childhood cancer. Pyscho-Oncology, 6, 115-128.

Harrington, A. D., Kimball, T. G., \& Bean, R. A. (2009). Families and childhood cancer: An exploration of the observations of a pediatric oncology treatment team. Families, Systems \& Health: The Journal of Collaborative Family HealthCare, 27(1), 16-27.

Hill-Smith, A., Taverner, R., Greensmith, H., \& Parsons, D., (2012). Staff relationships in multidisciplinary teams. Mental Health Practice, 15(8), 14-19.

Hinds, P.S., Birenbaum, L.K., Clarke-Steffen, L., Quargnenti, A., Kreissman, S., Kazak, A. ...Wilimas, J. (1996). Coming to terms: Parents' response to a first cancer recurrence in their child. Nursing Research, 45(3), 148-153. 
Hoekstra-Weebers, J.E.H.M., Jaspers, J. P. C., Kamps, W.A., \& Klip, E.C. (1998). Gender differences in psychological adaptation and coping in parents of pediatric cancer patients. Psycho-Oncology, 7, 26-36.

Hoekstra-Weebers, J.E.H.M., Jaspers, J.P.C., Kamps, W.A., \& Klip, E.C. (2001). Pyschological adaptation and social support of parents of pediatric cancer patients: A prospective longitudinal study. Journal of Pediatric Psychology, 26(4), 225-235.

Holm, K. E., Patterson, J. M., Rueter, M. A., \& Wamboldt, F. (2008). Impact of uncertainty associated with a child's chronic health condition on parents' health. Families, Systems \& Health: The Journal of Collaborative Family HealthCare, 26(3), 282-295.

Horner, S. D. (1997). Uncertainty in mothers' care for their ill children. Journal of Advanced Nursing, 26(4), 658-663.

Houghton, C., Casey, D., Shaw, D., \& Murphy, K. (2013). Rigour in qualitative case-study research. Nurse Researcher, 20(4), 12-17.

Hovey, J. K. (2005). Fathers parenting chronically ill children: Concerns and coping strategies. Issues in Comprehensive Pediatric Nursing , 28, 83-95.

Hutchinson, K. C., Willard, V. W., Hardy, K. K., \& Bonner, M. J. (2009). Adjustment of caregivers of pediatric patients with brain tumors: A cross-sectional analysis. PsychoOncology, 18(5), 515-523.

Humphris, G.M. (2008). The missing member of the head and neck multidisciplinary team: The psychologist. Why we need them. Current Opinion in Otolaryngology \& Head \& Neck Surgery, 16(2), 108-112.

Institute for Patient-and Family-Centered Care. (2010). What is patient- and family-centered care? Frequently Asked Questions. Retrieved from: http://www.ipfcc.org/faq.html

Jackson, A., Enderby, K., O'Toole, M., Thomas, S., Ashley, D., Rosenfeld, J., \& et al. (2009). The role of social support in families coping with childhood brain tumor. Journal of Psychosocial Oncology, 27(1), 1-24.

Kalnins, I.V. (1983). Cross-illness comparison of separation and divorce among parents having a child with a life-threatening illness. Children's Health Care, 12(2), 72-77.

Kästel, A., Ensär, K., \& Björk, O. (2011). Parents' views on information in childhood cancer. European Journal of Oncology Nursing, 15, 290-295. doi: 10.1016/j.ejon.2010.10.007

Katz, S. (2002). When the child's illness is life threatening: Impact on the parents. Pediatric Nursing, 28(5), 453.

Kazak, A.E. \& Baxt, C. (2007). Families of infants and young children with cancer: A posttraumatic stress framework, Pediatric Blood Cancer, 49, 1109-1113. doi:10.1002/pbc. 21345

Kaufman, K., Harbeck, C., Olson, R., \& Nitschke, R. (1992). The availability of pyschosocial interventions to children with cancer and their families. Children's Health Care, 21(1), 21. 
Kerr, L.M.J., Harrison, M.B., Medves, J., Tranmer, J.E., \& Fitch, M. (2007).

Understanding the supportive care needs of parents of children with cancer: An approach to local needs assessment. Journal of Pediatric Oncology Nursing, 4(5), 279-294.

Kiselev, M. (2010, March 16). Hospitals in distress: How the economy has affected financing of healthcare. Illinois Business Law Journal. Retrieved from:

http://www.law.illinois.edu/bljournal/post/2010/03/16/Hospitals-in-Distress-How-theEconomy-has-Affected-Financing-of-Health-Care.aspx

Koch, T. (1994). Establishing rigour in qualitative research: the decision trail. Journal of Advanced Nursing, 19, 976-986.

Kwok, C. \& Ho, M. (2011). Development and evaluation of a culturally sensitive support group program for Chinese-Australian women with breast cancer: A pilot study. European Journal of Cancer Care, 20, 795-802. doi: 10.1111/j.1365-2354.2011.01266.x

Llewellyn, C. D., McGurk, M., \& Weinman, J. (2005). Striking the right balance: A qualitative pilot study examining the role of information on the development of expectations in patients treated for head and neck cancer. Psychology, Health \& Medicine, 10(2), 180-193.

Lounsberry, J.L., McRae, H., Angen, M., Hoeber, M., \& Carlson, L.E. (2010). Feasibility study of a telehealth delivered, psychoeducational support group for allogeneic hematopoietic stem cell transplant patients. Psycho-Oncology, 19, 777-781. doi: 10.1002/pon.1617

Machado da Silva, F., Jacob, E., \& Nascimento, L.C. (2010). Impact of childhood cancer on parents' relationships: An integrative review. Journal of Nursing Scholarship, 42(3), 250-261. doi: 10.1111/j.1547-5069.2010.01360.x

Mawn, B. (1999). Raising a child with HIV: An emerging phenomenon. Families, Systems, \& Health, 17(2), 197-215.

McGrath, P., \& Phillips, E. (2008). "It is very hard": Treatment for childhood lymphoma from the parents' perspective. Issues in Comprehensive Pediatric Nursing, $31(1), 37-54$.

Miles, M.B. \& Huberman, A.M. (1994). Qualitative data analysis. $2^{\text {nd }}$ ed. Thousand Oaks, CA: Sage Publications.

Mishel, M. H. (1981). The measurement of uncertainty in illness. Nursing Research, 30, $258-263$

Mishel, M.H. (1983). Parent's perception of uncertainty concerning their hospitalized child. Nursing Research, 32(6), 324-330.

Mishel, M. H. (1988). Uncertainty in illness. Image: Journal of Nursing Scholarship, 20(4), 225-232. 
Mishel, M.H., Germino, B.B., Gil, K.M, Belyea, M., Carlton Laney, I., Stewart, J....Clayton, M. (2005). Benefits from an uncertainty management intervention for African-American and Caucasian older long-term breast cancer survivors. Psycho-Oncology, 14, 962-978. doi: 10.1002/pon.909

Neville, K. (1998). The relationships among uncertainty, social support, and psychological distress in adolescents recently diagnosed with cancer. Journal of Pediatric Oncology Nursing, 15(1), 37-46.

Nolbris, M., Abrahamsson, J., Hellström, A., Olofsson, L., Enskär, K. (2010). The experience of therapeutic support groups by siblings of children with cancer. Pediatric Nursing, 36(6), 298-304.

Novakovic, B., Fears, T., Wexler, L., McClure, L., Wilson, D., McCalla, J., Tucker, M., (1996). Experiences of cancer in children and adolescents. Cancer Nursing, 19(1), 54-59.

Patiño-Fernández, A.M., Pai, A.L.H., Alderfer, M., Hwang, W.T., Reilly, A., \& Kazak, A.E. (2008). Acute stress in parents of children with newly diagnosed cancer. Pediatric Cancer Blood, 50, 289-292. doi: 10.1002/pbc.21262

Penrod, J. (2001). Refinement of the concept of uncertainty. Journal of Advanced Nursing, 34(2), 238-245.

Price, I. (2000). Between groups vs repeated measures designs. Research Methods and Statistics PESS202 Lecture and Commentary Notes: Chapter Two Research Designs. Retrieved July 1,2012 from School of Psychology, University of New England from: http://www.une.edu.au/WebStat/unit_materials/index.htm

Ramfelt, E. \& Lützén, K. (2005). Patients with cancer: Their approaches to participation in treatment plan decisions. Nursing Ethics, 12(2), 143-155.

Richards, L. \& Morse, J.M. (2013). Readme First for a User's Guide to Qualitative Methods ( $3^{\text {rd }}$ ed.). Thousand Oaks, CA: Sage Publications.

Roberts, K., \& Clarke, C. (2009). Future disorientation following gynaecological cancer: Women's conceptualisation of risk after a life threatening illness. Health, Risk \& Society, 11(4), 353-366.

Ryan-Nicholls, D. \& Will, C.I. (2009). Rigour in qualitative research: mechanisms for control. Nurse Researcher, 16 (3), 70-85.

Santacroce, S. J. (2002). Uncertainty, anxiety, and symptoms of post-traumatic stress in parents of children recently diagnosed with cancer. Journal of Pediatric Oncology Nursing, 19(3), 104-111. doi: 10.1177/104345420201900305

Santacroce, S. J. (2003). Parental uncertainty and posttraumatic stress in serious childhood illness. Journal of Nursing Scholarship, 35(1), 45-51.

Schneider, M.A. \& Mannell, R.C. (2006). Beacon in the storm: An exploration of the spirituality and faith of parents whose children have cancer. Issues in Comprehensive Pediatric Nursing, 29(1), 3-24. 
Sekse, R.J.T., Blaaka, G., Buestad, I., Tengesdal, E., Paulson, A., \& Vika, M. (2014). Education and counselling group intervention for women treated for gynaecological cancer: Does it help? Scandanavian Journal of Caring Sciences, 28(1), 112-121. doi: 10.1111/scs.12024

Soanes, L., Hargrave, D., Smith, L., \& Gibson, F. (2009). What are the experiences of the child with a brain tumour and their parents? European Journal of Oncology Nursing, 13, 255-261. doi:10.1016/j.ejon.2009.03.009

Stewart, J.L. \& Mishel, M., (2000). Uncertainty in childhood illness: A synthesis of the parent and child literature. Scholarly Inquiry for Nursing Practice, 14(4), 299-313, 321-326.

Stewart, J.L., Mishel, M. H., Lynn, M.R., Terhorst, L. (2010). Test of a conceptual model of uncertainty in children and adolescents with cancer. Research in Nursing and Health, 33(3), 179-191. doi: 10.1002/nur.20374

Texas Department of State Health Services (2014). Incidence rate report for Texas by county. Texas Cancer Registry. Retrieved from: http://www.dshs.state.tx.us/tcr/childhood.shtm

Vrijmoet-Wiersma, C., van Klink, J., Kolk, A. M., Koopman, H. M., Ball, L. M., \& Egeler, R. M. (2008). Assessment of parental psychological stress in pediatric cancer: A review. Journal of Pediatric Psychology, 33(7), 694-706.

Williams, D. (2011, August 14). Qualitative inquiry in daily life: Exploring qualitative thought. [Web book post]. Retrieved from http://qualitativeinquirydailylife.wordpress.com/chapter3/chapter-3-kinds-of-field-notes/

Wong, M.Y.F. \& Chan, S.W.C. (2006). The qualitative experience of chinese parents with children diagnosed of cancer. Journal of Clinical Nursing, 15, 710-117.

doi: 10.1111/j.1365-2702.2006.01297.x

Yin, R.K. (2013). Case study research: Design and methods ( $5^{\text {th }}$ ed.).Thousand Oaks, CA: Sage Publications.

Zabalegui, A., Sanchez, S., Sanchez, P.D., Juando, C. (2005). Nursing and cancer support groups. Journal of Advanced Nursing, 51(4), 369-81.

Zucker, D. (2001). Using case study methodology in nursing research. The Qualitative Report, 6(2). Retrieved from: http://www.nova.edu/ssss/QR/QR6-2/zucker.html 


\section{Chapter Four}

\section{Summary and Conclusion}

This research project was designed in order to gain a specific picture regarding uncertainty in parents of children with cancer and to identify what supportive measures would be most feasible and helpful to these families within a childhood cancer center in south Texas. An initial integrative review indicated that interventions are necessary in the childhood cancer population, and they should be delivered through a combination of education and psychosupportive measures. Rather than focus on formal structured classes and support groups, researchers should investigate how diagnosis and treatment information is best delivered to parents and how to best facilitate information sharing between parents.

Utilizing a case study design allowed the principal investigator to gather in-depth information from multiple data sources focused on the suggestions provided in the integrative literature review. In total, 21 participants shared their experiences and perceptions on uncertainty in this population and the effectiveness of psychosocial support and education within the program. After analysis of their interviews was completed five themes were identified: meaning of uncertainty in parents and members of the health care team, facilitators of parental adaptation, education and psychosocial support, patient/family obstacles, and breaking through the institutional culture. Each of these also included various subthemes expressing the details of the participants' experiences working with parents of children with cancer or actually living with a child diagnosed with cancer.

The principal investigator had little difficulty in recruiting members of the health care team to participate. When the study was brought to their attention they willingly volunteered and made time to meet with the PI to complete the data collection. A purposive sample representing 
all areas of the team was achieved within 8 weeks from start of recruitment. However, recruiting parent participants took approximately 12 weeks. Most of them were not obtained until after the first six weeks of active recruitment. Once they had agreed to an appointment several said they had been meaning to set up a meeting earlier in the data collection period, but had not had time to do so. Ensuring the sample was between 40-60\% Hispanic was also difficult due to translation concerns with Spanish-speaking only families. Translation services were offered for the interviews through the help of a colleague, but in the end were not necessary. The final week of recruitment yielded two more participants who both self-identified as Hispanic and English speaking. In the future, it would be helpful to have someone fluent in the Spanish dialect of the region on the data collection team to focus on including other Spanish-speaking parents. It is important to get their input if nurses are to help guide interventions aimed at improving their experience.

It is important to note that both health care team participants and parent participants shared similar suggestions regarding the type of supportive interventions needed in this setting. Both agreed that early information sharing and education was important to help facilitate adaptation and reduce parental uncertainty and stress. They also agreed that education coordination across all phases of treatment would help reduce long term parental uncertainty and dispel any misconceptions the parents might have. Informal settings for education and psychosocial support were suggested frequently rather than more formalized support group-like interventions. Simply providing times for parents and children to visit, play, and share was regarded as a way to best meet this need. Parents need opportunities to share with other parents going through similar situations if they are to identify external resources and support networks. These opportunities are ideal in helping parents to reduce the stress they may feel regarding finances, time management, and home care concerns.

Major areas of concern are those of family-centered-care and interdisciplinary collaboration. Parents repeatedly shared experiences where the lack of attentiveness to the needs 
of their child and family were lacking. Many of these examples could be addressed by simply being more conscientious of customer service-like skills, especially when caring for very young infants and children.

Interdisciplinary collaboration is reportedly improving within the health care team, but there is still room to continue growing. Holding all members of the team accountable for their input and also valuing that input towards the successful adaptation of each family is vital in improving patient outcomes and reducing uncertainty. Also, creating a pattern of education and support service intervention delivery that allows each member of the team to focus on their role within the team will help facilitate this collaboration.

One area of concern that should be addressed very quickly is the lack of education coordination. The lack of a central education coordinator is contributing to variances in education delivery and increased parental uncertainty. It sows distrust in the team, especially the nursing staff, and leaves the parents feeling isolated and unprepared. Providing for an education coordinator may demonstrate immediate changes in patient outcomes and satisfaction scores related to education delivery, information sharing, and nursing care. Understanding how these factors affect parental uncertainty and increased levels of stress and anxiety is crucial for the health care team. Working collaboratively to address these concerns will provide for an approach that is family-centered, proactive, and effective at reducing levels of uncertainty and facilitating adaptation.

Future efforts to continue this program of research will begin with team meetings with the childhood cancer program administration and psychosocial support team. Early interventional studies will begin with routine informal parent sharing times in both the inpatient and clinic areas to measure improvement in the levels of uncertainty and facilitation of earlier adaptation. Another area to begin work quickly is the identification of ways to improve communication among team members and decrease the power differentials between the various professions. Also of interest is how to best facilitate psychosocial support to families receiving their oncology care through the 
few private physician offices. Discussion is already underway with the nursing director regarding the allocation of a position for education coordinator, as this is a crucial finding within this study and one that has the potential for making a significant and rapid impact. 


\section{References}

Boman, K., Lindahl, A., \& Björk, O. (2003). Disease-related distress in parents of children with cancer at various stages after the time of diagnosis. Acta Oncologica, 42(2), 137-146.

Boyd, J.R. \& Hunsberger, M. (1998). Chronically ill children coping with repeated hospitalizations: Their perceptions and suggested interventions. Journal of Pediatric Nursing, 13(6), 330-342.

Flury, M., Caflisch, U., Ullmann-Bremi, A., Spichiger, E. (2011). Experiences of parents with caring for their child after a cancer diagnosis. Journal of Pediatric Oncology Nursing, 28(3), 143-153.

Fuemmeler, B.F., Mullins, L.L., Marx, B.P. (2001). Posttraumatic stress and general distress among parents of children surviving a brain tumor. Children's Health Care, 20(3), 169182.

Gannoni, A.F. \& Shute, R. H. (2010). Parental and child perspectives on adaptation to childhood chronic illness: A qualitative study. Clinical Child Psychology and Psychiatry, 15(1), 39-53. doi : 10.1177/1359104509338432

Hovey, J. K. (2005). Fathers parenting chronically ill children: Concerns and coping strategies. Issues in Comprehensive Pediatric Nursing , 28, 83-95.

Lee, Y.L., Santacroce, S.J., Sadler, L. (2007). Predictors of healthy behavior in long-term survivors of childhood cancer. Journal of Nursing and Healthcare of Chronic Illness, 16(11c), 285-295.

Miles, M.B. \& Huberman, A.M. (1994). Qualitative data analysis. $2^{\text {nd }}$ ed. Thousand Oaks, CA: Sage Publications.

Mishel, M.H. (1983). Parent's perception of uncertainty concerning their hospitalized child. Nursing Research, 32(6), 324-330.

Mishel, M. H. (1988). Uncertainty in illness. Image: Journal of Nursing Scholarship, 20(4), 225232.

Neville, K. (1998). The relationships among uncertainty, social support, and psychological distress in adolescents recently diagnosed with cancer. Journal of Pediatric Oncology Nursing, 15(1), 37-46.

Santacroce, S. J. (2003). Parental uncertainty and posttraumatic stress in serious childhood illness. Journal of Nursing Scholarship, 35(1), 45-51.

Soanes, L., Hargrave, D., Smith, L., \& Gibson, F. (2009). What are the experiences of the child with a brain tumour and their parents? European Journal of Oncology Nursing, 13, 255261. doi: 10.1016/j.ejon.2009.03.009

Stewart, J.L. \& Mishel, M., (2000). Uncertainty in childhood illness: A synthesis of the parent and child literature. Scholarly Inquiry for Nursing Practice, 14(4), 299-313, 321-326. 
Texas Department of State Health Services (2014). Incidence rate report for Texas by county. Texas Cancer Registry. Retrieved from: http://www.dshs.state.tx.us/tcr/childhood.shtm

Yin, R.K. (2013). Case study research: Design and methods (5 ${ }^{\text {th }}$ ed.).Thousand Oaks, CA: Sage Publications. 
Appendix A

Model of Uncertainty in Illness

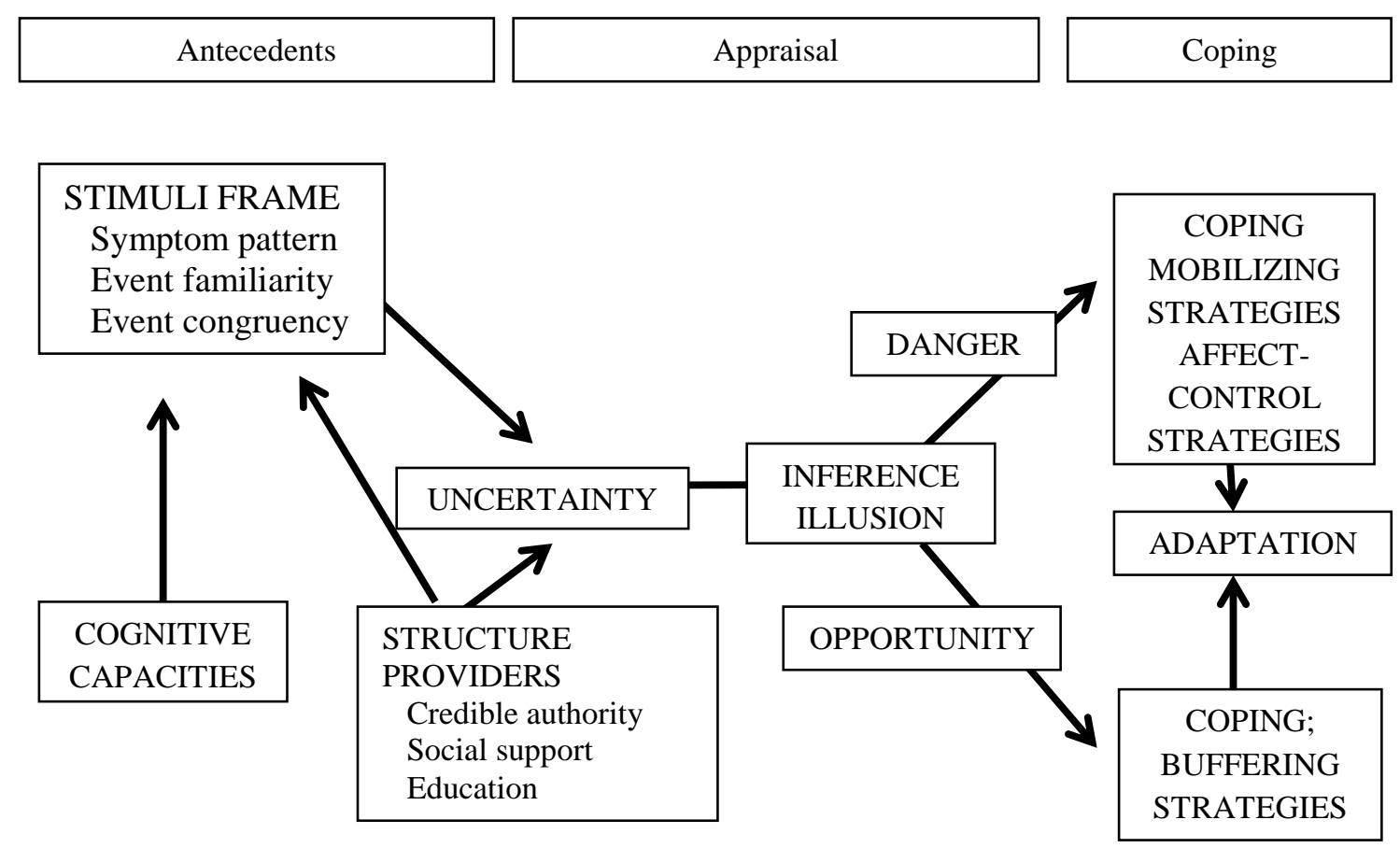

Model of Uncertainty in Illness Theory (Mishel, 1988). 
Appendix B

Letter of Support to Conduct Research within the Hospital Unit

From:Kimberly.Arellano@MHShealth.com

Sent: Thursday, April 24, 2014 10:03 AM

To: Gunter, Martha

Subject: RE: quick question

I am certainly still willing to support it! yes-come by and we can go to lunch!

Take care

From: Gunter, Martha [mailto:gunter@uiwtx.edu]

Sent: Thursday, April 24, 2014 10:02 AM

To: Arellano Kimberly

Subject: quick question

Kim,

Yesterday I defended my new research proposal. Yay! It went really well.

I have to go through the IRB at my university and then also again at $\mathrm{MCH}$, but I wanted to check

with you first and make sure you were still ok with me moving forward. This proposal is based on interviews with various members of the healthcare team and a few parents so that we can find out what support and education they really think is helpful and necessary. Then we can figure out what we can do that works and is still cost effective.

Is that something you are still willing to support?

I hope you are doing well. Haven't talked with you in a while. Maybe I can come steal you away

for lunch one day and we can visit. :)

Talk with you soon.

$\mathrm{D}$

M. Danielle Gunter, MSN, RN, CPN 
Appendix C

UT Tyler IRB Approval Letter

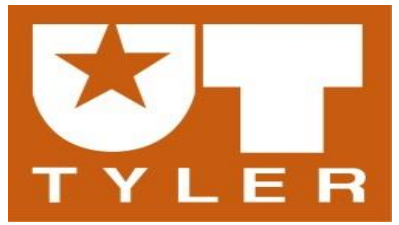

THE UNIVERSITY OF TEXAS AT TYLER

3900 University Blvd. • Tyler, TX $75799 \bullet 903.565 .5774$ • FAX: 903.565 .5858

\section{Office of Research and Technology Transfer}

\section{Institutional Review Board}

May 15, 2014

Dear Ms. Gunter,

Your request to conduct the study: Social Support to Reduce Uncertainty in Childhood Cancer in South Texas: A Case Study, IRB \#Sp2014-104 has been approved by The University of Texas at Tyler Institutional Review Board under expedited review. This approval includes the written informed consent that is attached to this letter, and your assurance of participant knowledge of the following prior to study participation: this is a research study; participation is completely voluntary with no obligations to continue participating, with no adverse consequences for nonparticipation; and assurance of confidentiality of their data.

In addition, please ensure that any research assistants are knowledgeable about research ethics and confidentiality, and any co-investigators have completed human protection training within the past three years, and have forwarded their certificates to the IRB office (G. Duke).

Please review the UT Tyler IRB Principal Investigator Responsibilities, and acknowledge your understanding of these responsibilities and the following through return of this email to the IRB Chair within one week after receipt of this approval letter:

- This approval is for one year, as of the date of the approval letter

- Request for Continuing Review must be completed for projects extending past one year

- Prompt reporting to the UT Tyler IRB of any proposed changes to this research activity 
Appendix C (Continued)

- Prompt reporting to the UT Tyler IRB and academic department administration will be done of any unanticipated problems involving risks to subjects or others

- Suspension or termination of approval may be done if there is evidence of any serious or continuing noncompliance with Federal Regulations or any aberrations in original proposal.

- Any change in proposal procedures must be promptly reported to the IRB prior to implementing any changes except when necessary to eliminate apparent immediate hazards to the subject.

Best of luck in your research, and do not hesitate to contact me if you need any further assistance.

Sincerely,

Dennis Combs, PhD

Delegated Reviewer, UT Tyler IRB 
Appendix D

Health Care System Approval Letter

From:Philip.Oilepo@MHShealth.com

Sent: Wednesday, May 07, 2014 4:07 PM

To: Gunter, Martha; Carolyn.King@MHShealth.com;

Kelly.Rountree@MHShealth.com

Subject: RE: Danielle Gunter--non-credentialed privileges to complete my dissertation study

Ms. Danielle,

I apologize for the delayed response.

Since you are no longer an employee or agent of MHS and the fact that your research is only restricted to interviews/observations, MHS is not considered engaged in the proposed research. Consequently, local IRB review and/or oversight is not required. I will however need a copy of the IRB approved protocol, IRB approval letters, accompanied with any permissions that you will receive from facilities where you will interact with research subjects. Please send these to me via email before initiating research activities.

Respectfully,

Philip Oilepo, MBA, CIP

Director, IRB

O: (210) 575.6910

M:(210) 771.4474

https://sites.google.com/site/mhsirbsatx/home 
Appendix E

Informed Consent Letter

\title{
THE UNIVERSITY OF TEXAS AT TYLER
}

Informed Consent to Participate in Research

\author{
Institutional Review Board \# Sp2014-104
}

Approval Date: May 15, 2014

1. Project Title: Social Support to Reduce Uncertainty in Childhood Cancer in South Texas: A Case Study Approach

2. Principal Investigator: M. Danielle Gunter, MSN, RN

\section{Participant's Name:}

\section{To the Participant:}

You are being asked to take part in this study at The University of Texas at Tyler (UT Tyler). This permission form explains:

- Why this research study is being done.

- What you will be doing if you take part in the study.

- Any risks and benefits you can expect if you take part in this study.

After talking with the person who asks you to take part in the study, you should be able to:

- Understand what the study is about.

- Choose to take part in this study because you understand what will happen

\section{Description of Project}

The purpose of this study is to use interviews to learn what helps in reducing the uncertainty felt in parents of children diagnosed with cancer in south Texas and what increases the behaviors that help these parents adapt to this situation. After identifying how interventions might help this particular population further research interventions could be developed to enhance nursing practice in this area.

\section{Research Procedures}

If you agree to be in this study, we will ask you to do the following things:

- Complete one 45-60 minute recorded interview with the principal investigator during which questions will be asked to help identify what steps could be taken to provide more educational and psychosocial support to parents of children with cancer in south Texas. 
Appendix E (Continued)

- Complete a short demographic survey.

\section{Side Effects/Risks}

- It is possible that the topics discussed in the interview might distress you as you work through your concerns about your child or those you know. If this occurs, the principal investigator, as a nurse with over ten years of experience in this area will be able to help you through this.

\section{Potential Benefits}

- You will receive a \$20 gift card for your time spent in the interview, but you will not receive any direct benefits from participating in this study.

\section{Understanding of Participants}

8. I have been given a chance to ask any questions about this research study. The researcher has answered my questions.

9. If I sign this consent form I know it means that:

- I am taking part in this study because I want to. I chose to take part in this study after having been told about the study and how it will affect me.

- I know that I am free to not be in this study. If I choose to not take part in the study, then nothing will happen to me as a result of my choice.

- I know that I have been told that if I choose to be in the study, then I can stop at any time. I know that if I do stop being a part of the study, then nothing will happen to me.

- I will be told about any new information that may affect my wanting to continue to be part of this study.

- The study may be changed or stopped at any time by the researcher or by The University of Texas at Tyler.

- The researcher will get my written permission for any changes that may affect me.

10. I have been promised that that my name will not be in any reports about this study unless I give my permission.

11. I also understand that any information collected during this study may be shared as long as no identifying information such as my name, address, or other contact information is provided). This information can include health information. Information may be shared with:

- Organization giving money to be able to conduct this study 
- Other researchers interested in putting together your information with information from other studies

- Information shared through presentations or publications

12. I understand The UT Tyler Institutional Review Board (the group that makes sure that research is done correctly and that procedures are in place to protect the safety of research participants) may look at the research documents. These documents may have information that identifies me on them. This is a part of their monitoring procedure. I also understand that my personal information will not be shared with anyone.

13. I have been told about any possible risks that can happen with my taking part in this research project.

14. I also understand that I will not be given money for any patents or discoveries that may result from my taking part in this research.

15. If I have any questions concerning my participation in this project, I will contact the principal researcher: M. Danielle Gunter, MSN, RN at 210-862-2668 or email mgunter2@patriots.uttyler.edu.

16. If I have any questions concerning my rights as a research subject, I will contact Dr. Gloria Duke, Chair of the IRB, at (903) 566-7023, gduke@uttyler.edu, or the University's Office of Sponsored Research:

The University of Texas at Tyler c/o Office of Sponsored Research 3900 University Blvd

Tyler, TX 75799

I understand that I may contact Dr. Duke with questions about research-related injuries.

\section{CONSENT/PERMISSION FOR PARTICIPATION IN THIS RESEARCH STUDY}

I have read and understood what has been explained to me. I give my permission to take part in this study as it is explained to me. I give the study researcher permission to register me in this study. I have received a signed copy of this consent form.

Signature of Participant

Date

In addition to participation in the study, I give permission to the principal investigator to complete auditory recording of our interview, and understand that I will have the opportunity to review the typed transcript of this interview. I also understand that this audio recording will be destroyed at the end of the study, and that no direct quotes will be used in any publication without my express permission. 
Appendix E (Continued)

Signature of Participant

Date

Signature of Person Responsible (e.g., legal guardian) Relationship to Participant

Witness to Signature

18. I have discussed this project with the participant, using language that is understandable and appropriate. I believe that I have fully informed this participant of the nature of this study and its possible benefits and risks. I believe the participant understood this explanation.

$\overline{\text { Researcher/Principal Investigator } \quad \text { Date }}$ 


\section{We Need Your Help!}

Research Study

\section{Do you have a child recently diagnosed with cancer?}

Researchers at The University of Texas at Tyler are trying to learn what types of support are needed for families with new pediatric cancer diagnoses.

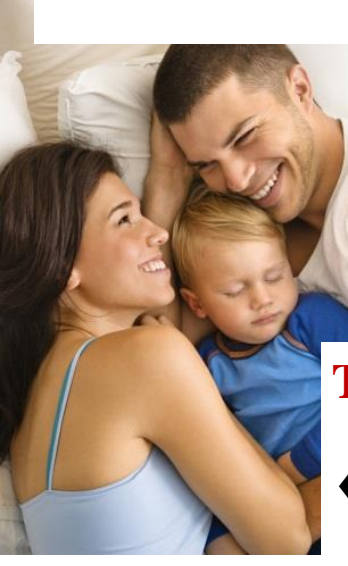

This study might be a good fit for you if:

- Have a child that was diagnosed with cancer in the last 12 months

- Speak and Read English

- Are willing to meet with the researcher one time for a 45-60 minute recorded interview.

To take part in this research study or for more information, please contact Danielle Gunter, MSN, RN at 210-862-2668 or by e-mail: mgunter2@patriots.uttyler.edu 
Appendix G

\section{Uncertainty in Childhood Cancer Demographic Questionnaire for Parent Participants}

Participant Name: Assigned Study ID \#

Participant e-mail: Participant phone \#

Phone number and e-mail will be used only for follow up regarding clarification of meaning of phrases and words you share in your interview. At no time will names or contact information be shared outside of this study.

Please complete the following demographic information to the best of your ability. Feel free to contact the principal investigator, Ms. Danielle Gunter, if you have any questions.

1. Age in years:

2. Gender: M $\mathrm{F}$

3. Relationship to child diagnosed:

4. Number living in your household:

5. Child's Diagnosis:

Leukemia Hemophilia Sickle Cell Disease

HIV/AIDS Neuroblastoma

Brain Tumor

Lymphoma Rhabdomyosarcoma

Osteosarcoma

Aplastic Anemia

Wilm's Tumor

Ewing's Sarcoma

Other

6. Age of child diagnosed:

7. Other children? If yes, ages: Child 1 Child 2 Child 3 Child 4

8. Marital status of child's primary parents/caregivers:

Married Divorced Remarried

Single (never married) Domestic Partners Other

9. Number of years with current spouse (if applicable):

10. Other adults living in household: 


\section{Appendix G (Continued)}

11. Race and Ethnicity:

White Non-Hispanic

White Hispanic

Black Non-Hispanic

Black Hispanic

Asian or PI

Native American/Alaskan _

Multiracial:

Other:

12. Education level of Parents/Caregivers:

Some HS__ Completed HS

Completed College or Tech. School

Completed Graduate School
Some College/Technical School

Some Graduate School

Professional Degree

13. Religious Affiliation:

Christian

Muslim

Hindu

Buddhist

Other

None
Jewish

Pagan

14. Preferred Language in the home:

English __ Spanish ___ Other 
Appendix $\mathrm{H}$

\section{Uncertainty in Childhood Cancer Demographic Questionnaire for}

\section{Health care Team Participants}

Participant Name: Assigned Study ID \#

Participant e-mail: Participant phone \#

Phone number and e-mail will be used only for follow up regarding clarification of meaning of phrases and words you share in your interview. At no time will names or contact information be shared outside of this study.

Please complete the following demographic information to the best of your ability. Feel free to contact the principal investigator, Ms. Danielle Gunter, if you have any questions.
1. Age in years:
2. Gender: $M$
$\mathrm{F}$

3. Role on the HEM/ONC/BMT health care team:

4. Number of years in this profession:

5. Number of years in this role on this health care team at this facility:

6. Number of years working on other HEM/ONC/BMT teams at other facilities:

7. Race and Ethnicity:

White Non-Hispanic

White Hispanic

Black Non-Hispanic

Black Hispanic

Asian or PI

Native American/Alaskan

Multiracial:

Other:

8. Education level:

Completed College or Tech. School

Some Graduate School

Completed Graduate School

Professional Degree/license

9. Religious Affiliation:

Christian

Muslim

Hindu

Buddhist

Jewish

Other

Pagan

None 


\section{Appendix I}

\section{Parent Participant Interview Question Guide}

1. Can we start with you telling me a little about your experience in childhood cancer?

2. Are you familiar with the term "uncertainty"? What does the term mean to you?

3. Do you think uncertainty is a concerning feeling for parents and families of children with cancer?

4. Can you share what type of emotions you've felt as a parent of a child with cancer?

5. What are some of your own life experiences that have helped you adapt to having a child with cancer?

6. How do you think we, as a pediatric oncology team, could reduce uncertainty and help build positive coping mechanisms?

7. As a parent of a child with cancer, what types of support and education mechanisms exist to reduce uncertainty within the current treatment program here?

8. Do these mechanisms work?

9. Why or why not?

10. What barriers do you think prevent support and education interventions from being successful here?

11. Why do you think these barriers exist?

12. What type of support and education do you think is necessary?

13. If you could do anything what type of support or education interventions would you like to see?

14. Is there anything else you would like to share at this time? 


\section{Appendix J}

\section{Health Care Team Participant Interview Question Guide}

1. Can we start with you telling me a little about your experience in childhood cancer?

2. Are you familiar with the term "uncertainty"? What does the term mean to you?

3. Can you share what type of emotions you think are common for parents of children with cancer?

4. What are some life experiences that help parents adapt to having a child with cancer?

5. How do you think we, as a pediatric oncology team, could reduce uncertainty and help build positive coping mechanisms?

6. In your role as, ___ (enter professional role ___, what types of support and education mechanisms exist to reduce uncertainty within the current childhood cancer treatment program here?

7. Can you tell me a little about what types of support and education you think the research says should be provided?

8. Do those suggestions work?

9. Why or why not?

10. What barriers do you think prevent support and education interventions from being successful here?

11. Why do you think these barriers exist?

12. What type of support and education do you think is necessary?

13. If you could do anything what type of support or education interventions would you like to see?

14. Is there anything else you would like to share at this time? 
Appendix K

Journal of Pediatric Oncology Nursing

Journal Submission Guidelines

http://www.sagepub.com/journals/Journal201668/manuscriptSubmission

Manuscript submissions. The editorial board welcomes submission of manuscripts for review for publication in the journal of pediatric oncology nursing. Query letters are also welcomed and should be sent to nancy.kline@ childrens.harvard.edu. All manuscripts should be submitted online through manuscript central: http://mc.manuscriptcentral.com/jopon where authors are required to set up an online account on the Sagetrack system powered by Scholarone.

Authors may download a copy of the submission guidelines from the sage publications web site at http://www.sagepub.com. Manuscripts are accepted for publication on the conditions that they are submitted solely to this journal, that the material is original, and that it has not been previously published. This is a refereed journal. All manuscripts are reviewed by at least three members of the editorial board. Accepted manuscripts are subject to editorial revision.

Authors are responsible for applying for permission for both print and electronic rights for all borrowed materials and are responsible for paying any fees related to the applications of these permissions. Authors of submitted manuscripts will be asked to sign a transfer of copyright to the association of pediatric hematology/oncology nurses. If the article is not accepted for publication, the copyright consent will be returned.

Preparing the manuscript. The first page of the manuscript should include the following information: (1) title of the paper, (2) author name(s), degree(s), and current position, (3) complete addresses for every author, (4) name and address of the author to whom communications should be addressed. E-mail addresses for each author should be included. The second page should include a 175-word or less abstract, 4-5 keywords, and a short bio for each author.

Illustrations and tables. The use of figures is encouraged. Original glossy photographs or electronic image files (tif, jpg or eps for-mats), preferably in black and white, must be supplied with the manuscript (photocopies cannot be used for reproduction). Files should be in tif, jpg, or eps format and line art images should be saved at $1200 \mathrm{dpi}$, and grayscale images should be saved at 300 dpi. Figures should be presented in separate electronic files and not incorporated into the word document. When original photographs are supplied, the figure number and author name should be identified on the back of each figure in soft pencil.

Use of a human being's photograph requires written consent from the individual. Release forms can be obtained by contacting the editor, Nancy Kline.

Figure legends should be included at the end of the manuscript. A legend must accompany each illustration. Contributors must bear the cost of reproducing color illustrations. 


\section{Appendix K (Continued)}

Each table should be typed on a separate sheet at the end of the manuscript file. The author should provide table titles on the same sheet as the table.

Figures and tables should be cited in order in the text using Arabic numerals. The author must provide per-mission to reprint figures and tables from other sources. Standard copyright permission forms are available from the editor.

References. References follow the style used by the American Psychological Association (APA). References should be cited in text with an author-date citation system and are listed alphabetically in the reference section in APA style. They should be typewritten and double-spaced, under the heading references. 


\section{Appendix L}

Coding Guide: Meaning of Uncertainty in Parents and Members of the Health Care Team

\begin{tabular}{|c|c|c|c|c|}
\hline Theme & Subthemes & Code & Key Words & Possible Example Phrases \\
\hline $\begin{array}{l}\text { Meaning of } \\
\text { uncertainty in } \\
\text { parents and } \\
\text { members of the } \\
\text { health care team }\end{array}$ & $\begin{array}{l}\text { Shock and subsequent } \\
\text { barrage of negative } \\
\text { emotions }\end{array}$ & $\begin{array}{l}\text { Shock, guilt, fear, } \\
\text { anger, loss of } \\
\text { control, grief }\end{array}$ & $\begin{array}{l}\text { Shock, guilt, fear, } \\
\text { anger, loss of } \\
\text { control, grieving lost } \\
\text { normalcy, } \\
\text { overwhelmed, } \\
\text { anxiety of the } \\
\text { unknown on a daily } \\
\text { basis, sadness, } \\
\text { confusion, doubt }\end{array}$ & $\begin{array}{l}\text { "PI: What kind of things do they go through? } \\
\text { S2: shock. } \\
\text { S1: yes, shock is the first one that comes to } \\
\text { my mind. Shock. } \\
\text { S2: And I think that within that first } \\
\text { diagnosis, shock." } \\
\text { "I think there is some guilt. You know a lot } \\
\text { of times there have been these vague } \\
\text { symptoms that they've put off for a little bit, } \\
\text { or they have gone to a doctor and the doctor } \\
\text { said also. What if I had recognized it sooner? } \\
\text { What if someone else had recognized it } \\
\text { sooner? Is there something I did?" } \\
\text { "I think the first thing most parents feel is } \\
\text { guilt. What did I do to cause my kids to have } \\
\text { cancer?" } \\
\text { "They are scared. I'd be terrified." } \\
\text { "Grieving their normal life. Anger. Some } \\
\text { people are so angry! Why me? Why my } \\
\text { family? So anger." } \\
\text { "They've lost all sense of control." }\end{array}$ \\
\hline
\end{tabular}


Appendix L (Continued)

\begin{tabular}{|c|c|c|c|c|}
\hline Theme & Subthemes & Code & Key Words & Possible Example Phrases \\
\hline & & & & $\begin{array}{l}\text { "A sense of being overwhelmed. A sense of } \\
\text { losing control of the care of their child, and I } \\
\text { think it is just the certain level of daily } \\
\text { anxiety to not know what each hour is going } \\
\text { to bring, or each day a new catastrophic } \\
\text { diagnosis." } \\
\text { "Shock, sadness, fear, confusion, } \\
\text { hopelessness." } \\
\text { "I think it comes from anxiety. I feel like } \\
\text { they have a lot of anxiety." } \\
\text { "I think at first like for me I went through } \\
\text { disbelief." } \\
\text { "You get angry. I started getting angry at } \\
\text { myself mostly because I was like why didn't } \\
\text { I take her sooner?" } \\
\text { "I was never angry, I was confused." } \\
\text { "I was just shocked." } \\
\text { "I need to know what it's going to look like, } \\
\text { it can't just be ',oh well you're going to do } \\
\text { this and then she'll be stable in seven } \\
\text { months." }\end{array}$ \\
\hline
\end{tabular}


Appendix L (Continued)

\begin{tabular}{|c|c|c|c|c|}
\hline Theme & Subthemes & Code & Key Words & Possible Example Phrases \\
\hline & $\begin{array}{l}\text { Health care provider } \\
\text { (physician) uncertainty } \\
\text { in guiding the steps of } \\
\text { treatment }\end{array}$ & $\begin{array}{l}\text { Provider and } \\
\text { physician } \\
\text { uncertainty } \\
\text { regarding treatment } \\
\text { choice options }\end{array}$ & $\begin{array}{l}\text { Physicians don't } \\
\text { know answers to } \\
\text { give, desire to have } \\
\text { parent make } \\
\text { decisions regarding } \\
\text { care, when the } \\
\text { provider has to give } \\
\text { blind advice (little } \\
\text { known about this } \\
\text { disease and } \\
\text { treatment), parents } \\
\text { left hanging after } \\
\text { being given the } \\
\text { diagnosis }\end{array}$ & $\begin{array}{l}\text { "Even just him telling me I've done a little } \\
\text { bit of research. So just from then the } \\
\text { oncology doctor told me no, I don't think she } \\
\text { needs radiation, but then he was like this is } \\
\text { why I think you should get it and these are } \\
\text { the reasons why maybe you shouldn't. You } \\
\text { have to look at both, but ultimately it's your } \\
\text { decision." } \\
\text { "We know basic stuff, it's the very specific } \\
\text { stuff we need to know; more than just surface } \\
\text { stuff. He told us that (referring to suboptimal } \\
\text { test results) and I was like 'What does that } \\
\text { mean?' and you know? You could see how } \\
\text { disappointed he was on his face from her } \\
\text { biopsy results and he just tells us and then } \\
\text { walks out of the room. } \\
\text { Then he says, 'So I need to talk to the tumor } \\
\text { board.' He didn't know what to do. }\end{array}$ \\
\hline
\end{tabular}


Appendix L (Continued)

\begin{tabular}{|c|c|c|c|c|}
\hline Theme & Subthemes & Code & Key Words & Possible Example Phrases \\
\hline & $\begin{array}{l}\text { Looking through the } \\
\text { black tunnel-Health care } \\
\text { team members' } \\
\text { perspectives on parental } \\
\text { uncertainty }\end{array}$ & $\begin{array}{l}\text { The unknown, loss } \\
\text { of control, anxieties } \\
\text { of treatment } \\
\text { prognosis and } \\
\text { changes in home life }\end{array}$ & $\begin{array}{l}\text { Don't know what to } \\
\text { expect, questions } \\
\text { about survival, can't } \\
\text { get answers, } \\
\text { unfamiliarity with } \\
\text { hospital and } \\
\text { policies/procedures, } \\
\text { leaving it to fate and } \\
\text { destiny, loss of } \\
\text { control regarding } \\
\text { day to day decisions, } \\
\text { worried about } \\
\text { finances, work, } \\
\text { treatment, future, } \\
\text { home life, other } \\
\text { children; fear of } \\
\text { death, overwhelmed, } \\
\text { not knowing }\end{array}$ & $\begin{array}{l}\text { Health care team members' descriptions } \\
\text { of what parental uncertainty means to } \\
\text { them. } \\
\text { "Don't know what to expect regarding the } \\
\text { disease process." } \\
\text { "Uncertain if their child is going to survive." } \\
\text { "What are the visitation rules? What are the } \\
\text { rules about how I talk with people? Can I tell } \\
\text { people not to come into the room? What are } \\
\text { the rules about me walking away to get food? } \\
\text { Where is the food? Are there people I can } \\
\text { ask? What are the resources? } \\
\text { Like they don't know what the resources } \\
\text { are." } \\
\text { "Well, the uncertainty is, is like a black } \\
\text { tunnel in front of them. They don't know } \\
\text { what's going to happen. " } \\
\text { "A sense of being overwhelmed. A sense of } \\
\text { losing control of the care of their child, and I } \\
\text { think it is just the certain level of daily } \\
\text { anxiety to not know what each hour is going }\end{array}$ \\
\hline
\end{tabular}


Appendix L (Continued)

\begin{tabular}{|c|c|c|c|c|}
\hline Theme & Subthemes & Code & Key Words & Possible Example Phrases \\
\hline & & & & $\begin{array}{l}\text { to bring, or each day a new catastrophic } \\
\text { diagnosis." } \\
\text { "As they get the diagnoses or as they go } \\
\text { through it there's all this unknown, they don't } \\
\text { have a schedule anymore. Their life is up in } \\
\text { the air, and they just have to roll with it. } \\
\text { Whatever happens, happens." } \\
\text { "The other thing they are uncertain about is } \\
\text { their own lives. A lot of the first few days } \\
\text { we've heard parents say, "Can I work? What } \\
\text { will my work say? What am I going to do } \\
\text { with the other kid?" All the uncertainty of } \\
\text { their own lives and how to handle what to do } \\
\text { with this, this thing. I can see that the word } \\
\text { Uncertainty is huge. They are uncertain also } \\
\text { about how they are going to think, because } \\
\text { they can't even think. They are flabbergasted } \\
\text { and their world is turned upside down and } \\
\text { they just don't know what to do. They are } \\
\text { really uncertain just about } \\
\text { everything.....about everything." } \\
\text { "They don't know what kind of treatment } \\
\text { they are going to get. How long it is going to } \\
\text { take? What side effects it will have? Who is }\end{array}$ \\
\hline
\end{tabular}


Appendix L (Continued)

\begin{tabular}{|c|c|c|c|c|}
\hline Theme & Subthemes & Code & Key Words & $\begin{array}{l}\text { Possible Example Phrases } \\
\end{array}$ \\
\hline & & & & $\begin{array}{l}\text { going to stay? How am I going to have any } \\
\text { income? Who's going to take care of the rest } \\
\text { of my family? There are so many } \\
\text { uncertainties when this catastrophic event } \\
\text { comes in. The whole picture, everything. } \\
\text { Everything. Um hmm. To the finances, } \\
\text { who's going to stop working? Who's going } \\
\text { to keep working? Right? Insurance, } \\
\text { everything. Even transportation to and from. } \\
\text { It's just everything. Who's going to notify } \\
\text { the rest of the family?" }\end{array}$ \\
\hline & $\begin{array}{l}\text { Burden of parental } \\
\text { ambiguity and decision } \\
\text { making }\end{array}$ & $\begin{array}{l}\text { The unknown, } \\
\text { financial, home life } \\
\text { and prognosis } \\
\text { worries: lack of trust } \\
\text { and burden of } \\
\text { indecisiveness }\end{array}$ & $\begin{array}{l}\text { Worried about } \\
\text { child's death, } \\
\text { worried about } \\
\text { finances, work, } \\
\text { treatment, future, } \\
\text { home life, other } \\
\text { children, waiting for } \\
\text { answers, not } \\
\text { knowing, lack of } \\
\text { trust, parental } \\
\text { indecisiveness and } \\
\text { weight of } \\
\text { responsibility } \\
\text { regarding decisions } \\
\text { for treatment. }\end{array}$ & $\begin{array}{l}\text { Parental Uncertainty from Parent } \\
\text { Perspective } \\
\text { "The very first thing that comes to my mind } \\
\text { is how long is my kid going to live?" } \\
\text { "He said she had to go into surgery pretty } \\
\text { quick, and that the tumor was in a tough spot, } \\
\text { I don't know if we're going to be able to do } \\
\text { it. So, like the uncertainty at first from me } \\
\text { was 'Are you telling me my child's going to } \\
\text { die from this?' Because I thought he was } \\
\text { telling me he was not going to be able to do } \\
\text { anything, that's it. And then they had to stop }\end{array}$ \\
\hline
\end{tabular}


Appendix L (Continued)

\begin{tabular}{|c|c|c|c|c|}
\hline Theme & Subthemes & Code & Key Words & Possible Example Phrases \\
\hline & & & & $\begin{array}{l}\text { and say no we're going to try but it's in a } \\
\text { tough spot. } \\
\text { So like my uncertainties were 'Is my child } \\
\text { going to live?" } \\
\text { "Well like in the beginning, It's not knowing } \\
\text { what's going on. Not knowing what } \\
\text { terminology is." } \\
\text { "How long are we going to have to be in the } \\
\text { hospital? You know, are we going to be able } \\
\text { to do it here? Are we going to have to } \\
\text { relocate? What am I going to do with my } \\
\text { other kids? " } \\
\text { "I wanted a definite and I had to come to the } \\
\text { realization that there wasn't any definite } \\
\text { answers for me. Like I know usually what I } \\
\text { heard the doctors tell me was okay we're } \\
\text { going to give you a map of her treatment. I } \\
\text { never received a map, like because it's so } \\
\text { hard for them, and then it was like we're } \\
\text { going to give you a calendar and I was like } \\
\text { okay I'm going to get a calendar with like } \\
\text { dates. And then I got here and it was like I'm } \\
\text { sorry because her protocol is so different we } \\
\text { can't really give you a calendar. We're just }\end{array}$ \\
\hline
\end{tabular}


Appendix L (Continued)

\begin{tabular}{|l|l|l|l|}
\hline Theme & Subthemes & Key Words & \multicolumn{1}{|c|}{ Possible Example Phrases } \\
\hline & & & $\begin{array}{l}\text { going to go day by day." } \\
\text { "Not knowing and he was just throwing out } \\
\text { well it could just be a tumor of some kind, it } \\
\text { doesn't mean it could be cancer. It could be } \\
\text { but. Just that not knowing what it is and then } \\
\text { how it's going to affect you know, your } \\
\text { child, it's just, of course that's the first thing } \\
\text { you think of when you hear the word cancer, } \\
\text { so especially when you haven't been in that } \\
\text { that kind of mindset at all." } \\
\text { "They came and pulled us aside and said we } \\
\text { want to take more tests. We're not too sure; } \\
\text { We can't see that much. We want to make } \\
\text { sure we know what it is. There's something } \\
\text { there. So then I started getting worried.....and } \\
\text { then when it really hit me was when she had } \\
\text { already done the scans and they told us wait } \\
\text { here so we can make sure with the doctor } \\
\text { what we took was okay and then you can go. } \\
\text { I was like okay, well when the lady came } \\
\text { back in she was like well now they want me } \\
\text { to take her chest and her head and her neck to } \\
\text { see if it spread anywhere. Well nobody had } \\
\text { told me anything up to that point, and I think } \\
\text { she even freaked out because my face had } \\
\text { probably turned white. And I was like what }\end{array}$ \\
\hline
\end{tabular}


Appendix L (Continued)

\begin{tabular}{|c|c|c|c|c|}
\hline Theme & Subthemes & Code & Key Words & $\begin{array}{l}\text { Possible Example Phrases } \\
\end{array}$ \\
\hline & & & & $\begin{array}{l}\text { are you talking about? That kind of freaked } \\
\text { me out." } \\
\text { "So we didn't know if she was going to have } \\
\text { paralysis. They had told me maybe paralysis } \\
\text { on one side of her body. Um if she was going } \\
\text { to be able to respond to any of us. " } \\
\text { "The uncertainty is okay do I go forward } \\
\text { with more treatment or do I wait and see } \\
\text { what happens and hope that it doesn't come } \\
\text { back. " } \\
\text { "For me I don't think the uncertainty hit until } \\
\text { probably last week. So up until probably just } \\
\text { recently I was pretty comfortable and } \\
\text { confident in knowing the education and } \\
\text { followed that until her doctor was like 'OK } \\
\text { she's good. I'll see you in four weeks.' I was } \\
\text { like, 'No wait hold on. I'm not ok with four } \\
\text { week visits or quarterly visits." } \\
\text { "I think when they call you at first you have } \\
\text { hospital stays and nurses and everyone } \\
\text { surrounding you. I think your uncertainty and } \\
\text { comfort level is pretty low. I think it's when } \\
\text { they're like you're on your own. Your child is } \\
\text { getting better. Because now I'm in panic }\end{array}$ \\
\hline
\end{tabular}


Appendix L (Continued)

\begin{tabular}{|c|c|c|c|c|}
\hline Theme & Subthemes & Code & Key Words & Possible Example Phrases \\
\hline & & & & $\begin{array}{l}\text { mode wondering what if this happens or this } \\
\text { happens." } \\
\text { "I think the uncertainty, well actually it was a } \\
\text { relief to find something out because we had } \\
\text { been in the hospital for two weeks, not } \\
\text { knowing anything and then it wasn't like, } \\
\text { 'Oh she has cancer great, but we had a plan } \\
\text { of attack." } \\
\text { "I think just the reassurance of knowing } \\
\text { every week that she was ok and the } \\
\text { reassurance of knowing like every month she } \\
\text { has LPs, every month we got confirmation } \\
\text { that she was doing ok, and then every week } \\
\text { we had lab draws, and I was like yeah ok } \\
\text { she's good." }\end{array}$ \\
\hline
\end{tabular}




\section{Appendix M}

\section{Coding Guide: Facilitators of Parental Adaptation}

\begin{tabular}{|c|c|c|c|c|}
\hline Theme & Subthemes & $\begin{array}{c}\text { Code } \\
\end{array}$ & Key Words & \begin{tabular}{|c|} 
Possible Example Phrases \\
\end{tabular} \\
\hline $\begin{array}{l}\text { Facilitators of } \\
\text { Parental } \\
\text { Adaptation }\end{array}$ & $\begin{array}{l}\text { Extended } \\
\text { Network } \\
\text { Support }\end{array}$ & $\begin{array}{l}\text { Family or extended } \\
\text { social network }\end{array}$ & $\begin{array}{l}\text { Family helping, church } \\
\text { network, friends, } \\
\text { support at work, visitors, } \\
\text { getting things done at } \\
\text { home }\end{array}$ & $\begin{array}{l}\text { "Family support. Beyond... extended family. When there } \\
\text { is extended family involved. Grandmas and grandpas, } \\
\text { aunts, uncles, holding hands, doing chores, giving hugs. If } \\
\text { they have a strong family element to fall back on. That } \\
\text { makes a big difference. Case in point, do you remember } \\
\text {.... grandma and grandpa were there and they'd take } \\
\text { shifts, and they were there for the whole long haul. That } \\
\text { made it easier because they had people they trusted and } \\
\text { could help each other." } \\
\text { "I think their support system that they have like a single } \\
\text { parent family versus if all the grandparents are around. It's } \\
\text { like who's there to help them through it?" } \\
\text { "I do have a great support system. I have my sisters and } \\
\text { they're, you know, my brother in laws are great...my } \\
\text { parents and I have extended family here too. I have my } \\
\text { support system at work and everybody had been great." } \\
\text { "My sister, they had some food brought into the hospital } \\
\text { for us. Some people cooked food and brought it, um, a lot } \\
\text { of people, I mean we got like a ton of gift cards to just like } \\
\text { places to eat. Besides the HEB ones. So that was helpful, } \\
\text { because even when we got out of the hospital and we were } \\
\text { recovering here at home." }\end{array}$ \\
\hline
\end{tabular}


Appendix M (Continued)

\begin{tabular}{|c|c|c|c|c|}
\hline Theme & Subthemes & Code & Key Words & \begin{tabular}{|c|} 
Possible Example Phrases \\
\end{tabular} \\
\hline & & & & $\begin{array}{l}\text { "You have all your immediate family and friends and } \\
\text { church, and you know you have the hospital staff, you } \\
\text { have everybody at immediate crises. And then like you } \\
\text { have all these things that happen right at the time of the } \\
\text { crises. And then } 6 \text { months down the road everyone goes } \\
\text { back to their own lives. That's like the cycle of crises, } \\
\text { that's the way it works." } \\
\text { "Like with our church the whole church came together and } \\
\text { had meals for months and we had help and we had fund } \\
\text { raising stuff. And people coming over to visit the girls. } \\
\text { And blood drives, and just lots and lots of stuff." }\end{array}$ \\
\hline & & Faith guides & $\begin{array}{l}\text { God's presence to lean } \\
\text { on }\end{array}$ & $\begin{array}{l}\text { "I've definitely seen folks that have a strong faith system } \\
\text { that that can help guide them during those difficult times." }\end{array}$ \\
\hline & Socioeconomic & Education level & $\begin{array}{l}\text { Parents with a formal } \\
\text { education, increased } \\
\text { understanding }\end{array}$ & $\begin{array}{l}\text { "I think if you have formal education I think you have a } \\
\text { better place to take that education here. A better } \\
\text { foundation and framework." } \\
\text { "I think that if you don't have that education or you are not } \\
\text { willing to learn all the new parts of their life that it is } \\
\text { harder." }\end{array}$ \\
\hline & & Socioeconomic Status & $\begin{array}{l}\text { Easier financially, } \\
\text { employer support of } \\
\text { leave, insurance, income } \\
\text { stable }\end{array}$ & $\begin{array}{l}\text { "If they don't have the resources, the money to take care } \\
\text { of these things and if these outside influences are huge, it } \\
\text { makes it much more challenging for the family to take } \\
\text { care of the cancer and not worry about the other stuff." }\end{array}$ \\
\hline
\end{tabular}


Appendix M (Continued)

\begin{tabular}{|c|c|c|c|c|}
\hline Theme & Subthemes & Code & Key Words & Possible Example Phrases \\
\hline & & & & $\begin{array}{l}\text { "Financial means reduces the stress. Our families that } \\
\text { come in and make a hundred thousand dollars a year they } \\
\text { may be shocked, but they recover quickly." } \\
\text { "They don't seem to be as emotionally stuck in 'Oh my } \\
\text { gosh what are we going to do??' They may have other } \\
\text { external things going on in their family that impact the } \\
\text { family and the child, but money won't be the issue." } \\
\text { "I took a leave during that time. You know, my director } \\
\text { and my manager came to the hospital. So I was very } \\
\text { supported in that aspect of work and I didn't have to worry } \\
\text { about that, financially it was very different." }\end{array}$ \\
\hline & Empowerment & $\begin{array}{l}\text { Being proactive and } \\
\text { seeking knowledge, } \\
\text { incorporated into } \\
\text { treatment plan }\end{array}$ & $\begin{array}{l}\text { Take charge attitude, } \\
\text { positive attitude, seeking } \\
\text { out information, parent } \\
\text { as being a part of the } \\
\text { treatment plan }\end{array}$ & $\begin{array}{l}\text { "I think another huge impact is their personalities. Some } \\
\text { might be more proactive and have more initiative. Might } \\
\text { read and do research and understand what's happening, or } \\
\text { maybe a higher educational level." } \\
\text { "I read everything, even if it didn't make sense, I read it. If } \\
\text { I read the sentence and it made no sense I just kept going. } \\
\text { I figured it would make sense at some point or I could ask } \\
\text { questions later if I needed to know." } \\
\text { "I read a book that was really helpful and was just like ok } \\
\text { we have a plan, for me to figure out oh this is what's going } \\
\text { to happen, this is how your kid might feel, and those kinds } \\
\text { of things, that helped me." }\end{array}$ \\
\hline
\end{tabular}


Appendix M (Continued)

\begin{tabular}{|c|c|c|c|c|}
\hline Theme & Subthemes & Code & Key Words & $\begin{array}{c}\text { Possible Example Phrases } \\
\end{array}$ \\
\hline & & & & $\begin{array}{l}\text { "I think I'm a more informed parent and the other parents I } \\
\text { know lack education they're not from the medical field, } \\
\text { and they don't ask a lot of questions. Like the doctor will } \\
\text { say this one time and they won't question it at all or they'll } \\
\text { ask the nurse or me. I keep saying that if you have } \\
\text { questions write them down and ask them when you get } \\
\text { there." } \\
\text { "It's just I don't want to be told her treatment plan, I want } \\
\text { to be in her treatment plan. I want to be a part of it; I want } \\
\text { to know it all." } \\
\text { "You don't have to have a great educational background to } \\
\text { be that proactive empowered person. No, you can Google } \\
\text { everything. You don't even have to have a degree. I think } \\
\text { it is the type of person that they are the seeker." }\end{array}$ \\
\hline
\end{tabular}




\section{Appendix N}

Coding Guide: Education and Psychosocial Support

\begin{tabular}{|c|c|c|c|c|}
\hline Theme & Subthemes & Code & Key Words & Possible Example Phrases \\
\hline $\begin{array}{l}\text { Education } \\
\text { and } \\
\text { Psycho- } \\
\text { Social } \\
\text { Support }\end{array}$ & Communication & $\begin{array}{l}\text { Information sharing } \\
\text { between parents, } \\
\text { acknowledging the } \\
\text { need to share with other } \\
\text { parents, but inhibited } \\
\text { by acuity of child, } \\
\text { anticipatory planning, } \\
\text { connecting with others }\end{array}$ & $\begin{array}{l}\text { Parent to parent sharing, } \\
\text { Interest in participation or } \\
\text { learning, sense of being in a } \\
\text { vortex, being overwhelmed } \\
\text { by sense of isolation and } \\
\text { they have all that they can } \\
\text { handle, in ability to see past } \\
\text { this immediate moment, } \\
\text { sense of craving to talk to } \\
\text { people in similar } \\
\text { circumstances, need to know } \\
\text { survival tips, need to be able } \\
\text { to talk with parents whom } \\
\text { they can relate to all that } \\
\text { they are going through }\end{array}$ & $\begin{array}{l}\text { "I think that if they talked to other parents, that helps. } \\
\text { Because I feel like when they first get diagnosed they } \\
\text { feel like it's a vortex. They're in the center and have no } \\
\text { idea what's going on around them. In their mind this is } \\
\text { it. This is as bad as it gets and no one else can know } \\
\text { how they are feeling. Someone else may be worse off } \\
\text { than them, but they can't even understand." } \\
\text { "I started with websites and then I finally I think they } \\
\text { had like a forum, and I met somebody and so we were } \\
\text { communicating. Of course I wish I met her sooner in } \\
\text { the treatment. It was further along, but maybe I would } \\
\text { have done things a little bit different. So I think its } \\
\text { best, I wish they had a little group for people like } \\
\text { locally, if it's something they can do." } \\
\text { "Think it is helpful because it's like you already have } \\
\text { to go through that story over and over again. That's } \\
\text { just because people want to know, but if you go } \\
\text { through it with somebody who's either going through } \\
\text { a similar situation or maybe is ahead of you or behind } \\
\text { you in treatment it's like a little more... I don't want } \\
\text { to say fulfilling, but I guess a little more comforting." } \\
\text { "The first time, we were in the hospital, and someone } \\
\text { came to the door and said that there were some moms } \\
\text { there that brought like some goodies in the playroom } \\
\text { and that they wanted us to come out. So I went out to }\end{array}$ \\
\hline
\end{tabular}


Appendix N (Continued)

\begin{tabular}{|c|c|c|c|c|}
\hline Theme & Subthemes & Code & Key Words & $\begin{array}{c}\text { Possible Example Phrases } \\
\end{array}$ \\
\hline & & & & $\begin{array}{l}\text { the hallway and there were two ladies and they said } \\
\text { that basically they were in the same place that I was at } \\
\text { the time. They were there a year ago with their child } \\
\text { and they had been through everything. And I really, } \\
\text { really, wanted to talk to them, but my daughter was } \\
\text { sick and I couldn't really go. I know that they weren't } \\
\text { trying to be intrusive and I guess that I didn't... I was } \\
\text { so worried about her at the time I didn't, although I } \\
\text { wanted to talk to them and just find, or just ask } \\
\text { questions, and hear their story. I didn't want to leave } \\
\text { her." } \\
\text { "It would be nice to kind of know what kind of thing } \\
\text { parents or even the child themselves, I mean if they're } \\
\text { of age that time, if there's anything they've run into } \\
\text { that they've had issues with. If it's something that we } \\
\text { can be proactive about." } \\
\text { "Like survival tips, what you need to bring, what } \\
\text { things help them the most while they stayed. Just } \\
\text { knowing that there are other families that are staying } \\
\text { for as long as period as you do, and you're not the } \\
\text { only one." } \\
\text { "I would, I feel like if people were willing to share } \\
\text { their experiences, like even though she has brain } \\
\text { cancer, and }\end{array}$ \\
\hline
\end{tabular}


Appendix N (Continued)

\begin{tabular}{|c|c|c|c|c|}
\hline Theme & Subthemes & Code & Key Words & Possible Example Phrases \\
\hline & & & & $\begin{array}{l}\text { could still relate. Even though it's two totally different } \\
\text { diagnoses you can still relate. Like a, 'You know let's } \\
\text { not talk about cancer today.' kind of thing. Get to } \\
\text { know one another so when we are in the hospital you } \\
\text { know, one night she happened to be right next door } \\
\text { because her daughter had to be here overnight, and it } \\
\text { just felt good like well I know her. At that time my } \\
\text { daughter was very sick and in my mind I was like, 'If } \\
\text { something really bad happens I have somebody that I } \\
\text { can talk to if I need something.' So that felt good, but } \\
\text { if I didn't know her I would've felt really alone, you } \\
\text { know, stuck in the room." } \\
\text { "We have somebody here now, this is a person. Here's } \\
\text { the card, I have a family that has gone through the } \\
\text { same exact thing. You let me know when you're ready } \\
\text { to talk to them.' You know? Those kinds of things, I } \\
\text { would love to talk to a family that's had their child } \\
\text { diagnosed with neuroblastoma." } \\
\text { "I guess it would have been nice to talk to a, maybe } \\
\text { have a number of a couple or a mom or somebody that } \\
\text { has the same diagnosis as your child. You know? } \\
\text { 'We've been there; we've done that; we know that } \\
\text { there's help at the end. Where y'all are at now.' You } \\
\text { know? Like a go to person?" }\end{array}$ \\
\hline & & Parent/Patient & Emphasis on education as & "Our job is to keep them informed about what is about \\
\hline
\end{tabular}


Appendix N (Continued)

\begin{tabular}{|c|c|c|c|c|}
\hline Theme & Subthemes & Code & Key Words & Possible Example Phrases \\
\hline & & $\begin{array}{l}\text { Education, focus on } \\
\text { education as critically } \\
\text { important and parent } \\
\text { understanding is } \\
\text { dependent on their } \\
\text { readiness and } \\
\text { consistency in delivery } \\
\text { of educational content }\end{array}$ & $\begin{array}{l}\text { the focal point, education } \\
\text { delivery is unstructured, and } \\
\text { lack of adherence to the } \\
\text { existing institutional } \\
\text { education guidelines, nurse } \\
\text { clinical knowledge and } \\
\text { experience contributes to } \\
\text { inconsistencies in delivery of } \\
\text { patient education, timeframe } \\
\text { for parent readiness for } \\
\text { education, understanding of } \\
\text { information dependent on } \\
\text { parent readiness for } \\
\text { education }\end{array}$ & $\begin{array}{l}\text { to happen today and tomorrow and next week. We can } \\
\text { give them kind of a fuzzy view of the future, but our } \\
\text { goal is to educate, educate, educate." } \\
\text { "I think we should probably have more ownership of } \\
\text { who is the teacher and what is being distributed. The } \\
\text { provider then the nurse. A more structured format } \\
\text { because then everyone knows that if you already met } \\
\text { with Nurse X then these issues have already been } \\
\text { discussed: drop in counts, risk for infection, etc., } \\
\text { because I think a new nurse comes in and they want to } \\
\text { do some teaching and they do have this kardex where } \\
\text { they sort of check what they have done and it just gets } \\
\text { lost." } \\
\text { "PI: Do you think there is a lot of variation between } \\
\text { what each nurse is teaching? } \\
\text { S. Yes and that to me is a reflection of their clinical } \\
\text { knowledge and experiences." } \\
\text { "This nurse said this and this nurse said this, so which } \\
\text { is the right. I mean I guess the nursing staff too like } \\
\text { they get on the same page." } \\
\text { "I don't know if it would have been too soon for me. I } \\
\text { think it would have been easier now that it's kind of } \\
\text { sunken in and we've been going through treatments. } \\
\text { Yeah, I think this would probably be the best time. I }\end{array}$ \\
\hline
\end{tabular}


Appendix N (Continued)

\begin{tabular}{|c|c|c|c|c|}
\hline Theme & Subthemes & Code & Key Words & Possible Example Phrases \\
\hline & & & & $\begin{array}{l}\text { think at the beginning it's so hard because you're still } \\
\text { trying to process what's going on. Although it's } \\
\text { helpful for some people to get it (education) early." } \\
\text { "It takes about } 3 \text { months for people to get over it and } \\
\text { start focusing again." } \\
\text { "There was literature that recommended we provided } \\
\text { a certain level of education about the disease process } \\
\text { and treatment. So I feel like how you do that in an age } \\
\text { appropriate way and how you build on that from initial } \\
\text { diagnosis through the treatment. } \\
\text { I think there is evidence that shows it should be } \\
\text { broken up, and we aren't doing a great job of that." }\end{array}$ \\
\hline & & $\begin{array}{l}\text { Delivery of diagnosis, } \\
\text { information and disease } \\
\text { and treatment } \\
\text { education, finding the } \\
\text { balance related to the } \\
\text { amount of information } \\
\text { given and when best to } \\
\text { provide it. }\end{array}$ & $\begin{array}{l}\text { Paradigm shift regarding the } \\
\text { context and manner of } \\
\text { diagnosis delivery, shock } \\
\text { factor of childhood cancer } \\
\text { diagnosis, perception of } \\
\text { secrecy related to child's } \\
\text { pending diagnosis, too much } \\
\text { information can equate to } \\
\text { fear, need for more planned } \\
\text { education delivery to } \\
\text { maximize retention of } \\
\text { information provided }\end{array}$ & $\begin{array}{l}\text { "What absolutely does not work in my opinion is, } \\
\text { generalized case example, a patient goes to the doctor } \\
\text { with the usual ALL workup and we start running labs } \\
\text { and say we need you to stay over in the hospital and } \\
\text { we have to run some tests on you, yadda yadda yadda, } \\
\text { give them antibiotics, and so they are in the hospital. } \\
\text { Admitted to the Hem/Onc unit and they have no idea } \\
\text { why they are here. We describe it as 'Because we are } \\
\text { hematology and your blood counts are bad' and they } \\
\text { have no idea it is cancer. And then they get the tests } \\
\text { done and have IV started and the whole life is turned } \\
\text { upside down for that } 24 \text { hours. Then the doc walks in } \\
\text { and says here are the test results. You have leukemia. }\end{array}$ \\
\hline
\end{tabular}


Appendix N (Continued)

\begin{tabular}{|c|c|c|c|c|}
\hline Theme & Subthemes & Code & Key Words & $\begin{array}{c}\text { Possible Example Phrases } \\
\end{array}$ \\
\hline & & & & $\begin{array}{l}\text { That's it. That's basically all they get. That is the most } \\
\text { horrifying thing I have ever seen parents go through." } \\
\text { "I just don't think it should be just the doctor coming } \\
\text { in and saying boom, you have cancer with no chance } \\
\text { to talk really. That's how it's going to be regardless. } \\
\text { It's going to be that big of a shock no matter how } \\
\text { many people are in the room regardless because if you } \\
\text { cover too much and you give them too much fear and } \\
\text { too much information. But the part that aggravates me } \\
\text { and what needs to be changed is that the doctor walks } \\
\text { out and then it sinks in and there's no one there to } \\
\text { explain until the doctor comes back and they have } \\
\text { fifteen million questions. " } \\
\text { "One of the things I read on low health literacy, you } \\
\text { can be very educated, but when it comes to medical } \\
\text { information, we just say things like list everything. } \\
\text { Throw it up all over the place. For some people this is } \\
\text { too much. I don't know how to recognize these } \\
\text { patients, Well I think we all can, but limit it to } 5 \text { things } \\
\text { or topics and say, 'These are the } 5 \text { things you need to } \\
\text { know to go home and be safe.' Mainly focus on the } \\
\text { five things so when they go home they have it } \\
\text { memorized." }\end{array}$ \\
\hline
\end{tabular}


Appendix N (Continued)

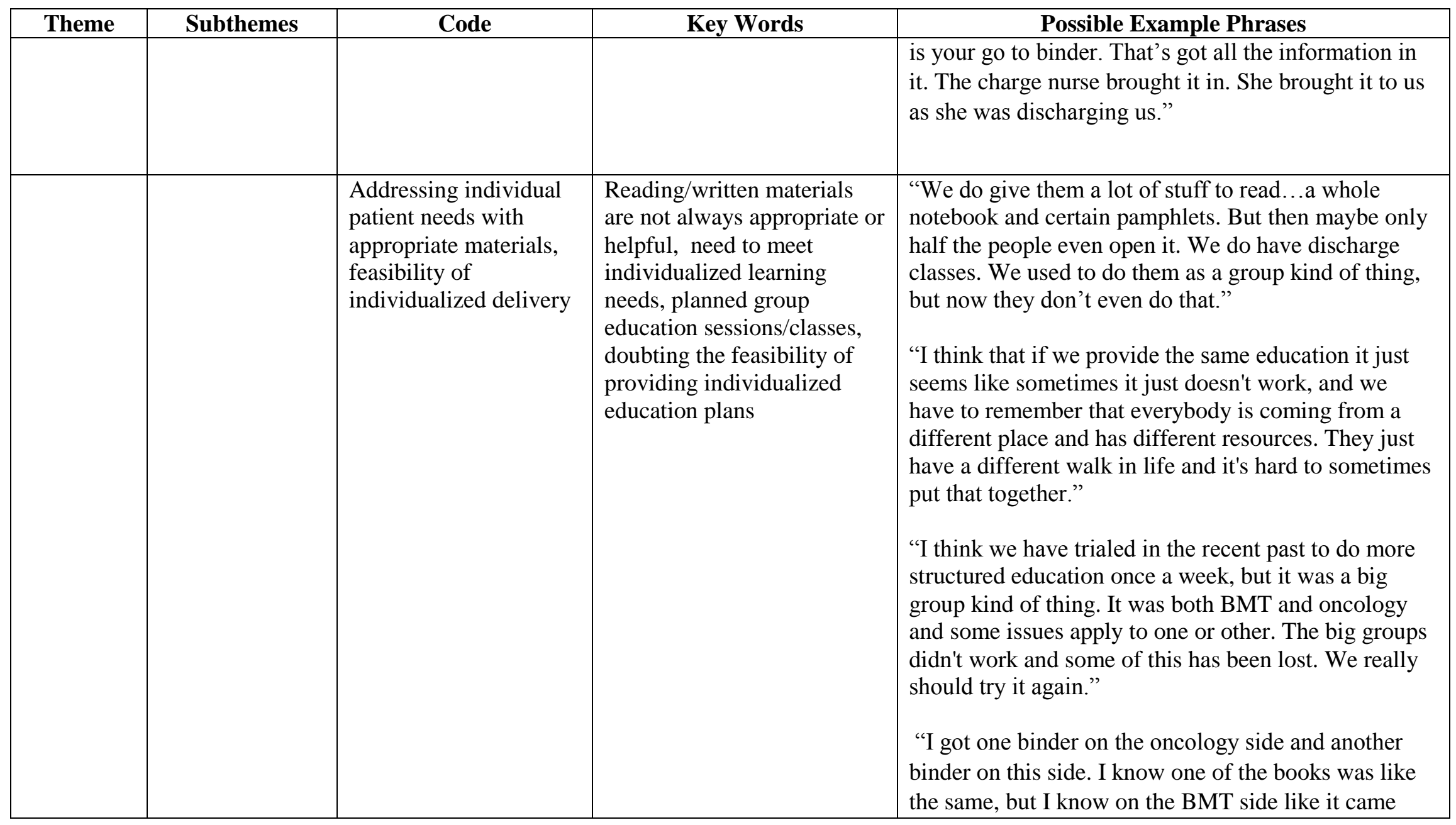


Appendix N (Continued)

\begin{tabular}{|c|c|c|c|c|}
\hline Theme & Subthemes & Code & Key Words & $\begin{array}{c}\text { Possible Example Phrases } \\
\end{array}$ \\
\hline & & & & $\begin{array}{l}\text { with tabs like for your labs, for your treatments, I love } \\
\text { that." } \\
\text { "I read a book that was really helpful and was just like } \\
\text { ok we have a plan, for me to figure out oh this is } \\
\text { what's going to happen, this is how your kid might } \\
\text { feel, and those kinds of things, that helped me." } \\
\text { "I think that when we had the classes it was such a big } \\
\text { patient satisfier. They loved it. Because they not only } \\
\text { loved the education, but they loved the interaction } \\
\text { with each other. So it was almost like you could have } \\
\text { some support stuff going on." } \\
\text { "Everything should be individualized, but you know I } \\
\text { don't know if number one, we have time to really } \\
\text { individualize everything." }\end{array}$ \\
\hline & $\begin{array}{l}\text { Providing } \\
\text { Information and } \\
\text { Sharing Support }\end{array}$ & $\begin{array}{l}\text { Facilitating proactive } \\
\text { behaviors through } \\
\text { support and } \\
\text { information sharing and } \\
\text { finding answers to the } \\
\text { unknown. }\end{array}$ & $\begin{array}{l}\text { Lack of school support and } \\
\text { transitions between } \\
\text { inpatient/outpatient stays } \\
\text { and school, school re-entry } \\
\text { at the end of treatment, long } \\
\text { term care clinics, worry } \\
\text { about future regarding long } \\
\text { term side effect } \\
\text { consequences and } \\
\text { management, desire to be }\end{array}$ & $\begin{array}{l}\text { "I wish we had a better grasp on school. Keeping up } \\
\text { with it and school re-entry. Yeah. Keeping up while in } \\
\text { the hospital and being able to go back and forth and to } \\
\text { help them adjust to the school. I think we do good } \\
\text { with what we have but I know there are other } \\
\text { programs that have school-based teachers inside the } \\
\text { hospital. So how far do our patients fall behind?" } \\
\text { "They're saying there's a chance she can't have kids. } \\
\text { You know, but I've heard of people that have had this }\end{array}$ \\
\hline
\end{tabular}


Appendix N (Continued)

\begin{tabular}{|l|l|l|l|l|}
\hline Theme & Subthemes & \multicolumn{1}{|c|}{ Code } & Key Words & \multicolumn{1}{c|}{ Possible Example Phrases } \\
\hline & & & proactive about the future & $\begin{array}{l}\text { type of thing and have had kids you know? If they did, } \\
\text { you know, are the kids okay? It's kind of like I guess } \\
\text { for me as a person, I'm a planner I like to know ahead, } \\
\text { even though it may not go according to plan." } \\
\text { "Would be nice to kind of know what kind of thing } \\
\text { parents or even the child themselves, I mean if they're } \\
\text { of age that time, if there's anything they've run into } \\
\text { that they've had issues with if it's something that we } \\
\text { can be proactive about. You know what I mean? Like } \\
\text { being that there's a chance she could even develop } \\
\text { breast cancer, for example, if you're 30 now, are you } \\
\text { doing mammograms now? Or have you done them } \\
\text { ever since you were 20 something?" }\end{array}$ \\
\hline
\end{tabular}




\section{Appendix $\mathrm{O}$}

Coding Guide: Patient/Family Obstacles

\begin{tabular}{|c|c|c|c|c|}
\hline Theme & Subthemes & Code & Key Words & Possible Example Phrases \\
\hline \multirow[t]{2}{*}{$\begin{array}{l}\text { Patient/ } \\
\text { Family } \\
\text { Obstacles }\end{array}$} & Family Stress at Home & $\begin{array}{l}\text { Discordant } \\
\text { family dynamics, } \\
\text { amplified stress }\end{array}$ & $\begin{array}{l}\text { Single parenting, divorce: } \\
\text { amicable versus not-adding } \\
\text { to the existing stress, } \\
\text { discordant family dynamics } \\
\text { can amplify stress, } \\
\text { disconnectedness, step- } \\
\text { parents in the picture, } \\
\text { importance of individualized } \\
\text { psychosocial assessment of } \\
\text { family dynamics }\end{array}$ & $\begin{array}{l}\text { "I think divorced families are probably the hardest. } \\
\text { Especially if they don't get along." } \\
\text { "Mom and dad are going through a divorce. Do you } \\
\text { know what I mean? It could be whatever. It just adds } \\
\text { to the stress. } \\
\text { PI: That the parent unit is not a cohesive team, and } \\
\text { they can be distracted from this? } \\
\text { S: Yes because there are already family dynamics } \\
\text { going on. I think that is a huge factor. They can't } \\
\text { focus on this because of outside things. Step mom } \\
\text { coming to visit. Other stress." } \\
\text { "I think all of those psychosocial factors can } \\
\text { contribute to stress depending on... it's kind of like } \\
\text { where the family is and their pre-existing kind of } \\
\text { world views: stability, resources, language, culture, } \\
\text { travel. All of those factors and the more that it } \\
\text { depends on how the family sees them, but if there is a } \\
\text { recent divorce or separation, any kind of other } \\
\text { psychosocial stressors that exist before the diagnosis } \\
\text { are going to be amplified by the additional stress on } \\
\text { the family." }\end{array}$ \\
\hline & Financial Instability & $\begin{array}{l}\text { Financial } \\
\text { instability, } \\
\text { seeking } \\
\text { information on } \\
\text { how to make }\end{array}$ & $\begin{array}{l}\text { Loss of employment, } \\
\text { socioeconomic status } \\
\text { prevents access to } \\
\text { governmental assistance, } \\
\text { loss of financial stability, }\end{array}$ & $\begin{array}{l}\text { "One parent almost always has to quit their job." } \\
\text { "The out of pocket expenses and the fact that they } \\
\text { have to be at the institution for several months you } \\
\text { know, 2-3 months at a time and that can provide a lot }\end{array}$ \\
\hline
\end{tabular}




\section{Appendix O (Continued)}

\begin{tabular}{|c|c|c|c|c|}
\hline Theme & Subthemes & Code & Key Words & $\begin{array}{c}\text { Possible Example Phrases } \\
\end{array}$ \\
\hline & & $\begin{array}{l}\text { decisions } \\
\text { regarding } \\
\text { resources }\end{array}$ & $\begin{array}{l}\text { seeking advice and } \\
\text { information on how to make } \\
\text { decisions about this, } \\
\text { restrictions of FMLA }\end{array}$ & $\begin{array}{l}\text { of stress. Someone might be out of work to be a } \\
\text { primary caregiver is a big deal." } \\
\text { "I think when they're in that middle class, the social } \\
\text { middle class, they have more stress because they } \\
\text { don't qualify for Medicaid. So they don't get help for } \\
\text { copays. They have to work things out like getting } \\
\text { prescriptions two weeks in advance." } \\
\text { "The families who seem to be stable and thought they } \\
\text { had benefits, and then when you hit them with } \\
\text { something this traumatic, they are like what do we do } \\
\text { now? One of us has to quit working, but if I quit we } \\
\text { can no longer afford what we could afford before. So } \\
\text { that's a big question that I get asked all the time from } \\
\text { families where both parents work. What do other } \\
\text { patients do in this situation? Do they quit their job or } \\
\text { keep working? I usually tell them you have to look at } \\
\text { your situation, and what is your work allowing. If } \\
\text { you quit your job would you have a job to go back to } \\
\text { in a year or two? Our goal is cure, and in a year or } \\
\text { two this is going to be a lot less than what it is now. } \\
\text { Who's going to support your kids? What's your plan } \\
\text { B?" } \\
\text { "I did use up a lot of my time and FMLA and stuff. } \\
\text { So the beginning when I got all the help I technically } \\
\text { didn't need it as much it wasn't until after I ran out of }\end{array}$ \\
\hline
\end{tabular}


Appendix O (Continued)

\begin{tabular}{|c|c|c|c|c|}
\hline Theme & Subthemes & Code & Key Words & Possible Example Phrases \\
\hline & & & & time and I wasn’t getting paid.” \\
\hline & $\begin{array}{l}\text { Disconnectedness, } \\
\text { Entrapment and } \\
\text { Isolation }\end{array}$ & $\begin{array}{l}\text { Being alone, } \\
\text { disconnectedness } \\
\text { from others, } \\
\text { trapped in } \\
\text { patient's hospital } \\
\text { room, parent } \\
\text { perception of } \\
\text { lack of support } \\
\text { and } \\
\text { individualized } \\
\text { education } \\
\text { through } \\
\text { transitions of } \\
\text { care }\end{array}$ & $\begin{array}{l}\text { Single parenting, no } \\
\text { assistance from staff, lack of } \\
\text { other parental figure } \\
\text { support, making medical } \\
\text { decisions alone, no other } \\
\text { family going through this, } \\
\text { isolation and being scared, } \\
\text { feeling of being trapped, no } \\
\text { escape, feeling alone, no one } \\
\text { else can relate to the } \\
\text { situation?, thoughts are } \\
\text { consumed with child's } \\
\text { situation, disconnect } \\
\text { between health care } \\
\text { professionals and the } \\
\text { parent's need for help, lack } \\
\text { of support while moving } \\
\text { between phases of } \\
\text { treatment, feeling } \\
\text { abandoned through } \\
\text { transitions of treatment }\end{array}$ & $\begin{array}{l}\text { "I just started going through this scared period of } \\
\text { course being a single mom, I mean their dad's around } \\
\text { and we do have the time with them just kind of } \\
\text { thinking am I going to have to go through this by } \\
\text { myself." } \\
\text { "Yeah I think a lot of it is just, obviously being a } \\
\text { single mom, the help that I need so that I can go to } \\
\text { work." } \\
\text { "Because I'm divorced my ex wasn't really, putting } \\
\text { in as much time, but I don't know if it was more that } \\
\text { I didn't want him to because I know how he is with } \\
\text { things." } \\
\text { "So I guess he's stressed about it, but I tell him you } \\
\text { don't have to think about it all day long. I'm actually } \\
\text { here and she's sick. There's no getting away from } \\
\text { here. I said if you're going to work you're working } \\
\text { on other things, like maybe when you get off you } \\
\text { think about it. I said it's constantly on my mind. } \\
\text { There's no out. I said there's no distraction here." } \\
\text { "Parents feel alone in this sea about nobody else's kid } \\
\text { has cancer." }\end{array}$ \\
\hline
\end{tabular}


Appendix O (Continued)

\begin{tabular}{|c|c|c|c|c|}
\hline Theme & Subthemes & Code & Key Words & $\begin{array}{c}\text { Possible Example Phrases } \\
\end{array}$ \\
\hline & & & & $\begin{array}{l}\text { "Even with my sisters, they know I'm alone and } \\
\text { they'll invite me to dinner and stuff, but I don't } \\
\text { always go because I feel like I'm intruding in their } \\
\text { family time. Because I'm alone." } \\
\text { "But because I didn't and I don't have that support, I } \\
\text { felt like that's what pushed me to fall out of love and } \\
\text { felt like I was all alone and I just didn't want to be, I } \\
\text { was unhappy." } \\
\text { "They would just handle outside stuff. I felt really } \\
\text { alone on making decisions; I would rely on his } \\
\text { doctor." } \\
\text { "You know you try to keep yourself busy, but really } \\
\text { there's nobody else here. It's just you and maybe the } \\
\text { nurse every once in a while, and they come in and } \\
\text { then it's just you and your child." } \\
\text { "Someone who does the support, and education, and } \\
\text { the follow ups. You're going into this part of } \\
\text { treatment. This is what's going to happen. I think it } \\
\text { could reduce the number of visits to the clinic and } \\
\text { reduces the stay at the hospital. It's very different for } \\
\text { the transition from frontline to maintenance." } \\
\text { "You don't have an educator person. You have a } \\
\text { nurse, who's on her } 12 \text { hour shift and has three other } \\
\text { patients. So I think it's harder when you don't have }\end{array}$ \\
\hline
\end{tabular}


Appendix O (Continued)

\begin{tabular}{|c|c|c|c|c|}
\hline Theme & Subthemes & Code & Key Words & Possible Example Phrases \\
\hline & & & & $\begin{array}{l}\text { that person and you have a rushed nurse instead. } \\
\text { Someone who's trying to get through this book and } \\
\text { tell you all this information, so she can tell her next } \\
\text { shift person she did the education." }\end{array}$ \\
\hline & $\begin{array}{l}\text { Lack of meaningfulness } \\
\text { of social service } \\
\text { provision }\end{array}$ & & $\begin{array}{l}\text { Trust, no one to answer } \\
\text { questions, not enough social } \\
\text { support, lack of instructions } \\
\text { or links to services, } \\
\text { variations in the quality of } \\
\text { social work support } \\
\text { provided, negative } \\
\text { perception of value } \\
\text { regarding social worker's } \\
\text { role due to the minutia, lack } \\
\text { of consistent sibling support, } \\
\text { anger at the system (lack of } \\
\text { resources for those not } \\
\text { eligible for government } \\
\text { assistance), social worker } \\
\text { role does not include follow } \\
\text { up after diagnosis period, } \\
\text { fighting for resources, } \\
\text { inequitable resource } \\
\text { offering, parking and food } \\
\text { access are consistently } \\
\text { problematic }\end{array}$ & $\begin{array}{l}\text { "We do have a social worker and a case manager and } \\
\text { I'd say most of them are running around with } \\
\text { minutia. Where are your meal tickets? Did you fill } \\
\text { out the forms for your work and insurance? You } \\
\text { know? Things that get you through the hospital stay. } \\
\text { Get your care going." } \\
\text { "A lot of them say they want more sibling support." } \\
\text { "I've had families that were very angry when they } \\
\text { found out there wasn't as much social support as they } \\
\text { would like. 'Why can't you apply for Medicaid for } \\
\text { me? You mean to tell me there's no resource to pay } \\
\text { my bills while I'm here?" } \\
\text { "If a social worker gets word they need something } \\
\text { then we address it, but it's like putting out fires more } \\
\text { sometimes than being able to help maintain. } \\
\text { PI: I wanted to ask you about that. So you're not } \\
\text { following up regularly then? } \\
\text { S: Unless they have a concern or something we need } \\
\text { to address than yeah it's only if we need to address it } \\
\text { or if we're notified about it." }\end{array}$ \\
\hline
\end{tabular}


Appendix O (Continued)

\begin{tabular}{|c|c|c|c|c|}
\hline Theme & Subthemes & Code & Key Words & Possible Example Phrases \\
\hline & & & & $\begin{array}{l}\text { "In the beginning I feel like they kind of get you } \\
\text { started, but then it's just you have to fight for your } \\
\text { own, once you jump in. Like I said, after that first } \\
\text { time you're like on your own. I know from a stand } \\
\text { point of that there's people coming in from Mexico, } \\
\text { they don't get some of the stuff and like for } \\
\text { insurance, like the Medicaid stuff the hospital helped } \\
\text { us with. I had to fight a lot for that stuff. I can't } \\
\text { imagine somebody never educated would get that." } \\
\text { "I heard someone say that some family just walked in } \\
\text { and was getting all the benefits possible, and I was } \\
\text { wondering why they didn't do that for us? You know } \\
\text { like why weren't we asked if we needed hotel } \\
\text { accommodations? Why weren't we given free food } \\
\text { vouchers, and free parking?" } \\
\text { "That's just the thing. No one told us or tells the } \\
\text { office, and we didn't know. We only saw our social } \\
\text { worker one time. The parking thing was one thing } \\
\text { and the meals were another. We had friends that } \\
\text { helped, but the meals were the most expensive parts } \\
\text { of our stays. It may seem like simple things but it's } \\
\text { every day, every day." } \\
\text { "No one ever asks you. 'Notice this is a mom by } \\
\text { herself, she's stayed here over night she's going to }\end{array}$ \\
\hline
\end{tabular}




\section{Appendix O (Continued)}

\begin{tabular}{|c|c|c|c|c|}
\hline Theme & Subthemes & Code & Key Words & Possible Example Phrases \\
\hline & & & & $\begin{array}{l}\text { want some breakfast right?' I always ask my moms, } \\
\text { 'Have you eaten today? When did you eat? Did you } \\
\text { take a shower? Ok you need to go rest and take a } \\
\text { shower. I'm going to watch the baby." }\end{array}$ \\
\hline & $\begin{array}{l}\text { Stigmatization of } \\
\text { "Support" }\end{array}$ & $\begin{array}{l}\text { Negative } \\
\text { connotation of } \\
\text { outside support } \\
\text { or help, denial of } \\
\text { need }\end{array}$ & $\begin{array}{l}\text { Feeling they don't need } \\
\text { help, "Support Group" is not } \\
\text { a positive word, too proud, } \\
\text { stigmatizing the term } \\
\text { "support", refusing help } \\
\text { when offered, }\end{array}$ & $\begin{array}{l}\text { "Some people are off put by that, but they feel like } \\
\text { 'Well everybody thinks we are having problems as a } \\
\text { couple, but you know it is stressful on couples." } \\
\text { "Yeah, so maybe if it was called something different, } \\
\text { because when I think of meeting I think we're going } \\
\text { to sit in a row and somebody is going to be speaking } \\
\text { in the middle. I think like support groups where you } \\
\text { can just sit and talk with other people." } \\
\text { "You know we were lucky enough to have people } \\
\text { help us but, um, some people don't like asking for } \\
\text { help, they just don't." }\end{array}$ \\
\hline & Cultural Barriers & $\begin{array}{l}\text { Culture, } \\
\text { language } \\
\text { barriers, } \\
\text { immigration } \\
\text { status, deference } \\
\text { to physician's } \\
\text { influence for } \\
\text { decision making }\end{array}$ & $\begin{array}{l}\text { Can't speak the language, } \\
\text { lack of accurate translation } \\
\text { services, access to care } \\
\text { related to immigration } \\
\text { status, different belief } \\
\text { system allowing for } \\
\text { physician to make decisions } \\
\text { based on trust in the } \\
\text { physician's knowledge, gaps }\end{array}$ & $\begin{array}{l}\text { "Then the resources that are available to people of } \\
\text { illegal status are limited or if they are available we } \\
\text { have health insurance for kids without status, but } \\
\text { there is a wait list, and then they are on a wait list for } \\
6 \text { months to a year." } \\
\text { "I think it affects the care they receive once they } \\
\text { leave the hospital. There may be some things they get } \\
\text { from nurses that speak Spanish and then they may go }\end{array}$ \\
\hline
\end{tabular}


Appendix O (Continued)

\begin{tabular}{|l|l|l|l|}
\hline Theme & Subthemes & \multicolumn{1}{|c|}{ Code } & \multicolumn{1}{c|}{ Possible Example Phrases } \\
\hline & & $\begin{array}{l}\text { in mutual understanding of } \\
\text { important information about } \\
\text { patient status }\end{array}$ & $\begin{array}{l}\text { a shift or two, 'Oh, we understand each other even } \\
\text { though they speak English. We understand each } \\
\text { other. They might understand 75\% enough to get by, } \\
\text { but not enough to retain any of the info you give } \\
\text { them and to follow up phone calls to communicate. } \\
\text { Like I'm calling in because my child whatever, but } \\
\text { the other person on the other end of the line doesn't } \\
\text { speak Spanish. So how am I supposed to talk to that } \\
\text { person? You got all my questions answered or do I } \\
\text { come in or not? Did I say it the way I was supposed } \\
\text { to and did they understand?" }\end{array}$ \\
& & $\begin{array}{l}\text { "I think that for the most part, their view, their ethnic } \\
\text { ackground, maybe their culture, that they are more } \\
\text { comfortable with letting the doctor make decisions. I } \\
\text { think a lot of our Hispanic families are very trusting } \\
\text { of us and most of them try to go with the flow of the } \\
\text { treatment and just sort of trust us blindly. Sometimes } \\
\text { that may be even more frustrating because you want } \\
\text { them to be more engaged." }\end{array}$ \\
& & & \\
& & &
\end{tabular}




\section{Appendix P}

\section{Coding Guide: Breaking Through Institutional Culture}

\begin{tabular}{|c|c|c|c|c|}
\hline Theme & Subthemes & Code & Key Words & Possible Example Phrases \\
\hline $\begin{array}{l}\text { Breaking } \\
\text { Through } \\
\text { Institutional } \\
\text { Culture }\end{array}$ & $\begin{array}{l}\text { Policy and } \\
\text { Institutional } \\
\text { Culture }\end{array}$ & $\begin{array}{l}\text { Incongruences of } \\
\text { practices and policies } \\
\text { among hospital and } \\
\text { private practice clinic } \\
\text { settings. }\end{array}$ & $\begin{array}{l}\text { Recognition of the Program/ } \\
\text { Unit, separation of the } \\
\text { programs, } \\
\text { access to all program resources, } \\
\text { equality of BMT and Hem/Onc } \\
\text { programs, separation of } \\
\text { physician care }\end{array}$ & $\begin{array}{l}\text { "I think it's time and money to be honest with } \\
\text { you. They're trying to do this. They're funded by } \\
\text { this program so they will only see these } \\
\text { patients." } \\
\text { "The BMT program hired her (the counselor). } \\
\text { She was hired specifically for that program." } \\
\text { "Especially for patients that are not under the } \\
\text { pedi-specialty physicians, like Dr. X. His } \\
\text { patients, we've been meaning to talk to his } \\
\text { office, I assume the nursing office he has there } \\
\text { does some of it, but I don't think he has a social } \\
\text { worker there. So how do they maintain and help } \\
\text { their patients out? What we usually tell patients } \\
\text { when they discharge, is if you need something } \\
\text { please tell us, because we don't see you. It's not } \\
\text { purposeful, but you're over there and we don't } \\
\text { go there. How do they do school re-entry and } \\
\text { like who keeps up with that?" }\end{array}$ \\
\hline
\end{tabular}


Appendix P (Continued)

\begin{tabular}{|c|c|c|c|c|}
\hline Theme & Subthemes & Code & Key Words & $\begin{array}{c}\text { Possible Example Phrases } \\
\end{array}$ \\
\hline & $\begin{array}{l}\text { Policy and } \\
\text { Institutional } \\
\text { Culture } \\
\text { Home-grown } \\
\text { Management } \\
\text { Experience }\end{array}$ & $\begin{array}{l}\text { Lack of accreditation } \\
\text { standards and advocacy }\end{array}$ & $\begin{array}{l}\text { Lack of accreditation standards } \\
\text { for Hem/Onc programs; } \\
\text { minimum standards in place not } \\
\text { allowing advocacy for meeting } \\
\text { patient/family needs; }\end{array}$ & $\begin{array}{l}\text { "It is true that the bone marrow program has } \\
\text { more support, but that is really only because in } \\
\text { order for us to continue the program we have to } \\
\text { maintain our FACT accreditation and it (a } \\
\text { psychologist) is now required. We can't } \\
\text { continue our accreditation if we don't meet all } \\
\text { these standards which are based on the research } \\
\text { and outcomes. Unfortunately there is no } \\
\text { accrediting body for Hem/Onc programs like } \\
\text { there is for bone marrow programs." } \\
\text { "We're lucky that in BMT we have so many } \\
\text { regulations including, 'This is the way it has to } \\
\text { be done.' So it helps advocate. Because it's } \\
\text { regulations, but there's not the same kind of } \\
\text { model on the oncology side. It's a little more } \\
\text { varied." }\end{array}$ \\
\hline & & Education not a priority & $\begin{array}{l}\text { Education not a priority of care; } \\
\text { passing the buck-lack of } \\
\text { ownership for education } \\
\text { responsibilities }\end{array}$ & $\begin{array}{l}\text { "You know nurses are so busy and they're so } \\
\text { rushed. There are a lot of variations that can } \\
\text { slow them down. It (referring to education) just } \\
\text { doesn't happen, or at least doesn't happen } \\
\text { thoroughly." } \\
\text { "The nurse says I don't have to do it because the } \\
\text { BMT coordinator did it. Then when the } \\
\text { coordinator doesn't do that job it's the day the } \\
\text { patient is leaving and there's no education that's } \\
\text { done." }\end{array}$ \\
\hline
\end{tabular}




\section{Appendix P (Continued)}

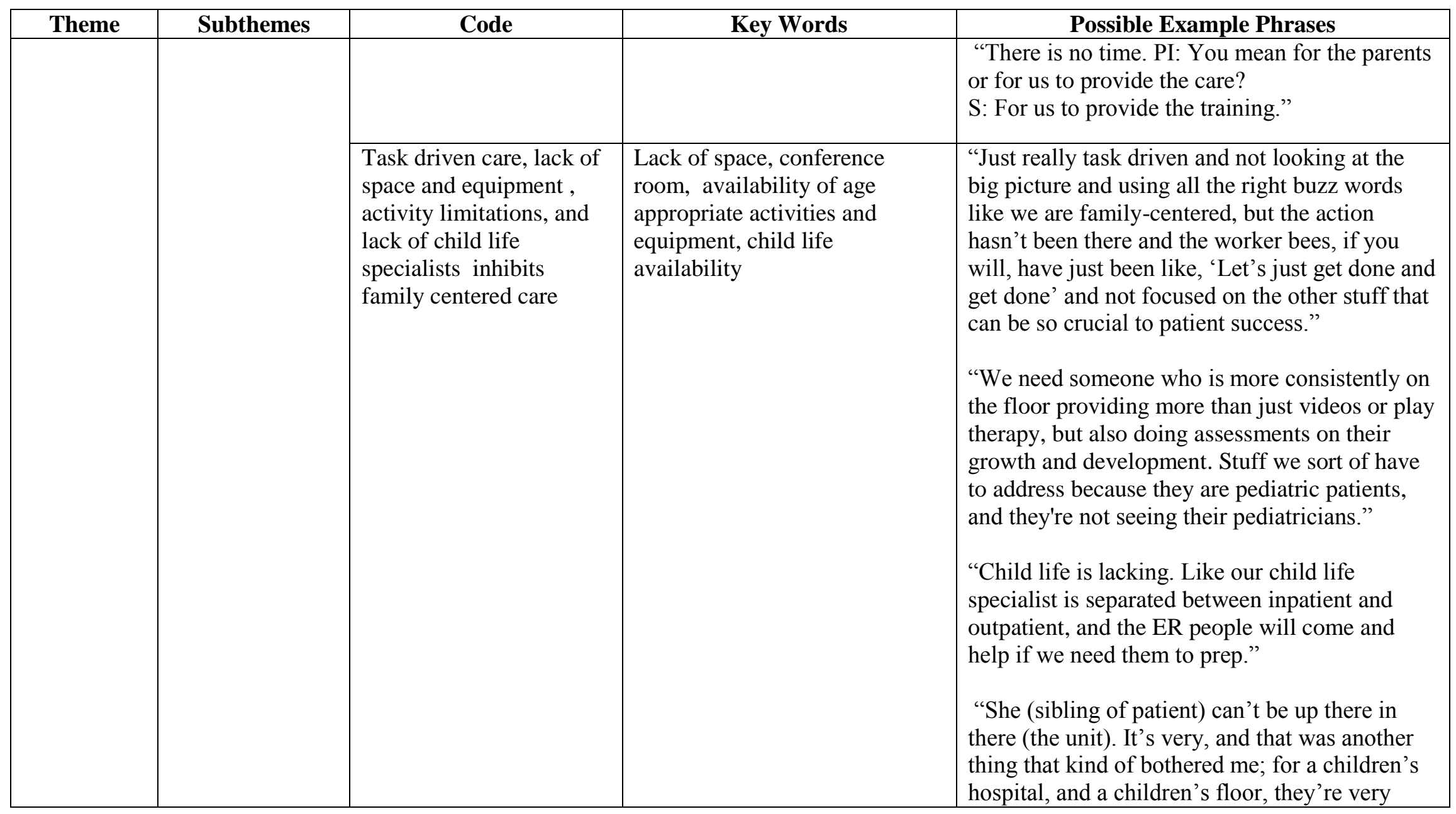


Appendix P (Continued)

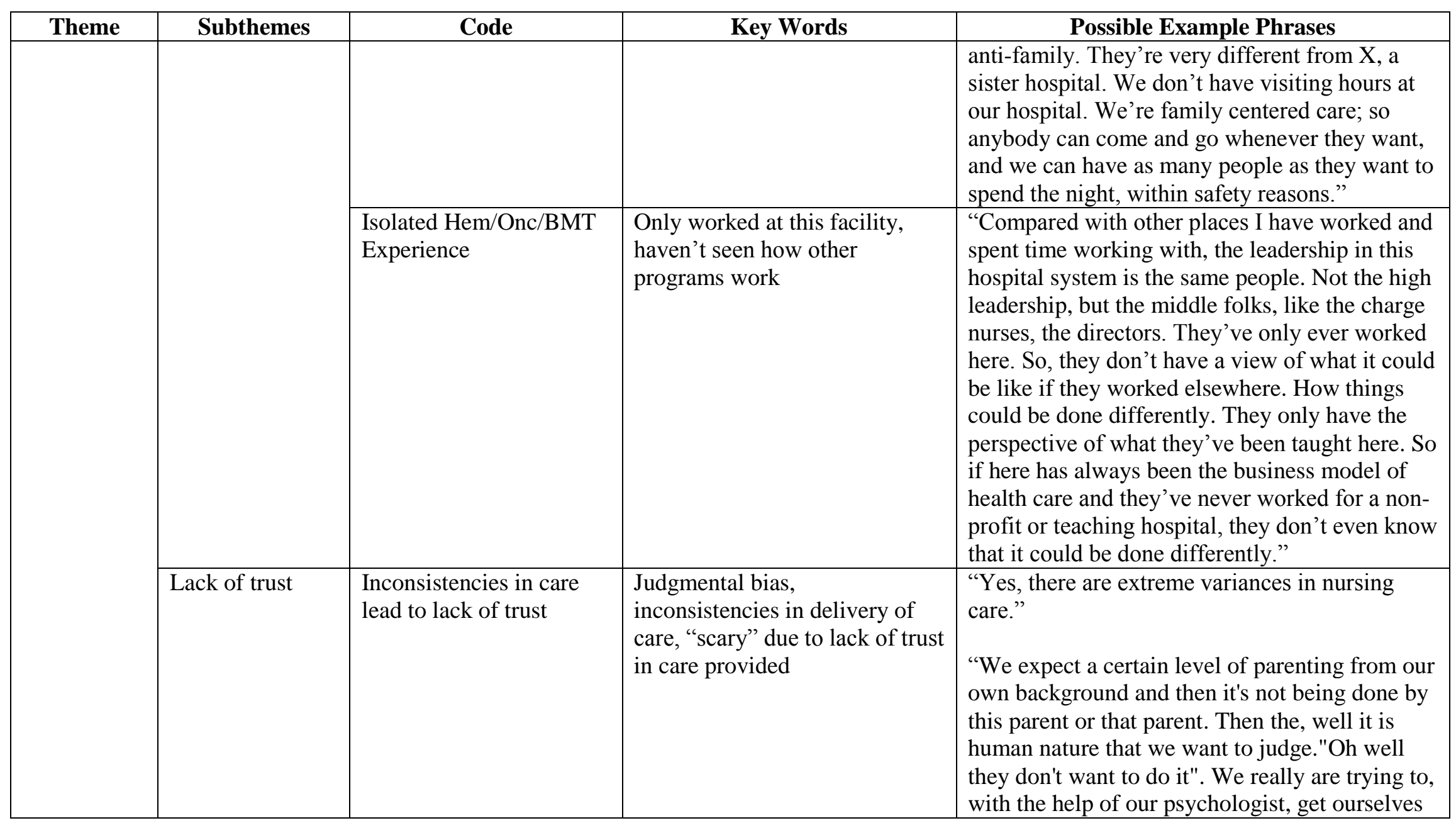


Appendix P (Continued)

\begin{tabular}{|c|c|c|c|c|}
\hline Theme & Subthemes & Code & Key Words & Possible Example Phrases \\
\hline & & & & $\begin{array}{l}\text { out of that equation because I don't think that } \\
\text { really helps." } \\
\text { "PI: Parents are saying they feel like they need } \\
\text { to come back and verify everything with my } \\
\text { doctor. } \\
\text { S: Yes they do. They ask me everything. They } \\
\text { do ask a lot to verify. I feel bad though because } \\
\text { we don't want them to have to ask and lose trust } \\
\text { in their nurses. They need to have 100\% } \\
\text { confidence in their nursing staff and this } \\
\text { undermines that." } \\
\text { "The care plan in the computer is such a robotic } \\
\text { thing that we just fill in. I'm sorry to say that it } \\
\text { is true. You know what your plan of care is, but } \\
\text { the way the system is set up now it is a must and } \\
\text { a requirement and it just gets done. If you don't } \\
\text { do it you aren't doing your job and you get in } \\
\text { trouble. That education sheet is just a sheet. It is } \\
\text { a task; it's not your care, and therefore it's } \\
\text { worthless." } \\
\text { "Sometimes it was scary. You know, depending } \\
\text { on what nurse you got, you know the ones you } \\
\text { could trust and the ones you couldn't." } \\
\text { "There could be any kind of education where }\end{array}$ \\
\hline
\end{tabular}


Appendix P (Continued)

\begin{tabular}{|c|c|c|c|c|}
\hline Theme & Subthemes & Code & Key Words & Possible Example Phrases \\
\hline & & & & $\begin{array}{l}\text { they thought information was being passed } \\
\text { down and they say, 'Well, I thought you did } \\
\text { that.' and another says, 'I thought you did.' } \\
\text { 'You ordered this med and it was supposed to be } \\
\text { this one' and the protocol hasn't been followed } \\
\text { correctly. It is interesting because now we all } \\
\text { have cell phones and we are instantly available, } \\
\text { but it is all worse than it could be better. I don't } \\
\text { know if there are more patients or more people } \\
\text { involved, or just doing way more than they used } \\
\text { to do. It's interesting that communication is } \\
\text { easier than ever, but yet we still struggle with it } \\
\text { so much." } \\
\text { Every single admission is different. Every single } \\
\text { nurse educates differently. Every single nurse } \\
\text { cleans the hubs differently." }\end{array}$ \\
\hline & $\begin{array}{l}\text { Interdisciplinary } \\
\text { collaboration: } \\
\text { An evolving } \\
\text { Model }\end{array}$ & $\begin{array}{l}\text { Evolving } \\
\text { interdisciplinary work, } \\
\text { changing culture }\end{array}$ & $\begin{array}{l}\text { Evolving model of effective } \\
\text { interdisciplinary team with } \\
\text { continuing resistance from } \\
\text { institutional culture; need to } \\
\text { eliminate passivity; lack of } \\
\text { team focus, interdisciplinary } \\
\text { medical model focus }\end{array}$ & $\begin{array}{l}\text { "I think (we have a functioning interdisciplinary } \\
\text { team) so now, but it is in the infancy stages. So } \\
\text { it's with our new psychologist, a new social } \\
\text { worker, and new art therapist, because of high } \\
\text { turnover and there was this whole team of new } \\
\text { people who wanted to sit down and say, 'Who } \\
\text { are we and how do we work together?' Now } \\
\text { they have planning and we are starting to see the } \\
\text { fruition of that labor. We are starting to see how } \\
\text { they are working together for patients." }\end{array}$ \\
\hline
\end{tabular}




\section{Appendix P (Continued)}

\begin{tabular}{|c|c|c|c|c|}
\hline Theme & Subthemes & Code & Key Words & Possible Example Phrases \\
\hline & & & & $\begin{array}{l}\text { "I think again we've had a culture where that } \\
\text { expectation was not present, but now my } \\
\text { feelings and thoughts are that everyone who is a } \\
\text { teammate or member must contribute } \\
\text { something. My expectations are very high out of } \\
\text { myself and everyone else. I hope I can model } \\
\text { that, and change that culture where everyone is } \\
\text { passive." } \\
\text { "We don't have a multidisciplinary concept per } \\
\text { say. We do try to talk about some of the more } \\
\text { challenging out-patient cases in tracking once a } \\
\text { week. This is where we will discuss some of the } \\
\text { chronic kids, or the kids that have reached end- } \\
\text { of- life issues and try to get feedback from the } \\
\text { team members in a group setting." } \\
\text { "I would have told you three months ago, 'No } \\
\text { our team is very broken', but what you are } \\
\text { asking today, it's not there yet, but it will be } \\
\text { soon. Because they are meeting every week } \\
\text { regularly, and we are now doing these } \\
\text { subcommittees and take a psychosocial issue to } \\
\text { work on together. This all came out of the } \\
\text { psychosocial team meetings." } \\
\text { "There's never been the support to say, even }\end{array}$ \\
\hline
\end{tabular}




\section{Appendix P (Continued)}

\begin{tabular}{|c|c|c|c|c|}
\hline Theme & Subthemes & Code & Key Words & Possible Example Phrases \\
\hline & & & & $\begin{array}{l}\text { internally, to recognize and say, 'Hey, there's } \\
\text { really a different way to do this.' Or what a big } \\
\text { part of the team they (members of the } \\
\text { psychosocial team) are and including them and } \\
\text { keeping them up to date on what's going on and } \\
\text { how they can help." } \\
\text { "I was just going to say that another barrier is } \\
\text { that the shift in health care overall has been } \\
\text { incorporating more psychosocial support and } \\
\text { more integration of the whole person. Whereas, } \\
\text { before the approach was 100\% medical. Just } \\
\text { focusing on the medication part and the body } \\
\text { and healing with that. During that transition I } \\
\text { think some are on board and some are not. There } \\
\text { is a gap there. It doesn't allow for the whole } \\
\text { psychosocial team to provide that support } \\
\text { equally or to balance it with the impact of the } \\
\text { traditional approach of medication." }\end{array}$ \\
\hline & & $\begin{array}{l}\text { Power Differentials } \\
\text { contributing to gaps in } \\
\text { patient care }\end{array}$ & $\begin{array}{l}\text { Power Hierarchy, deference to } \\
\text { medical model and physicians, } \\
\text { access to patients, waiting on } \\
\text { physicians to request } \\
\text { psychosocial consultation. }\end{array}$ & $\begin{array}{l}\text { "The doctors do make the diagnosis and I get } \\
\text { that, but we aren't idiots, and they shouldn't feel } \\
\text { like, 'Oh gosh! We (nursing or psychosocial } \\
\text { team) can't talk to them (parents/patients) about } \\
\text { it.' } \\
\text { PI: "Do you think that they really feel that way? } \\
\text { That we shouldn't talk to them about it? Or is }\end{array}$ \\
\hline
\end{tabular}


Appendix P (Continued)

\begin{tabular}{|l|l|l|l|}
\hline Theme & Subthemes & \multicolumn{1}{|c|}{ Code } & \multicolumn{1}{|c|}{ Possible Example Phrases } \\
\hline & & & $\begin{array}{l}\text { Key Words } \\
\text { that just our perception? } \\
\text { S: Maybe it is just our perception. I mean I think } \\
\text { there are doctors that have treated nurses like } \\
\text { that in the past, but maybe now it is more of our } \\
\text { perception too. We could always clarify with the } \\
\text { doc about saying, 'They are asking a lot of } \\
\text { questions and can I talk with them about it? I } \\
\text { know you haven't diagnosed, but can I explain } \\
\text { to them a little? You know?" }\end{array}$ \\
& $\begin{array}{l}\text { "A lot of the communication comes from the } \\
\text { doctors. So, yeah, we have to follow the doctors' } \\
\text { leads. If they don't want to discuss a diagnosis at } \\
\text { this particular time then we wait for him to start } \\
\text { the conversation. We wait for him to invite us in } \\
\text { the room to be present. } \\
\text { PI: Ok. So you don't have as much access to } \\
\text { patients without others opening doors? } \\
\text { S: or we don't necessarily know what's going on } \\
\text { until it is already happened. } \\
\text { PI: Do you guys have team meetings with the } \\
\text { physician groups and rounds? } \\
\text { S: Yes, but we talk about medical stuff, not } \\
\text { pyscho-social stuff and it doesn't get addressed." }\end{array}$ \\
& &
\end{tabular}




\section{BIOGRAPHICAL SKETCH}

Provide the following information for the Senior/key personnel and other significant contributors in the order listed on Form Page 2.

Follow this format for each person. DO NOT EXCEED FOUR PAGES.

\begin{tabular}{l|l}
\hline $\begin{array}{l}\text { NAME } \\
\text { Martha Danielle Gunter }\end{array}$ & $\begin{array}{l}\text { POSITION TITLE } \\
\text { Nursing Faculty }\end{array}$ \\
\cline { 1 - 1 } $\begin{array}{l}\text { eRA COMMONS USER NAME (credential, e.g., agency } \\
\text { login) }\end{array}$ & \\
\hline
\end{tabular}

EDUCATION/TRAINING (Begin with baccalaureate or other initial professional education, such as nursing, include postdoctoral training and residency training if applicable.)

\begin{tabular}{l|c|c|c}
\hline \multicolumn{1}{c|}{ INSTITUTION AND LOCATION } & $\begin{array}{c}\text { DEGREE } \\
\text { (if applicable) }\end{array}$ & MM/YY & FIELD OF STUDY \\
\hline $\begin{array}{l}\text { 1. University of Memphis, Memphis, TN } \\
\text { BSN }\end{array}$ & $12 / 02$ & Nursing \\
$\begin{array}{l}\text { 2. The University of the Incarnate Word, } \\
\text { San Antonio, TX }\end{array}$ & $\mathrm{MSN}$ & $12 / 2007$ & Nursing/CNL \\
$\begin{array}{l}\text { 3. The University of Texas at Tyler, Tyler, TX } \\
\text { ThD(c) }\end{array}$ & $12 / 2014$ & Nursing
\end{tabular}

Please refer to the application instructions in order to complete sections A, B, C, and D of the Biographical Sketch.

\section{A. Personal Statement}

I have been a Pediatric Hem/Onc/BMT nurse for almost 10 years. I am passionate about caring for these patients and families. One thing I have always found frustrating is the struggles families deal with as they adjust to the new diagnosis and try to maintain some sense of normalcy. I have seen families barely hold it together through a child's treatment only to have parents divorce a few months after treatment has ended. It is obviously a strain on them. I hate seeing families struggle so much without a break. I have always tried to help parents adjust to this as quickly as possible so that hopefully their family can return back to as close to normal as possible. Another struggle I have faced in my practice in south Texas is that of language barriers. In a field where personal connection with your healthcare team is so crucial why have we not found a way to help patients that don't speak the language access the resources necessary and build the same community and relationships that their English speaking peers are able to do? This proposed study is actually a follow up to my dissertation study and will provide substantially more information to help tailor a program that will address these concerns. It is the first of many studies 
Biographical Sketch (Continued)

on this topic: finding a way to help families adapt quicker and better, and bridging the communication gap between the healthcare team and our patients/families. The available resources at my academic institution, my continued relationships within the healthcare facility and my education will help me develop this lifelong program of research.

\section{B. Positions and Honors}

St. Jude Children's Research Hospital, Memphis, TN_BMT Unit Staff Nurse: 2002-2003

Methodist Children's Hospital, San Antonio, TX- Hem/Onc/BMT Unit Staff and Charge Nurse: 2003-2005

Methodist Children's Hospital, San Antonio, TX-Hem/Onc/BMT Unit Assistant Nurse Manager: 2005-2007

The University of the Incarnate Word, San Antonio, TX-Ila Faye Miller School of Nursing,

Faculty: 2007-present

Sigma Theta Tau, Delta Alpha at large chapter-Inducted 2002

Presidential Teaching Award Nominee, University of the Incarnate Word, 2011

\section{Selected Peer-reviewed Publications}

Muñoz, L.R., La France, Dominguez, D., Goei, K., Herbers, S., Gunter, M.D.,....Jones, M.E. (2014). Text messaging as a tool to increase physical activity in college students. The Physical Educator, 71, 437-453.

Parker, R.A., McNeill, J.A., Pelayo, L.W., Goei, K.A., Howard, J., Gunter, M.D. (2011). Pediatric clinical simulation: A pilot project. Journal of Nursing Education, 50(2), 105111.

Gilliland, I.; Nadeau, J., Williams, S., Munoz, L., Parker, R., Cook, J., McNeill, J.et al. (2010). Remembering wartime experiences: The role of spirituality among retired military nurses. Journal of Spirituality and Mental Health, 12(3), 224-239.

\section{Research Support}

Current Project: Utilizing a case study approach to discover the meaning differences in the meaning of uncertainty between members of a health care team at a childhood cancer program in south Texas and parents of children with cancer undergoing treatment there. It is proposed that uncertainty could be decreased and adaptation increased secondary to participation in formal support and education sessions, but thus far psychosocial support groups and education classes have not been sustainable. The goal of this project is also to discover what types of psychosocial support and education interventions are most likely to work in this environment. 
Biographical Sketch (Continued)

Other projects:

Significant involvement

Development of a text-message based support program during pedometer use to increase physical activity in freshmen college students. This was an NIH-EARDA grant funded interdisciplinary project with other members of our School of Nursing and Health Professions research team and several faculty members from other departments in the university. This was a two year project in which Ms. Gunter participated in the design development, the literature review, the text message intervention development, the grant application procedure, the implementation, and journal article composition. This article is in editor review at this time.

Moderate Involvement

Investigation into spirituality in retired military nurses through phenomenologic qualitative interviews. Ms. Gunter participated in the planning and analyzation of the data, and minimally in the journal article publication. The data from this study was published as listed above.

Development of a simulation program for our pediatric clinical course at the University of the Incarnate Word. This project was investigating the students' perceptions of their first experiences in a simulated clinical environment. It was a regional collaboration between several schools of nursing and was a national grant funded project. Ms. Gunter's participation was limited to implementation of the intervention, administration of measurement tool surveys to students, and article editing. This article was published as listed above.

All three of these projects were completed while Ms. Gunter was a new faculty member at UIW between 2008-2010. Although they are not specifically on the same topic as her own program of research these projects helped her learn more about the grant process and project development. Since that time, Ms. Gunter has been enrolled in a $\mathrm{PhD}$ program at the University of Texas at Tyler. She is expected to graduate in December 2014. 